University of South Florida

DIGITAL COMMONS

Digital Commons @ University of

@ UNIVERSITY OF SOUTH FLORIDA

South Florida

Integrative Biology Books

Integrative Biology

1923

\title{
Asteroids and Ophiuroids Collected by the Swedish Antarctic Expedition (1901-03)
}

Réne Koehler

John M. Lawrence

University of South Florida, lawr@usf.edu

Follow this and additional works at: https://digitalcommons.usf.edu/bin_books

\section{Recommended Citation}

Koehler, R. Asteroids and Ophiuroids Collected by the Swedish Antarctic Expedition (1901-03) (J. M. Lawrence, Trans.). Herizos Press, Tampa.

This Book is brought to you for free and open access by the Integrative Biology at Digital Commons @ University of South Florida. It has been accepted for inclusion in Integrative Biology Books by an authorized administrator of Digital Commons @ University of South Florida. For more information, please contact digitalcommons@usf.edu. 
FURTHER ZOOLOGICAL RESULTS

OF THE SWEDISH ANTARCTIC EXPEDITION

1901-1903

UNDER THE DIRECTION OF DR. OTTO NORDENSKJÖLD

EDITED BY T. ODHNER

VOL. 1 , NO. 1.

\title{
ASTEROIDS AND OPHIUROIDS
}

BY

\author{
R. KOEHLER
}

Professor at the University of Lyon

WITH 15 PLATES

WITH THE SUPPORT OF THE LANGMANSKA KULTURFONDEN

STOCKHOLM

P. A. NORSTEDT \& SÖNER

1923 
Koehler, R. 1923. Asteroids and ophiuroids collected by the Swedish Antarctic Expedition (1901-03). Translation by John M. Lawrence.

${ }^{\circledR}$ Herizos Press, Tampa 


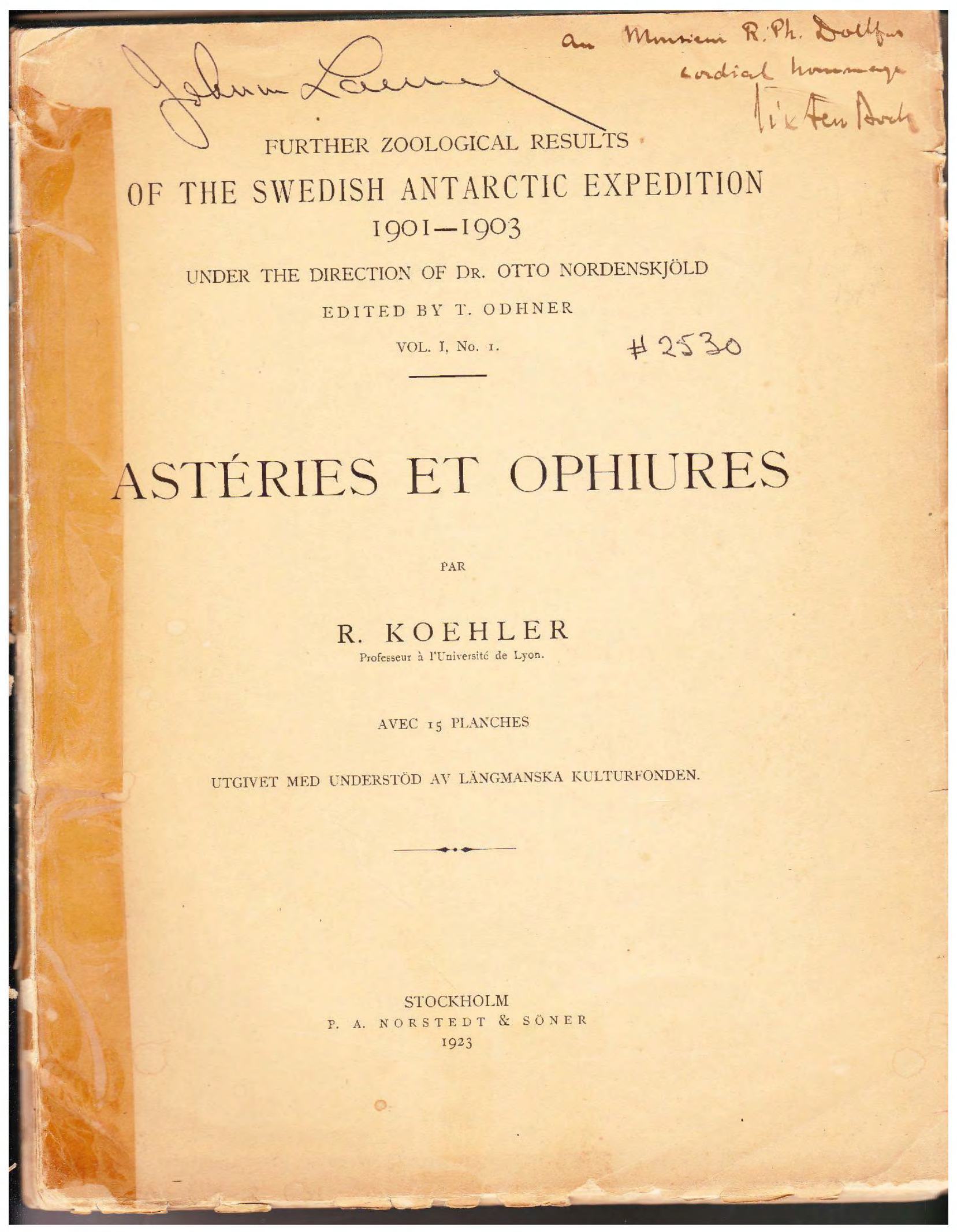




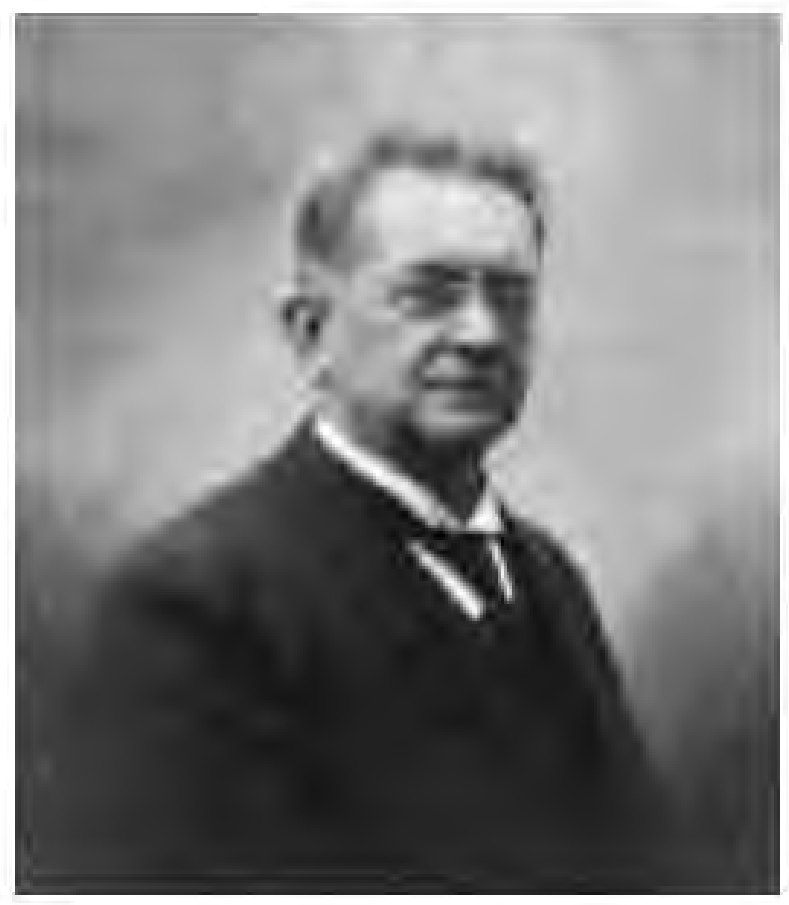

Réne Koehler

Jean Baptiste François René Kœhler was born 7 March 1860 in Saint-Dié and died 19 April 1931 in Lyon. He defended theses in both natural sciences and in medicine at Nancy in 1883. He entered the faculty of sciences at Nancy as préparateur in zoology and then at Lyon in 1889. He was named to the chair of zoology at Lyon in 1894. Koehler participated in cruises of the Princesse Alice with Prince Albert of Monaco. Koehler was a specialist in echinoderms but also worked with isopods. He was president of the Zoological Society of France in 1911. He became an Officer of the Legion of Honor in 1923. His extensive collection of echinoderms and his library are in the Collections de Zoologie, part of the Collections Patrimoniales Universitaires of the Université Claude Bernard (Lyon). 
Translator's note

Koehler referred the tube foot as tentacle (e.g. écaille tentaculaire). Hyman also used papillae as in the older French literature for tube feet: "Podia are however, present as small papillae, commonly called tentacles in the literature" and "One (podium) is usually protected by one or more altered spines known as tentacle scales...". However, tentacles seems obsolete (e.g., Hadjuk, 1992; Glass, 2006) and I use tube feet instead. I have translated écaille tentaculaire as tube foot scale and pores tentaculaires as tube feet pores.

Koehler used papilles for small calcareous elements attached to larger plates in ophiuroids. Hyman (1955) used papillae in this way: "These (the oral ends of the jaws) are edged by little scallops or teeth called oral papillae, wanting in some genera. At the jaw point to the aboral side of the terminal oral papilla may be seen a group of tooth papillae, also wanting in some genera." and "The edges of the bursal slits may be smooth or thrown into small scallops, the genital papillae." I have maintained Koehler's usage of papilles because "It is a general term that has long been used for the structures that Koehler had in mind." (G; Hendler pers. comm.).

Koehler refers to the boucliers buccaux. Hyman (1955) calls them the oral or buccal shields. Oral shields is the term more commonly used in current literature (G. Hendler, pers. comm.).

Glass, A. 2006. Pyritized tube feet in a protasterid ophiuroid from the Upper Ordovician of Kentucky, U.S.A. Acta Palaeontol. Pol. 51 (1): 171-184.

Hadjuk, S. L. 1992. Ultrastructure of the tube-foot of an ophiuroid echinoderm, Hemipholis elongata. Tissue and Cell.1992, 111-119.

Hyman, L. H. 1955. The Invertebrata: Echinodermata. Mc-Graw-Hill Book Company, Inc., New York.

I thank Gordon Hendler and Richard Turner for assistance with the meaning of Koeher's anatomical terms. 


\title{
Asteroids and Ophiuroids
}

\author{
collected by
}

\section{the Swedish Antarctic Expedition}

The adminnistration of the Museum of Natural History of Stockholm has kindly entrusted to me the study of an important collection of asteroids and ophiuroids coming from the Antarctic. Most of the species were collected in the course of the Expedition directed by Mr. Nordenskjöld in 1901-1903. They primarily came from South Georgia, Graham Land, the Falkland Islands and the archipelago of Tierra del Fuego. Some other specimens, although not numerous, were collected by the "Swedish Magellan Expedition" (1907-1909) under the direction of Prof. C. Skottsberg and Mr. E. Söring that visited South Georgia in 1904-1905. Finally, the single example of Ophiomages cristatusn. n. g. and sp. were dredged by Captain C. A. Larsen at the South Sandwich Islands in 1908 and belongs to the Museum of Oslo.

The number of species or varieties that I identified totaled sixty-three: forty-four asteroids and twenty-nine ophiuroids. Among these species, nineteen are new, twelve asteroids and five ophiuroids and two of them being types of new genera. Here is the list:

\section{Asteroids}

Labidiaster radiosus Lütken.

Labidiaster crassus sp. nov. ${ }^{1}$

Anasterias tenera Kœhler.

Anasterias Victoria Kœhler.

Anasterias octoradiata Kœhler.

Sporasterias anatarctica (Lütken).

Sporasterias pedicellaris sp. nov.

Cryptasterias brachiata sp. nov.

Podasterias Brandti (J. Bell)

Podasterias Steineni (Studer)

Podasterias meridionalis (Perrier).

Podasterias Brucei (Kœhler).

Comasterias radiata sp. nov.

Comasterias lurida (Philippi).

Kalyptasterias conferta nov. gen. nov. sp.

Allostichaster incequalis nov. sp.

Granaster nutrix (Studer).

Asterina fimbriata Perrier.

Echinaster diffidens nov. sp.

${ }^{1}$ The names of new species are in bold characters/ 
Henricia Pagenstecheri (Studer).

Cycethra verrucosa (Phillipi).

Cycethra cingulata nov. sp.

Ganeria Hahni Perrier.

Perknaster aurantiacus Kohler.

Cryaster Aurora Kœhler.

Lophaster antarcticus Kœhler.

Cuenotaster involutus (Kœhler).

Remaster Gourdoni Kœhler.

Diplopteraster verrucosus (Sladen)

Diplopterster Nordenskjoldi nov. sp.

Pteraster Hunteri Kœhler.

Acodontaster elongatus Sladen var. abbreviatus nov. var.

Asterodon gingularis (Müller and Troschel.).

Gnathaster validus (Koehler).

Gnathaster elegans (Kœhler).

Peridontaster Grayi (Bell).

Pseudontaster conspicus Kœhler.

Pseudontaster moderatus sp. nov.

Ceramaster patagonicus (Sladen)

Astropecten cingulatus Sladen

Ripaster longispinus Kœhler.

Leptoptychaster accrescens Kœhler.

Leptoptychaster mendosus sp. nov.

Bathybiaster Liouvillei Kœhler.

\section{Ophiuroids}

Gorgonocephalus cilensis (Phillipi).

Astrotoma Agassizii Lyman.

Astrochlamys brunneus Kœhler.

Ophiochondrus falklandiscus nov. $s p$.

Ophiacantha vivipara Ljungman.

Ophiodiplax disjuncta Kœhler.

Ophioripa ingrate (Kœhler).

Amphiura alternans nov. sp.

Amphiura complanata Ljungman.

Amphiura Eugenice Ljungman.

Amphiiura magellanica Ljungman.

Amphiura Mortenseni Kœhler.

Amphipholis patagonica Ljungman.

Amphiodia chilensis (Müller and Troschel).

Amphioplus affinisi (Studer).

Amphioplus peregrinator (Kohler).

Ophiactis asperula (Phillipi).

Ophiomages cristatus nov. gen., nov. sp. 
Ophioceres inciiens Kœhler.

Ophiocten amitinum Lyman.

Ophiomastus conveniens nov. sp.

Ophionotus Victoria Bell.

Ophionotus hexactis (Smith)

Ophiura Lymanin (Ljungman).

Ophiomaria Döderleini (Kœhler).

Amphiophiura antarctica nov. sp.

Ophioperla Ludwigi Kohler.

Ophiurolepsis resistens (Kœhler).

Ophiurolepsis gelida (Kœhler).

Among the most interesting forms of this collection, I call particular attention to following. I have created a new genus, Kalyptasterias, for an asteroid close to the genus Calvasterias, but which it appears necessary to separate considering the imprecise limits of the latter genus that I have restrict to the type, C. asterinoides. The other genus, Ophiomages, has for type an ophiuroid in the family of lepididines, characterized by the height of the dorsal arm plates and the dorsal plates of the disk, these latter completely equal and each armed with a large tubercle. This genus recalls by its characters at the same time the genera Ophiosteira, Ophiopyrgus and Ophiomastus.

Among the new species, I emphasize most particularly a species of the genus Labidiaster, $L$. crassus, remarkable for its very short, thick arms; a second species of the genus Cryptasterias distinguished recently by Verrill, in the same way that a second species of the genus Allostichaster that I established quite recently in a memoir on the asteroids collected by the "Australian Antarctic Expedition"; a new species of the genus Diplopteraster having six to seven arms; and finally a new Cycethra, $C$. cingulata, with very developed and very distinct retractable marginal plates in the "pentagonasteroid" forms of Perrier. Of the very numerous Cycethra collected by the "Swedish Antarctic Expedition", I have placed all of them in C. verrucosa and took the opportunity that it offered me to study this very difficult genus in order to compare the value of different species established by authors.

\section{Labidiaster radiosus Lütken}

(Pl. I, fig. 3)

See the bibliography:

Labidiaster radiosus Ludwig (1903), p. 58.

Labidiaster radiosus Kœhler (1912), p. 9

Labidiaster radiosus Verrill (1914), p. 352.

Station 2. 23 December 1901. Northern coast of Argentina. 37 50' S; 56 $11^{\circ}$ ' W. 100 m. Gravel mixed with sand. One specimen.

Station 39. 4 July 1902. Port William, Falkland Islands. 51 $40^{\circ}$ S; $57^{\circ} 41^{\prime}$ W. 40 m. Sand and small rocks with algae. One specimen.

In the individual from station 2, the disk is not exactly circular but oval. It measures 50 by $35 \mathrm{~mm}$.

The arms, most of which are elongated, were thirty-four in number. Among them, five are much smaller than the others and contiguous. They are regenerating and are only 15 to $16 \mathrm{~mm}$ in 
length. The length of the others is between 120 and $130 \mathrm{~mm}$. The largest part, found at some distance from their base, is $7.5 \mathrm{~mm}$ on average, and their height is $10 \mathrm{~mm}$. There is not a very clear relation between the basal region of the arms and the following part that is narrower and joined progressively to the preceding.

It is possible to distinguish on the dorsal surface of the disk a very coarse calcareous network with a large mesh from which are extended a few small spines in the central region. They are larger and more numerous towards the disk periphery. The madreporite plate, nearly marginal, is $5 \mathrm{~mm}$ in diameter and is surrounded by a circle of small, dense small spines. The papulae are small and project slightly.

As for the spacing of the transverse skeletal arcs and their correspondence with the adambulacral plates, I have already noted elsewhere that these arcs correspond to sometimes two sometimes three of these plates in L. radiosus. Perrier said in 1891 that the arcs have a regular appearance of two to two adambulacral plates. This rule is not absolute and I observe that the correspondence is never very regular in the arms of L. radiosus. There can even be three of them to three adambulacral plates when the arcs are separated from each other. This occurs, for example, in the individual collected by the "Charcot Expedition" that I reported in 1908.

\section{Labidiaster crassus nov. sp.}

(Pl. 1, Fig. 1 and 2)

One specimen. There is no indication of station.

The number of arms is thirty-one. They are smaller on nearly half the circumference of the disk where there are sixteen of which the smallest is only $5 \mathrm{~mm}$ in length and the longest $47 \mathrm{~mm}$. The other half of the circumference has fifteen arms in all that are in general much larger than the preceding, except for a group of three where the arms are only 47 to $50 \mathrm{~mm}$ in length and another group of two with a length between 40 and $22 \mathrm{~mm}$. The largest arms have a length between 70 and $95 \mathrm{~mm}$ and their width can reach $16 \mathrm{~mm}$ and a height of $20 \mathrm{~mm}$. But some of these arms are much shorter and are only $60 \mathrm{~mm}$.

The disk is slightly oval and measures $48 \times 43 \mathrm{~mm}$. Its dorsal surface is very convex and has large, thick, short, conical spines with a very rounded rugged end. These spines are surrounded by a thin envelope. They are not very dense and they often form more or less apparent radially arranged lines. The papulae between them are numerous, small and dense. Straight pedicellariae appear here and there.

The madreporite plate, separated from the edge of the disk by about $4 \mathrm{~mm}$, measures $5.5 \mathrm{~mm}$ in diameter. If projects and is surrounded by a circle of dense, small, conical very pointed spines that are a little unequal and oblique. Its surface has very fine radiating grooves arranged in a very regular manner.

The very short, thick and wide arms become thin in reality only in the last terminal part with a very slight length and do not reach even a third of the total length. This peculiarity gives an individual a completely characteristic appearance that separates it from the other species of Labidiaster in which the arms has the known characteristics. This remarkable increase in the height and width of the arms is accompanied by modifications in the skeleton of the lateral surfaces of the arms. In fact, the ventral marginal plates (initiales of the arcs of Perrier) and the dorsal marginal plates (cruciales plates of Perrier), instead of being connected by a single intermediary or supplemental plate, as in L. radiosus, are connected here, and on more than half of the length of 
the enlarged part of the arms, by two and even three very elongated and narrow successive plates. They, with the corresponding dorsal and ventral marginal plates, border large rectangular areas, very much taller than wide. The surface has some straight pedicellariae of diverse size and variable number. There are several isolated papulae. Each dorsal and ventral marginal plate has a spine. The ventral marginal spine is much sturdier than the dorsal marginal spine of the same arc, but the latter is sometimes divided into two. In addition, the dorsal marginal plates have a distal apophysis, a very small spine and, towards the lower border, another spine of the same size. The supplementary plate that follows often has, towards it lower border, a thin, shorter spine. This structure continues up to the fifteenth or sixteenth arc, after which the crucial plates no longer appear. The successive arcs, closer together, are no longer connected transversely. These successive arcs are not separated by perfectly equal intervals and they correspond sometimes to two and sometimes three adambulacral plates.

The skeleton of the arms is completed by the lateral plates in form of a cross, each with a small group of two to three spines and connected to each other by an elongated piece that usually has a spine. These lateral plates are often arranged alternately, one taller and the other lower in a way to form a zig-zag row. Each is connected to the corresponding dorsal plate by a small narrow, elongated ossicle. The dorsal and lateral plates do not extend past the twelfth transverse arc and then disappear. In consequence, the dorsal marginal plates disappear themselves. But the dorsal surface of the arms is not completely lacking in plates in the median region, because on a good part of the length of arms small rectangular plates form small transverse rows, entire or discontinuous. They connect together the lateral substance of the lateral arcs. In the more enlarged region of the arms, the lateral part of the skeletal arcs, containing the dorsal and ventral marginal plates along with the ossicles that connect them, do not form a very marked relief on the surface of the arms. But when the arms become narrow, these arcs become more projecting and form from then on the sides of the arms very apparent projecting lines that continue to the end. Although these arcs have at first only the spines reported above and crossed pedicellariae form only an incomplete crown at the base of each ventral marginal spine, afterwards the pedicellariae extend rapidly towards the dorsal surface and are developed the entire length of the projecting arc. They thus form on the arms very dense vertical crests covered with crossed pedicellariae. While in the preceding more enlarged region, the arcs have only some crossed pedicellaraie that are much less numerous than on the dorsal surface between the spines. The membranous spaces that separate the arcs have numerous papulae. All these formations, papulae, spines and pedicellariae, make a very dense covering on the dorsal sauce while the lateral surfaces of the arms are little covered. As for the ventral marginal spines, they are maintained with their crown of pedicellaraiae on the entire length of the arms but the other spines disappear little by little beyond the enlarged region.

The adambulacral spines are elongated, cylindrical, very sturdy, and a rounded end. The external spines have on nearly all their length and on the free half many crossed pedicellariae much smaller than the dorsal pedicellariae that are lacking moreover on the internal spines except on some between them.

As for the spacing of the transverse arcs and their correspondence with the adambulacral plates, I have already noted that these arcs in L. radiosus correspond sometimes to two sometimes to three adambulacral plates, contrary to what Perrier indicated. It is the same in L. crassus, and I note, on different arms, that this correspondence is completely irregular and that the arcs can correspond to three adambulacral plates.

To go back to the dimensions of the arms of L. crassus, their length does not reach twice the diameter of the disk while their length is much greater in the two other species of the genus. One 
can ask if the remarkable width and height at the commencement of the arms of the species collected by the "Swedish Antarctic Expedition" are not the result of great development of the gonads that are, in fact, very large and if, outside of the season where the gonads are very swollen, the thickness of the arms is much less. They can be considered as a possible hypothesis, at least as regards the thickness of the arms. But for the height, as that is determined by the dimensions of the successive skeletal ossicles, which can scarcely contract, it should not vary much. And even supposing that the dimensions of the arms can be reduced to a certain degree and on a certain part of their length itself cannot increase so much that the $R / r$ ratio always remains less in the species of the "Swedish Antarctic Expedition" than the number known in the other two species of the genus Labidiaster. One cannot accept the constitution of the skeleton has great variation under the influence of the gonads. Now, there is a very notable difference in the structure of the arcs of $L$. crassus and that of the two other known species. In the former, the plates that correspond without doubt to the dorsal and ventral marginal plates are united at least by two successive plates and sometimes by three so that the height of the arc is considerably increased. In L. radiosus, there is in the adult only a single intercalated plate (see Perrier, 1891, p. 150 and following). And it is the same when the arms are very swollen and elevated in their basal region. In the same way, this is the case in the example from Kerguelen that I showed in a photograph in 1917 (1917. P1. I, fig. 4) and that I have reported in L. annulatus. In both these species, there is never a single intercalated plate in this region of the disk.

The arms of L. crassus have a very characteristic form. They are extremely short, very wide, nearly fusiform. They are very narrow at their insertion to the disk. They rapidly increase to a length of 2 centimeters, after which their width decreases very slowly and progressively up to the proximity of their end so that one cannot distinguish in them the precise limit between the enlarged basal part and a narrow terminal region. We have seen moreover that the gonads and the gastric caeca are extended nearly the entire length of these arms. I must note in passing the exact form of the normal arms is not indicated in the photograph I give here (Pl. I, fig. 2) of an isolated arm because I had to dry it in order to bring out the characters of the skeleton. My photograph makes it possible to suppose that there is a great difference in height between the proximal and distal halves of the arms. This is in fact moreover that which is the case in the dried arms because, as a result of desiccation, the dorsal surface is not supported by the skeleton and comes to lie more or less closely on the ventral surface of the body. This is not the case when the arms are still in alcohol.

I have examined the pedicellariae of $L$. crassu and it is impossible for me to see any difference in their characters with those of L. radiosus and annulatus, including the large form of these pedicellariae whose valves reach 0.4 to $0.4 \mathrm{~mm}$ in length and those of the small form whose valves are 0.22 to $0.24 \mathrm{~mm}$.

Similarities and differences, -- L. crassus has a physiognomy so distinctive and so different from the well-known aspects of the other two species of the genus, L. radiosus and L. annulatus, that it does not appear possible to relate it to either of these species. Not only are the arms very short, thick and tall, but they are reduced to nearly their entire length to the gonadal region. The lateral arcs are made up of successive pieces, with an arrangement that is related to their development in height. It cannot be considered as related to the turgescence of the gonads filled with gametes. It is possible that the discovery of others examples will show that it is in reality only a very robust variety of $L$. radiosus with very short arms. But, for the moment, it appears to me necessary to give it a special name. 


\title{
Anasterias tenera Kœhler.
}

\author{
Anasterias tenera Kœhler (1906), p. 12, Pl. II, fig. 11 to 16; Pl. III, fig. 27 and 28; Pl. IV, fig.
} 41.

Anasterias tenera Kœhler (1908), p. 569.

Anasterias tenera Kohler (1912), p. 10.

Anasterias tenera Kohler (1920), p. 11, 17, Pl. II, fig. 1, 2, 3, 4 and 10.

All the specimens come from South Georgia, Cumberland Bay.

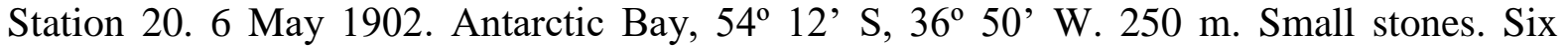
specimens.

Station 28. 24 May 1902. Entrance to Marmite Bay, $54^{\circ} 22^{\prime}$ S.; $36^{\circ} 28^{\prime}$ W. $12-15$ m. Sand and algae. Four specimens.

Station 31. 29 May 1902. South Fjord, before the glacier of Nordenskjöld, $54^{\circ} 24^{\prime}$ S.; $36^{\circ}$ $22^{\prime}$ W. $210 \mathrm{~m}$. Blue-gray clay mixed with some small stones. Temp. $+1.5^{\circ}$. Two specimens.

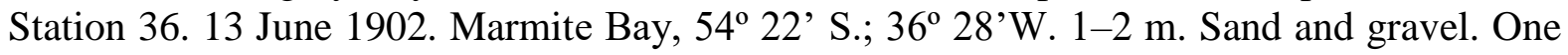
specimen.

Station 37. 14 June 1902. Same locality. 20 m. Mud. One specimen.

Marmite Bay. 18 May 1902. A very large specimen.

Cumberland Bay. 25 April 1902. Three specimens. Gift of E. Sörling.

In the largest specimen, from Marmite Bay, $R=90, r=17 \mathrm{~mm}$; in the other individuals, the average size, $R$ varies between 82 and $55 \mathrm{~mm}$. The others are smaller.

I have observed some variation in the general appearance of the specimens, but these variations result in large part from the mode of preservation. Sometimes the teguments are soft, sometimes they maintain a certain rigidity. I note the very great differences in the number of pedicellariae that enclose the pustules of the dorsal surface of the body, like the development of the pedicellariae surrounding the base of the marginal spines. As for the skeleton, this is strictly restricted to the dorsal surface of the disk in some individuals. Sometimes there is at the base of the arms some plates although not numerous. Sometimes these plates are more developed, larger and more numerous and form a small very distinct carinal range, sometimes discontinuous, in which each plate has a small spine.

All the individuals come from South Georgia and I cannot truly distinguish them from those collected either by the Charcot Expedition or by the Shackleton Expedition in other Antarctic regions.

In my recent work (1920) on the asteroids of the "Australian Antarctic Expedition", I had the occasion to specify the characters of A. tenera, in describing a new species discovered by the Aurora, A. Victorice. I have published some photographs of the first species. 


\section{Anasterias Victoriæ Kœhler}

Anasterias Victoria Kœhler (1920), p. 17, P1. II, fig. 5; P1. II, fig.1 to 6; P1. IV, fig 1-4; Pl. V, fig. 1 to 10; Pl. VI, fig. 1-4; PILVII, fig. 1.

Station 20. 6 May 1902. South Georgia, Cumberland Bay, Antarctic Bay, 54 $12^{\prime}$ ' ' $36^{\circ} 50^{\prime}$ W. $250 \mathrm{~m}$. Small stones. One specimen.

Port Louis, Greenpatch, Falkland Islands, 30 July 1902. Found among the holdfasts of stranded "kelp" thrown onto the coast by a storm. One large specimen.

The specimen from Port Louis is the largest: $R=88, \mathrm{r}=15 \mathrm{~mm}$; the arms measured $12 \mathrm{~mm}$ of width at the base.

The individuals shows much resemblance to the specimen of the "Australian Antararctic Expedition" that I have described recently that came from station 1 ( $66^{\circ} 50^{\prime} \mathrm{S}^{\prime} 142^{\circ} 6^{\prime} \mathrm{E}$; $354 \mathrm{fms}$.). This individual $\mathrm{C}$ is shown in Pl. II, fig. 5. The arms are narrow and long. The dorsal surface of the body shows, except for a central pentagon and five interradial extensions, only one discontinuous row of few, small ossicles. They extend on the carinal line of the arms in an irregular manner. Each has a small spine. These spines are very sturdy and occur the entire length of the arms. The pustules of the dorsal surface of the body are constituted by a very soft tissue. They are completely flat from drying and their pedicellariae are very apparent. They are numerous and dense. They appear to the naked eye as a very fine white powder. They are both crossed and straight pedicellariae. The former are more numerous and measure $0.3 \mathrm{~mm}$ in total length. The others, less numerous, reach a length of $0.4 \mathrm{~mm}$.

This individual could not have lived in a littoral station. It was in fact thrown onshore after a storm.

The other example, coming from station 20, has an external appearance different from the preceding. It is in an excellent state of preservation. In the individual in alcohol, the pustules are very distinct although very close to each other. They are especially well developed on the disk and on the median region of the arms. The disk has an external circle of dense, very sturdy spines and passing the pustules that surround them at the base $2 \mathrm{~mm}$ at least. Within this circle are several slightly smaller spines arranged in the same order. On the dorsal surface of the arms, the median region has first two or three very irregular rows of spines that extend nearly to the middle of the length of the arms. These spines then rapidly become shorter and soon disappear. On the sides of the arms, some isolated spines that are always very sturdy occur here and there. The spines of the dorsal and ventral marginal plates are very developed, especially the ventral spines that number two per plate. These spines, especially the ventral ones, are flat, enlarged at the end to take the form of a spatula. All these spines are surrounded at the base by collars with very large pedicellariae as seen in A. victoria but never as strong as in A. tenera. I dried this specimen in order to examine the internal skeleton and confirm my conclusion. A slight treatment with potash was sufficient to make these skeletal plates appear. They have an arrangement similar to that I observed in several specimens from the "Australian Antarctic Expedition", notably in those I showed in Pl. IV fig. I of my work. These plates are a little less sturdy but the tegument remains extremely firm and coriaceous despite the treatment with potash.

Some of the specimens collected by the "Australian Antararctic Expedition" were from $66^{\circ} \mathrm{S}$. and $142^{\circ}-145^{\circ} \mathrm{E}$. and the others from $44^{\circ}-66^{\circ} \mathrm{S}$. and $92^{\circ}-97^{\circ} \mathrm{E}$. at depths from 60 to $354 \mathrm{~m}$, 
consequently in localities very distant from those where the species has been found by Nordenskjöld.

\section{Anasterias octoradiata Kœhler}

(P1. VI, fig. 6)

Anasterias octoradiata Kœhler.

Station 19.23 April 1902. South Georgia, Cumberland Bay, Port Jason. 54 $14^{\prime}$ S; $31^{\circ} 31^{\prime}$ W; 10-15 m. Small stones and clay. One specimen.

The arms sometimes number nine and they are unequal: $R=29$ to $30 \mathrm{~mm}$. The individual is smaller than the type, represented by a single specimen that also was collected at South Georgia and which had eight arms but in each $R$ reached $85 \mathrm{~mm}$. Except from the difference in number of arms, the individual from the "Swedish Antarctic Expedition" is perfectly identical to the type.

\section{Sporasterias antarctica (Lütken).}

(Pl. VII, fig. 4)

See the bibliography:

Asterias rugispina Leitpoldt (1895), p. 563.

Sporasterias antarctica Ludwig (1903), p.39.

Asterias antarctica Meissner (1904), p. 10.

Asterias antarctica Loriol (1904), p. 36, Pl. IV, fig. 1.

Sporasterias antarctica Ludwig (1905), p. 70.

Asterias antarctica Kœhler (1908), p. 576.

Asterias antarctica Kœhler (1912), p. 11.

Sporasterias antarctica Kœhler (1917), p. 10.

Sporasterias antarctica Kohler (19290, p. 78, P1. XVIII, fig.1 to 4; P1. XXVII, fig. 1 and 4.

Ile Navarain, Tierra del Fuego. 4 March 1902. 0 m. One specimen.

All the other specimens of the expedition of Nordenskjöld come from the Falkland Islands.

Station 40. 19 July 1902 . Berkeley Sound. $51^{\circ} 33^{\prime}$ S.; $58^{\circ}$ 0' W. 16 m. Gravel, shells with algae. Temp. $+2.75^{\circ}$. Three specimens

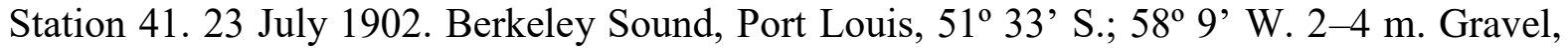
mud. Four specimens.

Station 47. 9 August 1902. Port Louis, entrance of Carenage Creek, $51^{\circ} 32^{\prime}$ ' S.; $58^{\circ}$ 'W. 3-4 m. Shells, stones. Eight specimens.

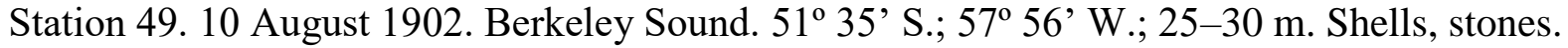
Four specimens.

Station 50. 12 August 1902. Port Louis. 7 m. Mud. One large specimen.

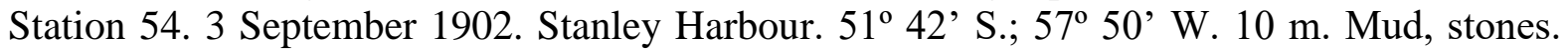
Two specimens.

Port Louis. 22 and 23 August 1902. Intertidal. Ten specimens. 
Swedish Magellan Expedition 1907-09. Station 9. 10 January 1908. Sparrow Cove, East Falkland. 11-13 m. Shell hash. Four specimens.

Same expedition. Station 17. 18 April 1908. Fitzroy Canal, between Otway and Skyring Waters, South Patagonia. Large gravel. 13-14 m. Rapid current. Two large and four small specimens.

Leitpoldt gave an extensive bibliography that reunited under the name Asterias rugispina ${ }^{2}$ Stimpson all Antarctic and subantarctic species having a single row of adambulacral spines, i.e. Asterias rugispina Stimpson, antaractica Lütken, varia (Phillipi), fulgens (Philippi), Cunninghami Perrier, Perrieri Smith, rupicola Verrill, rugispina Perrier, varia Perrier, spirabilis Bell, Verrilli Bell, Anasterias miniata Perrier, Calvasterias antipodum Bell and Calvasterias stolidota Sladen.

In the largest specimen cited by Leitpoldt, $R=59 \mathrm{~mm}$; Bell indicated $60 \mathrm{~mm}$ for his Asterias spirabilis.

Leitpoldt gave an extremely extended sense to $A$. antarctica (which he wrongly called $A$. rugispina). But I cannot adopt, with more information, all the synonymies that he recognizes. Some of these synonymies are absolutely without doubt. I will mention first Asterias rugispina Stimpson and spirabilis Bell, to which it is necessary to add A. Cunninghami. I have already had the occasion to speak of this latter species in my memoir of 1917 on the echinoderms of Ile de Kergulen remarked (p. 16) that it had, in reality, five arms. This is consequently an error, typographical or otherwise, that Perrier had attributed six to it.

In my memoir on the asteroids of the "Australian Antararctic Expedition" (1920, p. 13), I showed that Anasterias Perrier of Perrier was in reality Sporasterias antarctica and I believe also that Asterias Verilli Bell is a synonym of the latter. To the contrary, in this same memoir of 1920, I consider as distinct forms of Sporasterias antarctica the Sporasterias Perrieri from Isle Kerguelen with six arms and S. rupicola that also comes from Kerguelen. I described these two species that are better as local varieties, restricted to Ile de Kerguelen, one of which always had six arms. There can be no question of uniting it with Sp. antarctica. I no more believe that Calvasterias stolidota Sladen can be considered synonymous with $S p$. antarctica. Besides, it is very difficult accept an idea that Calvasterias antipodum that Leitpoldt cites among the synonymies of $S p$. antarctica and I prefer, for the moment, to lay this form completely to the side.

Most of the specimens collected by the "Swedish Antarctic Expedition" show well the typical characters of Sp. antartica and they conform to the descriptions that the authors (Lütken, Peerrier, Bell, Loriol, etc.) have given. The individuals do not pass an average size and, in general, $R$ is no greater than 25 or $30 \mathrm{~mm}$. Most of them have short thick arms that occur especially in specimens from stations 40 and 47, in those found at Port Louis 23 July 1902, as well as those collected 10 January 1908 by the "Swedish Magellan Expedition" (Station 9). In some individuals of small size, the size becomes a little larger. E.g. in an individual from Station 41 with $R=40$ and $r=12 \mathrm{~mm}$, in one from station $50(\mathrm{R}=70, \mathrm{r}=17)$, in one of two specimens from Station $54(R=50, r=11)$ and in two individuals collected 18 April 1908, in which $R$ is 55 and $48 \mathrm{~mm}$, respectively.

In the various specimens collected, the exterior aspect has variations that depend on the state of extension of the papulae that can form a more or less dense covering and more or less completely hide the spines, their number, size and form, either slightly elongated and cylindrical or short and

\footnotetext{
${ }^{2}$ I do not understand very well why Leitpoldt called the species Asterias rugispina Stimpson, a term that dates from 1860, while the designation Asteracanthion antarcticu had been used by Lütken in 1856 . It is true that Leitpoldt cites Asteracanthion antarcticum with a question mark as if he doubted the synonymy of this species. But this synonymy has been recognized for many years by all authors.
} 
large and even slightly capitate and even the development of the skeleton. The adambulacral spines are always arrange in a simple row. The ventral marginal plates, that follows them, are separated by an interval in which is seen an irregular series of a few latero-ventral spines. Moreover, there is a range of papulae between the adambulacrals and the ventral marginal. These latter plates are large and sturdy. Each has at least two and sometimes three very sturdy and thick spines that form a small oblique row. There is often added outside the corresponding latero-ventral spine that one can take at first glance as a spine belonging to the margino-ventral. The dorsal lateral plates occur at some distance, each of which generally has only a single spine. The space that separates the two rows has a row of very large papulae. Straight and crossed papulae, sometimes more or less numerous, sometimes very rare, appear. The adjacent spines of the dorsal marginal plates very often form a nearly regular row, but the others are always irregularly arranged. The dorsal surface of the disk and the arms has spines and crossed pedicellariae in the middle. Straight pedicellariae are rarer but they are however very numerous in the specimen from station 47 that I shall discuss later.

It is important to note the characters of the dorsal and ventral marginal plates. Although the number of spines of the latter is greater than those of the dorsal marginal plates, the ventral plates are however a little smaller than the dorsals. The latter are large and tall, longer than wide and their height is always due to the development of the ventral apophysis (Pl. VII, fig. 4). They have a triangular form. The principal part has a superior apophysis that joins the adjacent latero-dorsal plates, a proximal apophysis that is shorter than the superior one and covers the corresponding part of the preceding plate, and finally a ventral apophysis that is more elongated than the dorsal apophysis. It covers an apophysis nearly as developed coming from the corresponding ventral marginal plate. The principal part of the plate is very thick and has, towards the middle, a flat tubercle on which is inserted the corresponding spine. Sometimes there is a second small tubercle for the insertion of a second spine. The smaller ventral marginal plates have a principal part in the form of an oval directed obliquely and have at least two tubercles for the insertion of corresponding spines. Each plate has a short dorsal apophysis, covered by the end of the ventral apophysis of the corresponding dorsal marginal plate. Its proximal border covers the distal part of the preceding plate.

The ventral and dorsal marginal plates always form two very clear and regular rows, especially the dorsal marginal plates. They are distinguished from the adjacent latero-dorsal plates that are much smaller and contribute to the formation of an irregular network. I emphasize this character of the marginal plates and, in particular, the very regular and very defined row that the dorsal marginals form. I shall use this character later on to separate St. antarctica, a new species that I shall make the type of an equally new genus Kalyptasterias.

It appears to me that this form of the marginal plates can be used to confirm the separation of Sporasterias antarctica with five arms and Perrieri with six arms and contradics the opinion of authors such as Leitpoldt (1895, p. 564) who consider Sp. Perrieri of Kergulen as a simple form of Sp. antarctica with six arms. This thesis does not appear acceptable to me because, as I have said recently (1917, p. 14 and 23), the dorsal marginal row is little developed in Sp. Perrieri while it is much more important in Sp. antarctica.

I shall make special reference to the subject of specimens from station 47 of which the largest are remarkable for the number of spines and pedicellariae. The skeleton forms as usual an irregular network but the spines of the dorsal surface, otherwise inconstant, have a tendency to follow certain alignments that are never continuous on a large part of the arms. Between the spines of the dorsal surface are numerous crossed pedicellariae that have no special character and whose values 
measure 0.2 to 0.25 in length. In addition, straight pedicellariae are very numerous, especially on the sides of the arms. The values of these pedicellariae are triangular, a little rounded at the tip but never having the form of a spatula or claw of a cat that occurs in others asteroids. Their length reaches 0.6 to $0.8 \mathrm{~mm}$. The aspect of this example, with its numerous spines and abundant pedicellariae, is very distinctive. At first, one could be tempted to believe that it is a matter of a different species, but a careful analysis shows there is not a single character that permits it to be separated from $S p$. antarctica. The spines of the specimen from station 50 are equally numerous and large with a rounded tip. The specimen collected at Fitzroy Canal, South Patagonia, also has dense, large, thick spines, rounded at the end, more robust and shorter than in the specimen from station 47. It has abundant crossed pedicellariae between them but complete scattered and not at all grouped at the base of the spines. There is moreover very great variation in the number of crossed or straight pedicellariae. Some individuals, e.g., station 41, seem completely lacking in them. The specimens from Sparrow Cove, East Falkland, have very few of them. It is the same in individuals that Loriol described and that I showed in my memoir on the asteroids collected by the "Australian Antarctic Expedition" (Pl. XVIII, fig. 2). I have even found some that are completely lacking in pedicellariae. In general, in the specimens of Nordenskjöld, the crossed pedicellariae are sparse in the midst of the dorsal spines and form an incomplete collar at the base of the first ventral marginal spine. The straight pedicellariae are chiefly here and there among the marginal spines and in the ambulacral furrow.

Sporasterias pedicellaris sp. nov.

(Pl. V, fig. 1 to 6; Pl. VI, fig. 1 to 5 and 7 to 10 )

Anasterias Perreri Perrier (1891), p. 979 (non Studer 1885, p. 153).

Sporasterias antarctica Kœhler (1920), p. 78, Pl. XVIII, fig. 4.

Station 3. 6 January 1902. Tierra del Fuego, 54 43' S.; 64 8' W. 36 m. Pebbles, gravel. Five specimens.

Falkland Islands

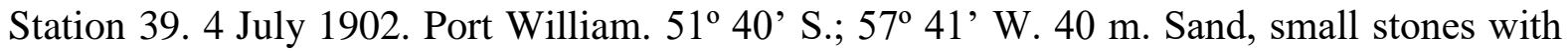
algae. Two specimens

Station 40. 19 July 1902. Berkeley Sound. 51³3' S., 580'W. 16 m. Gravel, shells with algae. Temp. $+2.75^{\circ}$. One specimen.

Station 42. 26 July 1902 . Port Louis, $51^{\circ} 33^{\prime}$ S.; $58^{\circ} 9^{\prime}$ W. 8 m. Mud, shells. Three specimens.

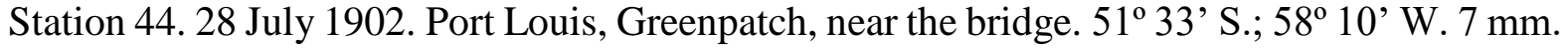
Mud and gravel with algae, immediately outside the Macrocystis zone. Six specimens.

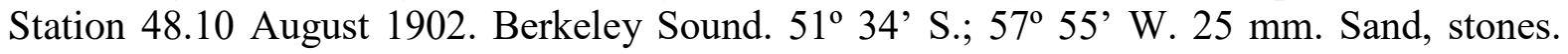
Temp. $+2.75^{\circ}$. Four specimens.

Station 50. 12 August 1902. Port Louis. 7 m. Mud. Seven specimens

Station54. 3 September 1902. Stanley Harbour. 51 42' S.; 57 50’ W. 16 m. Mud, shells. Five specimens.

Port Louis. One specimen.

Swedish Magellan Expedition 1907-09. 5 December 1907. Sparrow Cove, East Falkland. Four specimens. 
I believe it is necessary to consider as a new species an asteroid coming principally from the Falkland Islands and that is represented in the collection by several specimens offering, from the point of view of the development of a very distinctive skeleton, with very great variation. This skeleton is ordinarily constituted of a network of anastomosing trabeculae not of great thickness and having even sometimes a very great fineness. This network is very irregular in the middle of the dorsal surface of the disk and arms with thickenings at the points of intersection of the trusses. But it is often in more or less regular parallel transverse rows abutting the dorsal marginal plates on the sides of the arms. In some individuals, the irregular network is no longer continuous and has numerous interruptions. Finally, in addition, elsewhere the network is constituted of larger ossicles often with longitudinal alignment connected or not by fine trabeculae. The spines of the network can be more or less numerous or more of less developed. This network is clearly apparent on the dried skeleton and in individuals in alcohol. It is hidden under the tegument, generally very thick and soft that covers it. Also the asteroids have an external appearance that recalls that of the genus Anasterias. If one is limited to a superficial examination, one would be tempted to recall this genus. However, this tegument has an irregular surface and has small spines and pedicellariae, sometimes not numerous, sometimes abundant. One never notices the pustules characteristic of the genus Anasterias, i.e., this division into the well-known distinct polygonal fields of this genus.

One of the most typical individuals and whose characters are the best marked is that from Port Louis without station number. I show it here in Pl. V, fig. 3 and Pl. VI, fig. 7; $R=50 \mathrm{~mm}, r=12$ $\mathrm{mm}$. The skeletal network is very developed and the nodes are constituted of small ossicles that ordinarily have each a spine near some crossed pedicellariae. The spines form a carinal row on the side of which are found two more or less regular rows of latero-dorsals. The spines, which here are very numerous, are short, thick and slightly capitate. In the distal third of the arm, the network becomes discontinuous and much looser. On the sides of the arms, the trabeculae form transverse rows that are sinuous and irregular and lack spines and pedicellariae. They abut the dorsal apophyses of the dorsal maraginal plates. The dorsal surface of the disk is formed by a thicker network, border by more developed ossicles. The ensemble forms a polygon from which leave thick radial bands. The madreporic plate is located immediately outside this polygon and nearer the center than the border.

In an individual from station 44, shown in Pl. VI, fig.4, with $R=59 \mathrm{~mm}$ and $r=15 \mathrm{~mm}$, the calcareous skeletal network is a little less thick than in the preceding specimen and is discontinuous. This skeleton is formed of small ossicles constituting a carinal row and two lateral rows on each side. Each ossicle leaves from very short small or oblique transverse trusses that are rarely connected to each other. Between the second lateral row and the dorsal marginal plates are still smaller ossicles forming a third lateral row. The entire ensemble is very delicate but well formed.

The specimens of Sparrow Cove, East Falkland scarcely have distinct ossicles arranged in longitudinal rows but the system of transverse and oblique trusses is in contrast well developed. These more or less fine trusses constitute a discontinuous, very loose network that extends over all the dorsal surface of the arms and borders large irregular spaces through which pass numerous papulae. The spines and pedicellariae are very little developed and they are completely lacking in some specimens. In the largest individual in which $R=65 \mathrm{~mm}$ and which is shown in $\mathrm{Pl}$. V, fig. 1 , the very fine trusses are sinuous, often bifurcated and sometimes anastomosing. There are only some spines on the dorsal pentagon of the disk and the dorsal surface of the am itself is nearly completely lacks spines. They only appear towards the end with some crossed pedicellariae. In the second specimen, the network is a little more compact, but it still remains very fine and delicate. 
There are some very short, capitate and rugose spines with very rare pedicellariae. In the third specimen, the network exists only on the sides of the arms with some spines intermingled with crossed pedicellariae. In the fourth, the skeleton is very developed and is from chiefly of large ossicles tending to form some longitudinal alignments with transverse trusses on the sides of the arms. The spines are very numerous, fine, and pointed and intermixed with pedicellariae. The two other smaller specimens have analogous characters.

In another specimen form station $39(R=26, r=9 \mathrm{~mm})$ that is shown in Pl. VI, fig. 1, the network is very compact, although the trusses are not very large. It is possible to recognize a sinuous carinal row with small narrow plates. Then, outside, are some small, irregular ossicles and nearly all the dorsal surface of the arms is filled with numerous, compact transverse trabeculae. In some very small specimens, this network already is compact. This is the same in the individual from station 54 shown in Pl. VI, fig. 3, whose $R$ does not excede $14 \mathrm{~mm}$. The carinal line is formed by a continuous series of joined ossicles from which leave parallel compact trusses.

To the contrary, in the sample from station 42 shown in $\mathrm{Pl}$. V, fig.5, whose $R$ is only $20 \mathrm{~mm}$, the dorsal surface of the arms shows only isolated, relative large ossicles, each with a very sturdy spine and forming three more or less regular rows. In addition, some incomplete and inconstant transverse trusses are on the arms and here and there some rare crossed pedicellariae.

In the specimen from station 42 (Pl. V, fig. 2 and Pl. VI, fig 2 and 8) in which $R$ is 44 and $r$, $11 \mathrm{~mm}$, the trusses of the lateral parts of the arm still form parallel irregular lines, but the median region is constituted of ossicles with very variable form and dimensions. These ossicles are sometimes isolated, sometimes connected by short trusses. In sum, here the skeleton is less developed than in the preceding specimens while the teguments are thicker and hide the calcareous network in individuals in alcohol. Spines are lacking on the dorsal surface of the arms but in contrast crossed pedicellariae are very dense. An analogous disposition is found on the largest specimens of station $42(R=47, r=12)$, with some rare spines and a small number of straight pedicellaraie. This last individual carries a brood of young under the mouth.

The specimens from station 3 and the specimen from station 40 shown in Pl. VI, fig. 10, have very distinctive characters. The calcareous network is well developed. I is very fine, but compact in specimens of station 3 that has spines on the sides of the arms. In those of station 40 in which $R$ $=18 \mathrm{~mm}$, it is formed of very sturdier and more separated trusses and spines are lacking. The large straight pedicellariae of which I shall speaker later and that are abundantly distributed elsewhere are here very small and not numerous. But in contrast, the crossed pedicellariae become extremely abundant and so very dense as to give the dorsal surface of these specimens a distinctive aspect, as can be seen in the photographs shown here in Pl. V, fig. 6 and Pl. VI, fig.10. However, in one of the specimens from station 3 , these pedicellariae do not exist on the median region of the arms are only on the sides.

In the specimens from station 48 , there is also a large number of crossed pedicellariae on the dorsal surface of the arms and the calcareous network is very compact. The straight pediceellariae found on the sides are very large.

One sees, as I have just said, that there are great differences in the development of the dorsal skeleton of the arms in A. pedicellaris and one finds intermediates between the specimens in which the skeleton reaches a very great development, as for example the specimen from Port Louis that I described in the first place (Pl. V, fig. 3) up to the others where the skeleton is very reduced, for example in a specimen from station 42 and that although the sizes of the specimens are very close. This skeleton can be formed of ossicles reaching an appreciable size, isolated or connected by trabeculae, or to the contrary be constituted by a fine network, either irregular and with large 
meshes or forming to the contrary dense meshes, arranged chiefly in transverse trusses on the sides of the arms, and that in specimens of very different sizes. Finally, in other specimens of small size, this skeleton is completely rudimentary. The spines and the crossed pedicellariae also have great variations.

As for the dorsal and ventral plates, they are always very large and form all along the arms a double, very apparent and important row. These plates have dispositions analogous to those I described in some detail in Anasteris Victoriae (1920, p. 21-23). The plates have nearly the same dimensions in each row, or the dorsal marginals are slightly smaller than the ventral marginal. The former have a general cross shape and imbricate following the usual mode. Each has a spine, rarely two. The ventral marginal plates project more than the dorsals and slightly are taller. They each have two spines forming a small oblique row and one slightly larger than the dorsal spines (Pl. VI, fig. 2, 7, 8 and 9). On large species, one can distinguished between these spines and the adambulacral spines, an irregular row of spines that often seems continuous with those of the ventral marginal and that correspond to a more or less developed row of latero-ventral plates.

The adamabulacral spines are very thin, cylindrical, elongated with a rounded tip and very regularly arranged in a single row.

A very remarkable character of $S p$. pedicellaris is the presence of straight pedicellariae that often reach very large sizes and that are found in general very abundantly on the sides of the arms, the ventral marginal plates or the latero-ventral plates. These pepdicellariae are chiefly numerous in the proximal half of the arms but they can continue nearly the entire length. Of course, they occur equally in ambulacral furrow. I have stated the variations in the number and size of these pedicellariae, but their presence and development appear to me to be an essential character of the species. Some of the photographs I give here give an idea of their form and distribution (Pl. VI, fig. 2, 5, 7, 8 and 9). Their length reaches and passes $1 \mathrm{~mm}$. The form of the valves has some variations. Either these valves are simply triangular with the summit more or less rounded or they take a spatulate or biscuit form.

Exceptionally, the straight pedicellariae are not numerous and are small in the specimens of Sparrow Cove, East Falkland that, by its reticulate skeleton, shows well the same characters as the three other individuals. It is the same in the specimen from station 54, in the two from station 3 and in those of station 40. As I have said above, these three latter individuals have in turn an extraordinary abundance of crossed pedicellariae on the dorsal surface of the arms. In all the other specimens, these crossed pedicellariae are scattered on the dorsal surface of the arm, in general few and are not united in a collar around the base of the spines. They never form clumps around the dorsal and ventral marginal spines, in the same way as occurs for example in Anasterias tenera. The structure shows nothing iin particular. In the specimens in which $R$ reaches about $50 \mathrm{~mm}$, the length of their valves is $0.4 \mathrm{~mm}$.

I regard the specimens collection by the Mission of Cap Horn to the Falkland Islands and to which Perrier gave the name Anasterias Perrieri (1891, p. 97) should be changed to $S p$. pedicdllaris. In my memoir on the asteroids of the "Australian Antarctic Expedition" (1920, p.13), I already spoke of these specimens and I explained that because of a skeleton that had completely escaped Perrier, I had believed it necessary to place them in the genus Sporasterias. I would consider them as Sporasterias antarctica with a very reduced skeleton. But the comparison that I have been able to do with the Sp. pedicellaris of the "Swedish Antarctic Expedition" has shown me that they cannot be distinguished specifically and I think there is cause to give them the same name. These specimens have a skeleton formed of a very delicate and loose network. In addition 
it has large straight pedicellariae between the marginal spines of the lateral surfaces of the arms. These are so remarkable that I have indicated above in Sp. pedicellaris collected by Nordenskjöld.

It is indisputable that the species of the Mission du Cap Horn that Perrier named Anasterias Perrieri, (and that is thus Sporasterias pedicellaris), does not correspond at all to Anasterias Perrier of South Georgia described by Studer. It perhaps is useful to note here that this latter should certainly be an Anasterias and that Studer has not committed the same error as Perrier. The Swiss author took care to note that the skeleton of his species contains only adambulacral plates and marginal plates, the dorsal surface has only a reticulated calcareous ring bordering the disk. The entire remaining surface, adds Studer, is covered by a soft tegument.

The reduction of the skeleton, accompanied by a reduction in the number of spines, as well as the presence of large straight pedicellaria on the sides of the body, constitute two characters that appear sufficiently important to me to justify a specific separation. I also wonder if some individuals considered by the authors to be Sporasterias antarctica with a more or less reduced skeleton should not be similar to Sp. pedicellaris. In this regard, I recall that Meissner indicated that the skeleton of $S p$. antarctica has great variation, but it would be necessary to examine the specimens to be certain of the determination.

By the external appearance, the more or less soft consistency of the dorsal surface of the body, Sporasterias pedicellaris recalls rather Anasterias. To make a correct identification, it is absolutely essential to examine dried specimens.

To what extent the dorsal skeleton of Sp. pedicellaris is more reduced than in Sp. antarcticus, it is necessary to ask another question. Should Sp. pedicellaris not be considered as an Anasterias with a very developed skeleton rather than as a Sporasterias with a reduced skeleton? Obviously, this latter point of view could be supported but then it would be necessary to give a very much greater extension to the genus Anasterias. If one believes it is correct to attribute to this genus of asteroids a calcareous network completely covering the dorsal surface of the arms, what characters could we use to separate the genus Sporasterias? I do not see any for my part. I thus regard there is reason to characterize the genus Anasterias, in the same way that has done up to the present by all authors, by its reduced dorsal skeleton on the dorsal surface of the disk, with some ordinarily isolated ossicles that are uniformly scattered at the base of the arms, the remainder of the dorsal surface itself being nearly lacking of a skeleton. But one cannot conceive a case in which it will be difficult or even impossible to relate with certainty any individual to the genus Anasterias instead of the genus Sporasterias.

Similarities and differences. Sp. pedicellaris is distinguished from Sp. antarctica by the very marked reduction of the dorsal skeleton and by the presence of large straight pedicellaria on the sides of the arms.

\section{Cryptasterias brachiate nov. sp.}

(Pl. I, fig. 9 and 10.)

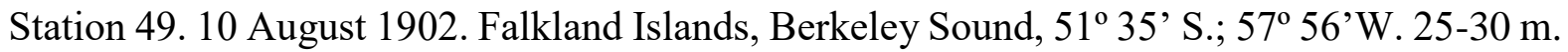
Stones, shells. A single example with eight unequal arms.

$R=60, r=14 \mathrm{~mm}$. The arms measure 10 to $11 \mathrm{~mm}$ at their base, they are narrow and the taper progressively up to their end which terminates in an obtuse point. 
I believe it is necessary to place this species in the genus Cryptasterias established by Verrill in 1914 for the Antarctic asteroid that I described in 1906 under the name Diplasterias Turqueti. The general appearance is the same, the adambulacral spines are arranged in two rows and there is a skeleton form of a very fine and very delicate network that offers also very little resistance.

In the example in alcohol, the dorsal surface is covered with cutaneous expansions or pustules with irregular contours, very dense and small. Each pustule contains a spine that it covers completely and some crossed pedicellaraie. But the essential characters of the asteroid can be studied only in the dried animal that I show here in the photographs Pl. I, fig. 9 and 10. One recognizes first of all on the dorsal surface of the disk and the arms numerous relative short and thick spines no longer than one $\mathrm{mm}$ in length, slightly swollen towards the end that is rounded and measures 0.6 to $0.8 \mathrm{~mm}$ in diameter on the disk. The spines on the arms are a little smaller. Each has fine spinules that make the surface rough. Around each spine is a circle of six to twelve crossed pedicellariae emerging from a dark tissue that is a dried pustule. The valves of these pedicellalraie are 0.2 to $0.25 \mathrm{~mm}$ in length. These spines are near each other and generally arranged without order. However, one can see on some arms and in their first quarter a tendency to form some alignment, at least in the carinal line.

The madreporite plate is single and very near an interarm angle. It is small, rounded with a diameter slightly more than $1.5 \mathrm{~mm}$. Its surface has very apparent grooves. Between the clumps of crossed pedicellariae are straight pedicellariae that appear chiefly on the sides of the arms. Their valves reach 0.7 to $0.8 \mathrm{~mm}$ in length. These valves are elongated, triangular, not at all intersecting at the end and have no particular characteristic.

One can see without preparation that the spines come from a network with a very tight mesh on the disk. It becomes less dense on the dorsal surface of the arms and especially on their sides. But a treatment with potash is necessary for a complete study of the network. In spite of my extreme caution in the treatment, the network disintegrated very quickly so that I do not have a photograph. This network is extraordinarily delicate and the wall of the body in the dried animal is a true pellicle. Whatever it is, the network is very irregular on the dorsal surface of the disk. The trusses that make it up are chiefly directed transversally on the dorsal surface of the arms. On their sides, the transverse arrangement of the trusses becomes still more marked and the ossicles are arranged very regularly one after another, forming parallel trusses that enclose rectangular, narrow areas (fig. 10). These trusses contact the dorsal marginal plates. The area they border has dense pustules that surround spines, a very dense covering completely hiding the underlying skeleton.

The dorsal marginal spines, one per plate, are slightly larger than the adjacent ones. They are surrounded by a thicker collar with numerous pedicellariae. These plates have the usual form, i.e. they are taller than wide, triangular with a dorsal very short apophysis, an elongated ventral apophysis partially covering the corresponding ventral marginal plate. The ventral apophysis surround spaces through which pass several papulae. Each of the small marginal plates has a single spine that is very large, flat and much more developed than the dorsal marginal spines. These spines are surrounded by a very developed collar. Between them, as also in the space that separates the two marginal rows are some large straight pedicellariae.

The ventral surface of the body has, between the ventral marginal plates and the adambulacrals, an interval that decreases rapidly and has a row of plates with a distinct contour but lacks spines. One sees only some very rare straight pedicellariae. This row disappears towards the middle of the arm length. In the furrow are several very large straight pedicellariae, especially towards the mouth where some reach or surpass a length of $1 \mathrm{~mm}$. 
The ambulacral furrows are very large. The tube feet are small and very dense. The adambulacral spines are very regularly arranged in two rows. They are elongated, cylindrical, with rounded ends.

The color of the specimen in alcohol was grayish.

Similarities and differences. - The genus Clyptasterias was known only by a single species, C. Turqueti, which is also Antarctic that was discovered by the first Charcot Expedition at BothWandel Island. This species has only five arms. The new Cryptaterias is distinguished immediately by the number of arms, the much more numerous and smaller spines surrounded by small pustules containing crossed pedicellariae. The calcareous network is also much more delicate than in C. Turqueti.

\section{Podasterias Brandti (J. Bell.)}

(Pl. II, fig. 2 and 3.)

See the bibliography

Diplasterias Brandti Meissner (1904), p. 7.

Diplasterias Brandti Kœhler (1908), p. 572, P1. V, fig. 50 and 51.

Diplasterias Brandti Bell (1908), p. 7.

Diplasterias Brandti Kœhler (1912), p. 19, Pl. I, fig. 3, 5 and 6.

Diplasterias Brandti Kœhler (1917), p.26, Pl. IV, fig. 16 and 17; Pl. V, fig. 11, 13 and 14.

Diplasterias Brandti Kœhler (1920), p. 4 1, 51, Pl. XII, fig. 11; Pl. XIV, fig. 5 and 6.

Station 20. 6 May 1902. South Georgia, Antarctic Bay, 52 12’S.; 54 12’ S; 250 m. Small stones. A small specimen.

South Georgia without other information. Two large specimens.

Falkland Islands, Port Louis:

Station 41. 23 July 1902. Berkeley Sound. 51º 33' S.; 58 9' W. 2-4 m. Three very small specimens.

Station 44. 28 July 1902. Greenpatch. $51^{\circ} 33^{\prime}$ S.; $58^{\circ} 10^{\prime} \mathrm{W} .7$ m. One specimen.

Station 50. 12 August $1902.5^{\circ} 33^{\prime} \mathrm{S} . ; 58^{\circ} 9^{\prime} \mathrm{W} .7 \mathrm{~m}$. One small specimen.

I will consider here chiefly the two large specimens from South Georgia. One has five arms and the other, six. The other specimens are small with an $R$ is less than $22 \mathrm{~mm}$. That of station 20 (South Georgia) has six arms and the others coming from the Falkland Islands have only five.

In the specimen with five arms, $R$ is from 50 to $55 \mathrm{~mm}$ and $r$ is $11 \mathrm{~mm}$. The arms of the individual with six arms are a little unequal. In the largest, $R$ is $72 \mathrm{~mm}, r=13 \mathrm{~mm}$. There is a single madreporite. As for the general structure, these two individuals are perfectly identical. The skeleton is formed of an irregular network made up of distinct ossicles that surround irregular popular areas. On the sides of the arms they are arranged in more or less exactly parallel rows. On the median carinal line, the ossicles are scarcely larger than the adjacent ones. They form a line that, although very distinct, is not conspicuous. The dorsal spines are numerous but short. The spines of the dorsal marginal plates, one per plate, are a little longer and sturdier. Those of the ventral marginal plates, two per plate, are larger, thicker, flat and often enlarged at the end that is more or less truncate. A row of latero-ventral spines do not reach even half the length of the arms. 
The two individuals are remarkable by the presence on the dorsal surface of numerous straight pedicellariae intermixed with crossed pedicellariae. But these do not form particularly distinct collars around the spines except around the dorsal marginal spines and on the dorsal side of the ventral marginal spines. Elsewhere these collars are not very developed. The straight pedicellariae are equally numerous on the lateral surfaces of the arms, between the marginal rows and in the midst of the marginal spines, and pm the ventral surface where they are larger than on the dorsal surface. They can reach one mm in length. Their triangular valves are often rounded at the end but they are never spatulate. The valves of the crossed pedicellaria are 0.5 and even $0.6 \mathrm{~mm}$ in length.

The photographs I give here show the distinctive aspect of the dorsal surface of the body because of the presence of numerous straight pedicellariae (Pl. II, fig. 2 and 3).

I believed it was necessary to give some information on the characters of these individuals that show a form little different from that which one knows typically in P. Brandti. In addition, it is very interesting to note that the species can have six arms. This is the first example of this. These two individuals of Georgia are completely identical to each other except for the number of arms. However, perhaps there is cause to establish a name for this variation by a name and to consider the form with six arms as a variety that I propose to call sexbrachiata of Podasterias Brandti.

The small individual with six arms from station 20 has some crossed pedicellariae around the dorsal spines and some straight pedicellariae.

Asterias Studeri described by Studer (1884, p. 8, Pl. I, fig. I) also has six arms. It was collected at a depth of $100 \mathrm{fms}$ at $47^{\circ} 5^{\prime} \mathrm{S}$. and $66^{\circ} 41^{\prime} \mathrm{W}$. Studer believed it necessary to distinguish it from Asterias meridionalis, but without clearly describing its characters. It does not appear to me possible to indicate in a precise manner the differences of these two species. Is Asterias Studeri also Podasterias Brandti var. sexradiata or indeed is it Pod. meridionalis? This is impossible for me to decide but the two alternatives are possible.

\section{Podasterias Brandti, var. glomerata (Sladen)}

(Pl. II, fig. 4.)

Asterias glomerata Sladen (1889), p. 57 1, pl. CV, fig. 1 to 4.

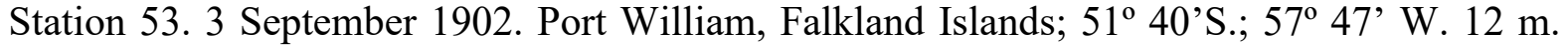
Sand and gravel. One specimen.

Station 59. 12 September 1902. Burdwood Bank to the south of W. Falkland; $53^{\circ} 45$ S.; $61^{\circ}$ 10' W. 137-150 m. Shell hash and stones. Two specimens.

Swedish Magellan Expedition. St. 8. 5 December 1907. West Point Island, West Falkland. 0 m. Rocks. One specimen.

One specimen from station 59 is very small and one has regenerating arms. The other specimens are very large. They measure respectively $R: 55,65$ and $65 \mathrm{~mm}, r: 10,12$ and $15 \mathrm{~mm}$.

In the individuals from station 53 and those of 1907, the arms are comparatively a little larger at the base and a little shorter than in the larger specimen from station 59 where they are relatively narrow and taper progressively to the end which is pointed. In the smaller individual of station 59, one of the arms is regenerating. All three specimens conform well to the description of Sladen.

As I had the occasion to say in 1908 (p. 57), 1912 (p. 18) and 1917 (p. 26), P. Brandti is a polymorphic species for which there is no reason for separating specifically $P$. Loveni (Perrier), Lütkeni (Perrier), Belli, Studeri and glomerta (Sladen), neglecta (Bell). I always maintain this same 
point of view, but I consider that, when possible, i.e., when the specimens have certain constant characters and also when the descriptions of the authors are sufficiently precise and accompanied by good figures, it is useful to distinguish the forms to which the rank of varieties can be given.

This, it seems to me, is the case of the asteroid that Sladen described under the specific name Asterias glomerata for specimens coming from the Falkland Islands and from the Atlantic entrance of the Strait of Magellan. The three individuals that I mentioned above completely conform to the description and figures of Sladen. They are distinguished by the dense and very regular clumps of large crossed pedicellariae that surround the base of the spines and form with them very regular longitudinal rows, the large straight pedicellariae that occur here and there between these clumps, chiefly on the lateral surfaces and the ventral surface of the arms. These individuals thus have a very distinctive physiognomy. The photograph of the individual from station 59 will give a good idea. (Pl. II, fig. 4)

\section{Podasterias Steineni (Studer).}

(Pl. III, fig. 7, 8 and 9.)

Asterias Steinenii Studer (1885), p. 152, Pl. I, fig. 4a, b).

Diplasterias Steineni Perrier (1891), p. 84.

Diplasterias Steineni Kœhler (1912), p. 20, Pl. I, fig. 4, 7 and 10.

Diplasterias Steineni Kœhler (1917), p. 26.

Diplasterias Steineni Kœhler (1920), p. 41.

Station 59. 12 September 1902. Burdwood Bank to the south of West Falkland. $53^{\circ} 45$ ' $\mathrm{S} ; 61^{\circ}$ 10 'W; 127-150 m. Shell hash and stones. One specimen. $R=36, r=7 \mathrm{~mm}$.

Station 60. 15 September 1902. East opening of the Beagle Channel, Tierra del Fuego; $55^{\circ} 10^{\prime}$ $\mathrm{S}$.; $66^{\circ} 15^{\prime}$ W. $100 \mathrm{~m}$. Shell hash. One specimen. $R=30, r=7 \mathrm{~mm}$.

The original description by Studer was completed by Perrier in 1891 from two specimens collected south of Cape Horn. The determination was confirmed by the comparison Perrier was able to do with one of the types of Studer coming from South Georgia. I myself studied the specimens from the Mission of Cap Horn and I had the opportunity to publish some photographs in 1912 (Pl. I, fig. 4, 7 and 10).

The individuals described by Studer had arms very swollen at the base while those of Perrier were much less. The smallest individual collected by the "Swedish Antarctic Expedition" from station 60 greatly resemble in form that that I described in 1912. The other individual has slightly larger arms and the form is a little different. They are not in any ways swollen at the base but are cylindrical, relatively long and narrow, and slow taper to the end which is obtuse. The photograph of this individual is in Pl. III fig. 8. In all these specimens, the general characters of tegumentary appendices remain absolutely the same. The spines, papulae, straight and crossed pedicellariae reach to nearly the same level and remain very dense. As Perrier said, "The covering of the dorsal surface of the disk and the arms appears made up by a kind of homogeneous granulation and as smooth..." In the dried specimens, the spines are elevated however in a notable way above the other parts of the tegument. They are much larger and thicker than the adjacent pedicellariae that are always crossed. They spines, moreover very short, end in a rounded head with small sides having fine spinules. The valves of the crossed pedicellariae are $0.35 \mathrm{~mm}$ and those of straight pedicellariae are $0.8 \mathrm{~mm}$ in length. 
I treated a portion of the arm of the specimen from station 59 with potash and I am able to confirm that the skeleton is made up of a very compact irregular network formed of irregularly arranged ossicles except on the carinal line of the arms where they form a slightly irregular longitudinal row. These ossicles are slightly larger than the adjacent ones (P1. III, fig. 9). This arrangement is quite identical to that I have described in other species of the genus Podasterias where the species is thus correctly placed.

\section{Podasterias meridionalis (Perrier).}

Podasterias meridionalis Perrier (1875), p. 76.

Podasterias meridionalis Smith (1879), p. 72

Podasterias meridionalis Kœhler (1917) p. 20, PL II, fig 11 and 12; Pl. III, fig. 1, 2, 4, 5, 6 and 7; Pl. VI, fig 8; Pl. VII, fig. 9.

Two individuals from South Georgia without other indication of station. Both have six arms.

I dried one of the specimens in order to study the characters of the skeleton. This is shown in a photograph here (Pl. II, fig. I). The other individual remains in alcohol.

These two specimens completely resemble various individuals collected at Kerguelen by Rallier du Baty or by the "Gauss Expedition" and it is impossible for me to separate them specifically.

In the dry individual, the arms are narrow at the base and taper very slowly. The disc is rather small; $R=56, \mathrm{r}=14 \mathrm{~mm}$. The arms are $12 \mathrm{~mm}$ wide at the base and diameter of the disk is $24 \mathrm{~mm}$. The $R / r$ ratio is 4 . This individual greatly resembles the individual from Kerguelen that I described in 1917 (Pl. II, fig. 2). Compared o the other specimen, the $\mathrm{R} / \mathrm{r}$ ratio is nearly the same, the arms are however a little narrower at the base. The spines of the dorsal surface are not numerous, scattered and very short. It is difficult to distinguish a very clear carinal row or at least it is very irregular. However towards the middle of the arms the spines are larger and instead of being cylindrical, as in the individuals from Kerguelen, they are clearly capitate. Their head has numerous short conical and pointed spinules that give them a striated aspect. On the sides of the arms, the spines, few and irregularly distributed, tend to become cylindrical. Those of the ventral marginal plates are also a little sturdier, flat and sometimes there is only one per plate. A row of very narrow, rectangular latero-venral plates, longer than wide, can be distinguished. But they do not pass the middle of the arms. Some plates alone have a spine. The adambulacral spines are biserial some some irregularities.

Crossed pedicellariae occur towards the base of the spines but do not form very regular collars. Or those that exist do not contain many pedicellariae. Collars are much better formed, more apparent and much more regular at the base of the dorsal marginal spines, while the ventral marginal spines have only demi-collars. Moreover, there are very large straight pedicellariae scattered on the dorsal surface of the body. They become larger on the lateral surface and especially in the region of the mouth in the ambulacral furrow where the length reaches $1.5 \mathrm{~mm}$. In the rest of the furrow, these pedicellariae remain still very large but they are not very numerous. The specimen in alcohol is a little larger than the preceding: $R=$ approximately $80 \mathrm{~mm}$. The dimensions cannot be measured with certainty because the animal is fixed in the brooding posture. The disk 
and the proximal region of the arms are greatly elevated. However, there are no young under the mouth.

The dorsal surface of the disk and the arms has very short, thick spines that end in a rounded head. They are irregularly distributed on the dorsal surface of the disk where they are a little larger than on the arms. In the latter, the spines do not follow in general regular alignments except here and there. However, outside of a carinal range, there are two lateral rows on each side that are both distinct. Each spine is encircled by a collar or pustule. These very large collars are contiguous and even made polygonal by reciprocal pressure. They are more developed and projecting around the dorsal and ventral marginal spines. They form two very apparent and very regular rows on each side of the arms. This individual greatly resembles the specimen from Kerguelen whose photograph I gave in 1917 (Pl. VII, fig. 9). But the contours of the collars that surround the spines at their base are only a little less clear. From the point of view of posture, this individual has arms more separated from each other than in the specimen from Kergulen and their distal half is nearly horizontal.

Compared to the crossed pedicellariae of the two specimens of P. Brandti from South Georgia that I described above, and with similar dimensions, the pedicellariae of $P$. meridionalis are much smaller and their length scarcely passes $0.25 \mathrm{~mm}$. In the specimens from Kerguelen to which I compared these two individuals, the crossed pedicellariae are similarly few. They appear only in the area of the ventral marginal spines. They are however a little larger than in the specimens from South Georgia and their length can reach $0.4 \mathrm{~mm}$. But is necessary to recognize also that the individuals are a little larger. The straight pedicellariae are likewise few and occur only the ventral surface. Their length does not exceed $1 \mathrm{~mm}$.

The other individual from South Georgia that is in alcohol is perfectly identical to the preceding. It is a little larger: $R=65 \mathrm{~mm}$. On the disk, the spines are surrounded by large dense pustules, becoming polygonal be reciprocal pressure and separated by fine but very distinct lines. The separation of the pustules is less clear on the arms and is seen only in places. The spines are not regularly aligned. The two dorsal and ventral marginal rows are, as usual, well-marked and made up of thick collars.

The specimen from station 20 is a little larger than the preceding and $R=125$ to $130 \mathrm{~mm}, r=$ $18-19 \mathrm{~mm}$. The arms are $25 \mathrm{~mm}$ in width at $2 \mathrm{~cm}$ from their base because they slightly narrow at their insertion onto the disk. This individual is remarkable for the regular arrangement of the spines of the dorsal surface of the arms, or better of the collars with pedicellariae that surround the base of these spines. The carinal row is very distinct and sinuous. Outside it at the base of the arms are two and even three irregular rows of pustules that disappear in the last third of the arms. The carinal row continues to decrease regularly and gradually in size up to the end of the arms. The dorsal and ventral marginal rows are extremely developed and form two very regular bands that limit the lateral vertical surfaces of the arms. This specimen, greatly resembling other $P$. meridionalis from Kerguelen, so that, for example, that I showed in my memoir of 1917, Pl. III, fig.2 and Pl. VI, fig. 9 , but here the pustules are much more regular and apparent. The carinal row is notably much more distinct on the specimen from station 20. This can be taken into account in comparing the photograph I give here Pl. XIII, fig. I, to the photograph published Pl. III, fig. 2 of my memoir of 1917. The arrangements recall quite particularly those that I have had the occasion to describe in $P$. Bruce $i$ and I even wondered about this subject if one should not consider the latter as a form of $P$. meridionalis with five arms, the same as we saw above that $P$. Brandti has a form with five arms and another with six. I thus carefully compared $P$. meridionalis, and most particularly that of station 20, with specimens of P. Brucei. The comparison was all the more indicated as the 
collection of Nordenskjöld contained a specimen of $P$. Brucei from station 6. I must say that the result of this comparison has been that the species, while being more or less near each other, are however quite distinct. I say "more or less" because $P$. meridionalis has great variation in its characters, notable those concerning form, arrangement, number, size, etc. of the spines of the dorsal surface of the body, variations already indicated by Smith and to which I returned in greater detail in 1917. Laying aside for the moment the number of arms, I will first of all remark that, in the specimens of the same size, the dimensions of the pustules or collars of the dorsal surface of the body of greater in P. Brucei and notably these pustules are more projecting, more marked in $P$. meridionalis. They are more distinct from one another and separated by deeper spaces. The appearance is always different as one can judge in comparing the photographs of $P$. Brucei and meridionalis that I give here (Pl. XIII, fig. 1 and 2). Moreover, and this is a character of the greatest importance, there is always a very developed row of spines in P. Brucei, nearly equal to the adjacent ventral marginal spines and surrounded like them with a collar of pedicellaria located between these spines and the adambulacral spines. They continue very far on the arm and even pass the mid-length of thearm. To the contrary, in $P$. meridionalis, there remains between the ventral marginal plates and the adambulacral spines a very wide space that, most usually, has only some papulae. Spines are encountered there accidentally and very rarely. When they exist, they remain very few in number, are irregularly arranged, and always widely separated from one another.

The characters taken from the arrangement of the spines and the form of the collars of pedicellariae that surround the base of the spines appear less variable in $P$. Brucei than in $P$. meridionalis. However, I have had the occasion to indicate formerly two specimens of P. Brucei collected by Shackleton at Cape Royds that are very different from the type point of view in the distribution of the dorsal spines, because I had first believed to have a matter of a new species. But the two specimens that I had afterwards related to $P$. Bruce $i$ had the characteristic range of lateroventral spines that I always encounter in P. Brucei.

As for the pedicellariae, some differences can be noted between those of P. Brucei and meridionalis. These differences are very weak. However, the crossed pedicellariae appear to me comparatively small in $P$. meridionalis. In measuring the valves of specimens of the same size $(P$. meridionalis of station 20 and the two P. Brucei of station 6), I find that in the first species the valves of the crossed pedicellariae are $0.2 \mathrm{~mm}$ in length, while those in the second species reach 0.27 . In any case, there can be no question of reuniting the two species and of considering P. Brucei as a variety of $P$. meridionalis with five arms.

I believe it must be reported likewise of four small $P$. meridionalis with six arms from stations 17, 20 and 20 in which $R$ varies between 18 and $28 \mathrm{~mm}$.

\section{Podasterias Brucei (Kœhler)}

$$
\text { (Pl. XIII, fig.2.) }
$$

Stolasterias Brucei Kœhler (1908), p. 41, Pl. VI, fig. 46 and 47.

Coscinasterias Brucei Kœhler (1911), p. 30, P1. V., fig. 5.

Coscinasterias Victoria Kœhler (1911), p. 32, P1. V, fig. 3 and 4.

Coscinasterias Victoria Kœhler (1912), p. 24.

Podasterias Brucei Kœhler (1920), p. 42, PL. IX, fig. 5 to 7;Pl. XIII, fig. 1 to 9; Pl. XIV, fig. 4 and 7 to 11; Pl. XI, fig. 4 and 5. 
Station 6. 20 January 1902. Graham's Land, to the southeast of Snow Hill Island. 64 ${ }^{\circ} 36^{\prime}$ S.; $57^{\circ} 42^{\prime}$ W. 125 m. Stones and gravel. A large specimen.

$R=120, r=21 \mathrm{~mm}$. The specimen is in excellent state of preservation. The arms are stretched out and there is no indication of eggs.

The carinal line of the arms is marked by a sinuous row of large pustules, each enclosing a spine whose terminal part emerges from the pustule. On each side are two or three irregular rows of pustules that are a little smaller. Only one is found in the last quarter of the arms. The spines of the lateral pustules are smaller than the carinal spines and they rarely emerge outside the pustule that envelopes them. The carinal pustules progressively decrease in size in the distal part of the arms. On the ventral surface, between the adambulacrals and ventral marginal, is a row of pustules smaller than the adjacent ventral marginal. Each encloses a small latero-ventral spine. The pustules disappear towards the middle of the arms but the spines continue further. The adambulacral spines are greatly flattened and their obtuse end is often enlarged.

The individual is nearly the same size as the largest of the three specimens collected by the Scottish Antarctic Expedition that I used to describe the species. In the same way I said above on the subject of $P$. meridionalis, this species is completely justified and would not be considered a variety of $P$. meridionalis with five arms.

In my memoir on the asteroids of the "Australian Antarctic Expedition", I have given the reasons for which our species should be transferred to the genus Podasterias. I have studied some specimens of $P$. Bruce $i$ and I have published the photographs of some of them. I ask the reader to refer to this memoir. Nevertheless, it appears to me to be of interest to place here, beside each other (Pl. XIII, fig. 1 and 2) a P. Brucei and a P. meridionalis, both seen by the dorsal surface, in order to make it possible to judge the difference in external appearance of the two species.

\section{Cosmasterias radiata nov. sp.}

(Pl. II, fig. 5; Pl. III, fig.1 and 2.)

Station 17. 19 April 1902. Shag Rock Bank, between the Falkland Islands and South Georgia. $53^{\circ} 34^{\prime}$ S.; $43^{\circ} 23^{\prime}$ 'W. 160 m. Gravel and sand.

Six specimens, five to eight arms and one with ten arms all equal or unequal. The arms are very regularly arranged regularly around the disk and do not give the least indication of regeneration or fissiparity. All the specimens are yellowish white in alcohol, except for one that is very deep brownish gray.

In the largest individuals with eight arms, the total diameter is $32 \mathrm{~mm}$ and only 15 in the smallest. It is $31 \mathrm{~mm}$ in the individual with ten arms.

These asteroids are completely different from the other species of the same family that I have reported above either in the genus Podasterias or the genus Cryptasterias and I consider it as new. It is possible that the individuals are not adults. It can be said however that in the six individuals collected, the dimensions are very near and that the individuals came from the same locality. Moreover, I do not know any species with several arms, Antarctic or sub-Antarctic, to which it would be possible to relate it. 
I shall describe the species according to the largest specimen with a total diameter of $32 \mathrm{~mm}$. The diameter of the disc is $10 \mathrm{~mm} ; R 16 \mathrm{~mm}, r 5 \mathrm{~mm}$. The arms are $3 \mathrm{~mm}$ at the base. The specimen is shown in Pl. II, fig. 1 and 2.

The arms are equal, very distinct from the disk at their base. They narrow slowly up to their end that is very obtuse. The dorsal surface of the disk is formed of numerous crowded ossicles, forming a network from which is raised short spines, two to four per ossicle. They become a little larger towards the periphery of the disk. These projecting ossicles have a tendency to be arranged in concentric circles towards the periphery of the disk. Near the base of the arms is a very clear circle formed by ossicles a little more projecting that the others and whose spines are at the same time a little loner and sturdier. The single madreporite plate is very large, projecting and rounded. It is $1.6 \mathrm{~mm}$ in diameter. It is close to the border of the disk than the center and has several radiating grooves. Only at its periphery are two close spines that are a little larger than the adjacent spines. In the other individuals, including the specimen with ten arms, the madreporite plate is likewise single.

The ossicles of the arms are united in a way to form a regular network where the ossicles are larger, forming a carinal line that is a little sinuous. On each side between the carinal row and the dorsal marginal row is a row of smaller ossicles but arranged following a very regular line. These ossicles are connected by small transverse trusses surrounding irregular spaces that form four very irregular rows on the first half of the arms. They become confluent in the second half. Each of the ossicles has one to three small spines identical to those found on the border of the disk. They are cylindrical with an obtuse end. They have small spines on their surface that come more marked towards the end. At the base of these spines are some isolated crossed pedicellariae, one, two and sometimes three per spine but not forming a definite collar. Each papulae area encloses one to four papulae according to their size.

The vertical lateral surfaces of the arms are limited by the dorsal and ventral marginal rows. They are formed of twenty-two to twenty-five plates per row. They have the usual form, i.e. that the dorsal marginals are taller and larger, taller than long of a lozenge shape. They have a proximal apophysis covering the rod of the preceding plate and a more developed ventral apophysis corresponding to the ventral marginal plate. They surround the large, rounded popular areas. These spaces limited by the dorsal and ventral marginal plates are naked and I observed neither spines nor pedicellariae. The dorsal marginal plates have one or two spines on their dorsal border that are a little larger than the adjacent spines. At their base are one or two crossed pedicellariae. The ventral marginal plates, which are smaller and a little longer than tall, each have in general a spine that is a little longer than the corresponding dorsal spine and sometimes another smaller spine. At the base are one or two crossed pedicellariae. The narrow space that separates the ventral marginal from the adamblacral spines is naked or has one or two pedicellariae in the proximal region.

The adambulacral spines are very regularly arranged in two divergent rows. They are cylindrical and strongly spinulose in their distal half.

Each tooth has at the end a very large horizontal spine that is much larger than the adjacent adamblacral spines. On their ventral surface they have a spine analogous to the adambulacral spines and arranged obliquely. The ambulacral furrow has very numerous straight pedicellariae. They are very large, 0.35 to $0.4 \mathrm{~mm}$ in total length.

Similarities and differences. It is very difficult to decide because of the small size of the subjects, related perhaps to their young age, if the species should be placed in the genus Comasterias or in the genus Podasterias. The very regular arrangement of three longitudinal rows 
of ossicles on the dorsal surface of the arms would correspond to that in the genus Comasterias, but it could be objected that, as it involves young animals, it is possible that this regular arrangement disappears with age and that the species should be in Podasterias. However, I do not believe this because the young individuals of various species of Podasterias that I have had the opportunity to examine always have a more or less irregular reticulum. Whether the species incubates or not would be necessary to establish the generic position of the asteroid. This is not possible to decide at the present. I thus place it, provisionally at least, in the genus Comasterias. But whether it is a species of this genus or of the genus Podasterias, it is incontestable that it has a scarcely known form.

Among the diplacanthid species having numerous arms to which it could be compared, it is first necessary to separate $C$. fernandensis because it has fissiparous reproduction and has very unequal arms, something that does not exist in our species. Moreover, in $C$. fernandensisi the arms are generally less than eight and their triangular form together with the characters of the spines, etc. are completely different in the two species.

Asterias Rodophi Bell, a poorly known Antarctic species with six arms, is a large species with six arms and irregular groups of spines that does not exist at all in our species.

Cryptasterias brachiate that I have described above is also very different. Our species is certainly not the young form because the skeleton, formed in the same way of distinct ossicles arranged in regular longitudinal rows, is much more resistant and the ossicles themselves are larger and stronger. It is not a form with eight or ten arms of Podiasterias Brandti because if it is admissible that a species ordinarily having five arms can have six of them accidentally, it is very difficult to accept that the same species can acquire eight or even ten of them, and this in six individuals at the same time and station. Moreover, young Podasterias Brandti such as those of stations 41, 44 and 50, as well as others that I possess in my collection and which are scarcely larger than the $C$. radiata of station 17, have a more irregular reticulated skeleton and have large straight pedicellariae on the dorsal surface of their arms. Moreover, their aspect is completely different from that of our individuals.

Comasterias lurida (Phlippi).

See the bibliography:

Asterias sulcifera Leitpoldt (1895), p. 553.

Comasterias lurida Ludwig (1903), p. 40.

Comasterias lurida Loriol (1904), p. 39

Comasterias lurida Kœhler (1912), p. 22, PL. II, fig. 1 to 7; Pl. V, fig. i.

Comasterias luridaVerrill (1914), p. 358.

Two specimens without indication of locality; $R$ measures $140 \mathrm{~mm}$ in the larger and $65 \mathrm{~mm}$ in the smaller.

The large paddle-like pedicellariae, whose valves end in lobes crossed with those of the opposite valve, are particularly numerous in the large specimen. The valves with three unequal lobes that I have described and figured elsewhere (1912, p. 23, Pl. II, fig.5, 6 and 7), are always the most frequent. It is only exceptionally that valves ending in four or five lobes and found. 


\section{Ctenasterias georgiana (Studer)}

(PI. III, fig. 3 to 7 and 10.)

Asterias georgiana (1885), p. 150, Pl. I, fig 3a-3d).

Diplasterias georgiana Perrier (1891), p. 7.

Podasterias georgiana Kœhler (1917), p. 26.

Podaserias georgiana Kœhler (1920), p. 41.

Station 17. 19 April 1902. Shag Rock Bank, between the Falkland Islands and South Georgia. $53^{\circ} 34^{\prime}$ S.; $43^{\circ} 24^{\text {'W }}$. 160 m. Sand and gravel One specimen.

All the other specimens come from Cumberland Bay, South Georgia:

Station 19. 23 April 1902. Jason Port; 54 14' S.; $36^{\circ} 31^{\prime}$ W. 75 m. Clay, some algae. Two specimens.

Station 36. 13 June 1902. Marmite Bay; $54^{\circ} 22^{\prime}$ S.; $36^{\circ} 28^{\prime}$ W. 1-2 m. Sand and gravel. Two specimens.

Same location. 24 May 1902. Kelp holdfasts. Several specimens.

Same location. March and April 1905. Four specimens. Gift of E. Sörling.

Swedish Magellan Expedition. 24 April 1909. Stomnes fjord, South Georgia, 8 m. Stones. Three specimens.

The specimens have some variations, but I think they belong to the one and same species I reported as Asterias georgiana Studer.

The description this author gave of this species is not complete and notably the characters of the skeleton are not indicated in a very precise manner. Moreover, the figures are not very demonstrative. But I possess in my collection one of the specimens from the collection studied by Studer that has permitted me to confirm my identification. The specimen in particular is nearly identical to the three specimens collected 24 April 1909 by the "Swedish Magellan Expedition".

In the individuals from Marmite Bay, which are perfectly identical in structure (Pl. III, fig. 3 and 4), the greatest dimensions are R, 30 to $35 \mathrm{~mm}$, with r, 6 to $7 \mathrm{~mm}$. They, in summary, conform well to the type of Studer, but the skeleton is made up of a more delicate and finer network, bordering membranous spaces larger than Studer indicated and shows his figure. The trusses that make up this network are narrow, especially those arranged transversally. The membranous spaces are also widened transversally on the sides of the arms, principally those that precede the dorsal marginal plates that are small and not conspicuous. The ventral marginal plates are larger than the dorsals. They are united by narrow vertical trusses that border the rectangular or nearly square spaces filled with a very thin tegument that have papulae. There is not a distinct row of carinal plates. This structure of skeletal network greatly resembles that described by the authors in Asterias spitzbergensis. One can be convinced of this by comparing figures published elsewhere by Danielssen and Koren (1884, Pl. I, fig. I) with the photographs in Pl. III, fig. 5 and 6. Their spines which have calcareous trusses are generally in a single row. As they follow the direction of the skeletal trusses, they form chiefly small transverse combs. The dorsal marginal plates have two to four spines identical to the others. The ventral marginal plates have one oblique row with three and slightly sturdier spines. The adambulacral spines are very regularly biserial. All the spines are elongated, cylindrical and a little enlarged at the end. But they do not merit the name capitate. They have some small spinules on their last quarter. The crossed pedicellariae are small and not abundant. The straight pedicellaria are found chiefly on the sides of the body, between the dorsal 
and ventral marginal rows. They are elongated and narrow and conform perfectly to the figure of Studer (Pl. I, fig. 3d). They measure 0.45 to $0.5 \mathrm{~mm}$ in length. All have the same characters. The color of individuals in alcohol is very clear gray and even whitish. They were noted as "graybrown above" in live animals.

In the three individuals collected 24 April 1909 by the "Swedish Magellan Expedition", the general structure is more robust than in the preceding individuals (Pl. III, fig. 3 and 4). The arms are a little wider and a little shorter. The skeletal network is very large and the membranous spaces are still very large although a little shorter than in the previous specimens. The spines are a little shorter than in these. They terminate in a very marked head bearing sturdy dense spinules. The specimens in alcohol are grayish-brown. They are, as I have said above, completely comparable to a specimen studied and identified by Studer that I possess in my collection. I show one of them dried (Pl. III, fig.3), and a larger fragment of the dorsal surface (fig. 4).

Most of the other specimens are smaller. Their arms are comparatively thinner and their spines are less numerous and less developed. There are in the same way variations in the form of the spines that, in an individual from station 36 with only four arms, is still very strongly capitate. All these individuals are gray, sometimes clear, sometimes very dark. The very large and short crossed pedicellariae measure $0.3 \mathrm{~mm}$ in length and $0.2 \mathrm{~mm}$ in width. They are always isolated among spines of the dorsal surface but never very abundant.

In an individual collected by E. Sörling in March 1905, with $R=20 \mathrm{~mm}$, the general color is a very deep brown red. The spines are not at all capitate and one can note a large number of always isolated crossed pedicellariae between them. These pedicellariae are much more numerous in a specimen from station 22 ( $\mathrm{R}=16 \mathrm{~mm}$ only) that I show here (fig.7 and 10) that has a very clear gray color. In it, the spines are relatively little abundant, evidently replacing part of the spines. These individuals have a physiognomy a little different from the others but I believe nevertheless able to relate them to $C t$. georgiana.

Studer placed the species from South Georgia in the genus Asterias and Peerrier in the genus Diplasterias. I suggested in 1917 that it has its place in the genus Podasterias, but before I had the opportunity to study it. Now I confirm that the characters of the skeleton separate it from the genus Podasterias, while they greatly recall those of Ctenasterias spitzbergensis that Verrill made the type of the genus Ctenasterias. I find equally a very great resemblance between my specimens of Ctenasterias georgiana and Asterias groenlandica that Döderlein represented in 1900 (see Pl. V, fig.3 and Pl. IX, fig. 5). One knows moreover that Asterias groenlandica, placed recently in the genus Ctenasterias, is very close to Ct. spitzbergensis and that the two species should without doubt by united. Verrill, who took Asterias spitzbergensis Danielssen and Koren as type of the genus Ctenasterias, gave among the characters of the genus Ctenasterias the presence of two kinds of straight pedicellriae, one with triangular valves, the other with widened valves (lyriform pedicellariae of Danielssen and Koren). These latter do not appear to me to differ from spatulate pedicellariae known in various asteroids. Now, I have observed only a single form of straight pedicellariae in Ct. georgiana. But I must remark on this subject that Döderlein has reported only a single kind of straight pedicellariae in Asterias groenlandica. One can moreover wonder if the presence of two kinds of straight pedicellariae constitutes or not a generic character. I do not believe it and I think that one can without inconvenience place Asterias georgiana in the genus Ctenasterias. The two species of Urasterias, U. Linckii and panopla, also have from the point of view the form of the straight pedicellariae, very great important differences without authors judging it necessary to use this difference to place the two species in different genera. 
Kalyptasterias nov. gen.

(Pl. IV, fig. 1 to 7.)

The skeleton is formed by a network of irregularly arranged ossicles surrounding large popular areas. The dorsal marginal plates are little developed. They form a very irregular row and sometimes have a single spine but this is completely inconstant. To the contrary, the ventral marge plates are large and form a very conspicuous row. The two marginal rows come together near the ventral border of the arms. The spines of the dorsal surface of the disk and the arms are not vey numerous and are hidden by a thick, sot tegument that covers the entire body and hides the contours of the plates. The papulae are numerous and form areas arranged in continuous longitudinal rows. The adambulacral plates are uniserial.

In the type of the genus, the pedicellariae are not numerous and do not form collars at the base of the spines. Moreover, they are little developed.

The genus Kalyptasterias has affinities chiefly with the genera Calvasterias and Sporasterias and it seems preferable to me to discuss its affinities after having described in detail the specimens collected by the "Swedish Antarctic Expedition".

\section{Kalyptasterias conferta nov. sp.}

(Plate IV, fig. 1 to 7.$)$

Falkland Islands, Port Louis:

Station 44. 28 July 1902. Greenpatch, near the bridge. $51^{\circ} 33^{\prime}$ S.; $58^{\circ} 10^{\prime}$ W. 7 m. Mud and gravel with some algae. Two specimens.

Station 45. 6 August 1902. In the port. $51^{\circ} 33^{\prime}$ S.; $58^{\circ} 10^{\prime} \mathrm{W} .4 \mathrm{~m}$. Algae and stones. One specimen.

The three specimens are in excellent state of preservations and their dimensions are very similar. I have dried one of them in order to study the skeletal characters. Here are the principal dimensions that I have made on these individuals:

\begin{tabular}{llll} 
& \multicolumn{1}{c}{$R$} & $r$ & Width of the arm at the base \\
A dried specimen (Station 44) & $60-70 \mathrm{~mm}$ & $18 \mathrm{~mm}$ & $19-20 \mathrm{~mm}$ \\
B (Station 44) & $62 \mathrm{~mm}$ & $20 \mathrm{~mm}$ & $21-22 \mathrm{~mm}$ \\
C (Station 45) & $60-65 \mathrm{~mm}$ & $18 \mathrm{~mm}$ & $21 \mathrm{~mm}$
\end{tabular}

The animal altogether (Pl. IV, fig. 3 and 4) appears robust and stocky. The relatively short arms are first a little retracted at their immediate insertion onto the disk. But they become very large and thick and they taper very slowly up to their end that is rounded. The disk is not at all very large. The dorsal surface of the body is very convex; the ventral surface is flat. In the specimens in alcohol, the dorsal surface of the disk and arms scarcely allow recognition of the elongated papulae that are very developed, thick, numerous and dense. They form four to five irregular rows on each side of the median line and emerge from the thick, soft and slightly folded tegument. This tegument forms, on the dorsal and lateral surfaces of the arms, some more or less regular bands between the rows of papulae. One of these bands the entire length of the dorsal carinal line. It is difficult to distinguish some spines that are not numerous. Their ends only emerge 
from this tegument but are felt clearly at touch. This is true only on the border of the arms. On the edge of the arm and on the ventral surface, these spines can be distinguished. They are large and thick and form oblique rows, each enclosing two to three spines on the ventral marginal plates.

The structure of the skeleton can be studied only on the dried specimen as I show here ( $\mathrm{Pl}$. IV, fig. 1, 2, 5, 6 and 7). One sees a very irregular network formed of unequal ossicles arranged in three very irregular bands. The large one is the carinal line of the arms and the two narrower ones are on each side. These bands have inflexions and sinuosities as well as inequality in their width. Moreover, they are very poorly defined. They are connected by narrow trusses with a transverse sinuous direction. Between them are very unequal and very irregular membranes though which pass large and numerous papulae. The rest of the dorsal surface is chiefly formed by irregular transverse trusses that anastomose and that surround two lateral rows of popular areas that are larger than the others. They are always unequal and with an irregular form, usually wider than long. Between these two rows are some ossicles that are larger than the others located where the trusses intersect so as to form a small lateral row, however poorly indicated.

A dorsal marginal row is found on the sides of the arms made of very small, irregular dense ossicles. But they have no very constant form. They make up a very irregular, very sinuous series on some arms and a straighter line on others. This row is very near the ventral border of the arms and is not greatly developed. Because of if slight importance, the rows is very different from the very regular and well developed row the dorsal marginal plates usually form in asteriids, notably in the close genera in which the adambulacral spines are uniserial as e.g. in the genus Sporasterias. Each ossicle with an irregular lozenge form that makes up this dorsal marginal row has a tubercle for the insertion of a spine. But this is completely inconstant. I would even say that it is very rare. These plates are covered by their adjacent borders and they are continuous below with a narrow lobe that connects the corresponding ventral marginal plates. This limits a series of round popular areas with very uniform dimensions. The ventral marginal plates, which are larger than the dorsal marginals also have a lozenge form. But they are longer than tall and each always has two articulating tubercles. The regular row the ventral marginal plates form is found very near the adambulacral plates. However, an interval between the two rows is sufficient for a series of small latero-ventral plates. These are also a little longer than wide. Thus a good part of the surface is occupied by an articulating tubercle. These latero-ventral plates are continuous at least three quarters the length of the arms.

The dorsal surface of the disk is formed of solidly united ossicles and constitutes a very compact, irregular network, limiting the unequal and sometimes small popular areas. The small, rounded madreporite plate, with a diameter equal to ca. $3.5 \mathrm{~mm}$, is located nearly in the center of the disk and is very sunken. Its surface has numerous fine, radiating and sinuous furrows. There is not the least indication of a circle of spines towards its periphery.

The spines of the dorsal surface are very numerous, short, not very large, often slightly capitate with a length that does not pass $2 \mathrm{~mm}$. They also are distributed in a very irregular manner on the dorsal surface of the arms. They form however a very regular series in the carinal line but without being denser and larger than the others. These can be seen in the photographs of lateral views of the arms that I show here (Pl. IV, fig.1, 2 and 7). The dorsal marginal spines are not longer and thicker than the adjacent ones. They remain notably smaller than the ventral marginal spines. These are very sturdy, thick, and wider in the distal half that is sometimes a little flattened which ends in a round or truncate border. They can reach $4 \mathrm{~mm}$ in length. These spines form on each plate an oblique row to which is added the spine of the adjacent latero-ventral plate. This spine is a little shorter and inconstant but, when it exists, often appears to continue the small row of ventral 
marginal spines. The ventral marginal spines are very near the adambulacral spines. It is necessary to say that the space limited above and below by the dorsal and ventral marginal plates of spines, a space moreover of little importance, follows the general curve of the arms and does not determine on its lateral regions vertical surfaces as is often found in related genera. A row of large papulae is found between the dorsal and marginal row of spines, but the narrow space the separates the ventral marginal row and the adambulacral spines has only a row of small papular areas.

The adambulacral spines are very sturdy, cylindrical and slight widened in their distal half. They are very regularly uniserial.

The proximal end of the teeth ends in a horizontal spine that is identical to the adjacent adambulacral spines. On the ventral surface of the teeth is a ventral slightly thicker spine.

All the spines of the surface of the body are enveloped by a very thin tegument.

The crossed pedicellariae are not very abundant. They never form collars around the spines that are moreover sunken into the tegument. They scarcely show on the distal half of the arms, principally in the area of the dorsal marginal spines and in the space that separate these spines from the ventral marginal spines. These pedicellariae are likewise completely lacking on a large part of the length of the arms. They are likewise very rare in the area of the marginal spines. In addition, they are very small relatively too the size of the individual. Their length is only $0.4 \mathrm{~mm}$. Some straight pedicellariae occur between the latero-ventral spines and among the adambuacral spines in the furrow. The valves are triangular and have no unusual character. They become more abundant in the region of the mouth but always remain small. Their length does not exceed 0.8 mm.

The color of living animals was "bluish green". The specimens in alcohol are yellow or yellowish white.

It seems to me there is a very great external resemblance between Kalyptasterias conferta and the Calvasterias stolidota described by Sladen. But regarding the latter species, it seems necessary to me, having made all comparison, to ask a preliminary question. Should the $C$. solidota, which was collected by the "Challenger" at the Falkland Islands (Port William, 5-10 fms) be placed in the genus Calvasterias? We know that this genus was established by Perrier and the type was C.asterinoïdes, a small monacanthid species $(R=22, r=11 \mathrm{~mm})$ from the Torres Strait. The structure of the genus Calvasterias was given by Perrier in a very clear manner. He said "The skeleton, completely embedded in a thick tegument, is formed of diverse notched ossicles, often having the form of a trefoil or of a star with four short, wide branches and on slightly notched at the top. These plates are arranged on the dorsal surface of the arms in nine longitudinal series and including the marginal plates. In each series they are imbricated with each other in Asterina, etc...." (Perrier, Revision, p. 84). I must add that one can now only refer to the description of Perrier, because the $C$. asterinoïdes he described appears to be lost, at least the search to find this asteroid in the Jardin des Plantes has been in vain.

There is cause to consider chiefly, among the characters of the genus Calvasrias, two very important structures. First, the dorsal skeleton is covered by a very thick tegument that completely hides it. Second, the skeleton is formed of plates arranged in nine imbricated series in the type of the genus. Perrier compared, two or three times, this imbrication to that which is known for the genera Asterina and Stichaster, adding that true spines do not exist on the dorsal surface of the body, but only some tubercles. Some isolated straight pedicellariae occur in the ambulacral furrows or between the adambulacral spines and the marginal spines. Some also are found on the dorsal 
surface of the body. According to Perrier, these pedicellariae have a very long membranous peduncle but there is no trace of crossed pedicellariae.

Verrill, in speaking of imbrication of the dorsal plates of the genus Calvasterias, said likewise that this imbrication is identical to that observed in the genus Stichaster.

Are the essential characters of the genus Calvasterias found in the Calvasterias stolidota of Sladen?

It is unfortunately impossible to respond in a precise manner to this queston because Sladen said not a word on the structure of the skeleton in this species. Did he examine and recognize that this skeleton presents well the so remarkable structure of the genus Calvasterias? He says nothing about it. However, in his synoptic table of the genera of the family of asteriids $(1884$, p. 506), he says formally regarding the genus Calvasterias: "Abactinal skeleton composed of broad imbricating plates, etc...". It is thus permissible to think that if he placed this species in the genus Calvasterias, essentially characterized by imbricated plates, he did it knowingly. In until proof to the contrary, we can suppose that the $C$. stolidota is really a Calvastserias. And in that case, $C$. stolidota, having the dorsal skeleton made up by imbricated plates and without doubt arranged as in C. asterinoïdes in longitudinal rows and has nothing in common with Kalyptasterias comferta of the "Swedish Antarctic Expedition" whose skeleton is completely different.

A third species likewise has been attributed to the genus Calvasterias. This is C. antipodum, encountered in the course of the voyage of "Erebus" and of "Terror". Bell, who described it, has given some very summary information about it. He says mainly, "The spines developed on the surface are rather scale-like rounded processes ornamented with a radial striation." What do these formulations belong to? Bell's figure does not inform us. Are they very short, capitate spines with a striated head as in for example various stichasterids? This type of spines form an irregular carinal row. Bell also says "modified spines...". This is all very vague. The author adds moreover that there are true marginal spines.

Whatever it is, there is nothing in Kalyptasterias conferta that resembles the structures mentioned by Bell. The other part of this species is described in a sufficient insufficient manner that it is not possible to make comparisons.

The result of the preceding remarks is the two following conclusions:

1) The species of the "Swedish Antarctic Expedition" cannot in any way return to the genus Calvasterias as has been established by Perrier. The general external appearance of individuals in alcohol is perhaps the because of the thickness of the tegument that covers it, the considerable development of the papulae, the rarity of spines, etc. But these external characters have only a secondary importance. The characters of the skeleton itself must be considered above all. As a consequence, the creation of the genus Kalyptasterias is perfectly justified.

2) If the skeleton of Calvasterias stolidota of Sladen is really formed of plates arranged in longitudinal, imbricated rows, there is nothing in common, other than a purely external resemblance, between this form and the asteroid of the "Swedish Antarctic Expedition" and the creation of a new species proves equally justified. However, note that I say, "If the skeleton is really formed of imbricated plates..." because there is reason to have reservations on this subject. I have already recalled above that Sladen did not describe the skeleton of Calvasterias stolidota, recognizing that he limited himself, to place his species in the genus Calvasterias, to consider only the external characters and that in his synoptic table of the asteriids. He has simply repeated a phrase of Perrier without investigating the degree it applied to the asteroid of the "Challenger". Nothing since then would prove that this is related to the genus Calvasterias. I shall remark moreover that I am not the only one to raise some doubt on this subject. Regarding the characters 
of the genus Calvasterias, Verrill (1914, p. 357) judged, after having cited the characters of the type, "Description and figures of other species do not show the character of the plates and some may not be congeneric..." and there would perhaps be reason, he said, to create another genus.

If the skeleton of Calvasterias stolidota is not made up of imbricated plates, what should one think of this form, both as genus and species? Can it remain in the genus Calvasterias and what are its relations to the form discovered by the "Swedish Antarctic Expedition", Kalyptasterias conforta? As regards the genus itself, the response is very simple and completely shown. In the hypothesis above, the species of Sladen does not belong to the genus Calvasterias. There would thus be reason to classify it in a new genus and, quite naturally, we must ask if $C$. stolidota could not find its place in the genus Kalyptasterias that I just described. This position would seem to be supported and it appears to me very probable. But it would be necessary, to adopt it definitively, to know the characters of the skeleton, of which we are ignorant.

We go further still. We suppose that the skeleton of $C$. stolidota is formed by a network of plates comparable to those that exist in $K$. conferta. Must one then consider that the two species are different? It is very difficult, and even impossible, to respond exactly to this question that is however necessary to consider at the least because the two forms both come from the Falkland Islands. The species of the "Challenger" is smaller than those of the "Swedish Antarctic Expedition": $R$ measures $44 \mathrm{~mm}$ and $r, 11 \mathrm{~mm}$. The width of the arms at their base is $13.5 \mathrm{~mm}$. These are comparatively narrower than in $K$. conferta and their ventral lateral surfaces are limited by the row dorsal and ventral marginal spines. The general aspect appears however very similar. The tegument forms a very thick, soft layer, with large popular areas arranged in longitudinal rows, etc. On the other hand, I note that Sladen indicated the presence of pedicellarriae (he does not say if they are straight or crossed), rare on the dorsal surface but very numerous in the area of the dorsal and ventral marginal plate. The spines of the dorsal surface of the arms, not very numerous, are localized on the carinal line and are capitate. The madreporite plate is encircled by some spinose, sturdy spines. There are there incontestably some characters that do not conform to those of $K$. conferta, notably those concerning the form of the arms, the rarity of dorsal spines, the presence of numerous pedicellariae, and final the existence of a circle of sturdy spines around the madreporite plate. These characters perhaps are not of importance of the first order. And I recognize that if I had been able to prove that the skeleton is identical in the two forms, I would have not hesitated to place Calvasterias stolidota in the genus Kalyptasterias and unite to the species of the "Challenger", the three specimens collected by the "Swedish Antarctic Expedition". But having the question that remains, it appears prudent to me to give another specific name to these three specimens and to provisionally keep the generic and specific name Sladen gave the form collected by the "Challenger".

Finally, it remains to be determined the relations of the genus Kalyptaterias with the genus Sporasterias. It has, as the latter, adambulacral spines arranged in a single row. But it is clearly distinguished by a number of characters and there should not be confusion between these two genera. In fact, the skeleton in the genus Sporasterias is not cover by a thick, soft tegument, the spines of the dorsal surface, admittedly not abundant in some specimens, are however less rare than in the genus Kalyptasterias and the dorsal marginal row in particular is always very apparent. The dorsal marginal plates themselves are much more developed, very distinct one from another and form ossicles a little larger than the ventral marginal plates. In comparing the photograph that I have here of the lateral surface of an arm of Sporasterias) Pl. VII, fig. 4) to the lateral view of the arms of Kalyptasterias conferta (Pl. IV, fig. 1, 2 and 7), it is possible to establish how the structure of the marginal plates is different in the genera Sporasterias and Kalyptasterias. 
Allostichaster inæqualis nov. sp.

(Pl. I, fig. 7 and 8; Pl. VII, fig. 1 to 3.)

Station 2. 23 December 1901. Northern coast of Argentina. 37 50' S.; 56 $16^{\circ}$ ' W. 100 m. Gravel mixed with sand. Three specimens, one very small.

Station 44. 28 July 1902. Falkland Islands, Port Louis, Greenpatch. $51^{\circ} 33^{\prime}$ S.; $58^{\circ} 10^{\circ}$ W. 7 $\mathrm{m}$. Mud and gravel with algae. One small specimen.

All the individuals have six unequal arms. In the largest, three arms are much larger than the three others and the difference is most marked in the individual shown here in the photograph (Pl. VII, fig. 1 to 3 ) and which serves me as the type. $R$ measures $30 \mathrm{~mm}$ on the longest arm and $25 \mathrm{~mm}$ in one of the smallest arms; $r=5 \mathrm{~mm}$. The largest arm is $6 \mathrm{~mm}$ wide at the base. In the second specimen, R measures $26 \mathrm{~mm}$ on the largest arm and $20 \mathrm{~mm}$ on the three smallest. In the two small specimens, $R$ varies between 13 and $10 \mathrm{~mm} ; r$, between 4 and $5 \mathrm{~mm}$.

The genus Allostichaster presently contains two species, both separated from the former genus Stichaster. One is the type of the genus as established by Verrill in 1914, A. polplax of New Zealand. The other is Stichaster insignis Farquhar, also of New Zealand, that must, as I have shown (1920, p.85-87) also be placed in the genus Allostichaster.

The new species shares in the characters of both A. polyplax and insignis, but it is very distinct from both.

The dorsal surface of the disk is covered with dense, irregularly arranged plates with small short, thick, capitate spines. Their length scarcely passes 0.5 to $0.6 \mathrm{~mm}$ and a little narrower in their middle. They are 0.22 to $0.25 \mathrm{~mm}$ wide at their base and 0.25 to 0.28 at the head. Other spines are shorter, thicker and their better marked head is $0.4 \mathrm{~mm}$ wide although they measure 0.3 at the base. Their height is $0.4 \mathrm{~mm}$. Small papular areas with small groups of three or four papulae are between the spines. The madreporite plates are small and not apparent. They are difficult to see and have only a few furrows. There are only two of them in the largest individual that serves as my type. One is large, bordered by two large spines. The other small one is placed between two smaller spines. The second smaller specimen has three. These madreporites are located nearly equidistant from the center and an interradial angle.

The dorsal plates of the arms have an arrangement clearly stichasteroid, as is indicated in examining the denuded arm shown here (Pl. VII, fig. 3). I can affirm that this arrangement is absolutely identical to that I have indicated in Allostichaster polyplax and that I photographed in my memoir on the asteroids of the "Australian Antarctic Expedition" (Pl. XIX, fig.9 and 11). Between these plates that are arranged in very regular rows are round and regular papular spaces forming two longitudinal rows on the dorsal surface of the arms. Another row of round and slightly unequal areas occurs between the dorsal and ventral marginal plates. The spines of the dorsal surface of the arms have nearly the same form. They are short and slightly capitate. There are three or four on the carinal plates and two in general on the dorsal lateral plates. Each dorsal marginal plate has three spines. One is located on the upper angle, another towards the proximal summit, and the third, longer than the others, on the lower angle of the plate. Each ventral marginal plate has two much larger and sturdier than the others. They are thick and wide, with the end a little flattened. They form a small oblique row to which is added a third spine of the corresponding latero-ventral plates. One of the large arms has twenty six dorsal and ventral marginal plates and 
corresponds nearly regularly to the carinals and latero-dorsals. Between the spines are crossed pedicellariae of only $0.2 \mathrm{~mm}$ in length. These pedicellariae are especially very abundant in the area of the marginal species but they never form crowns around the spines. They are irregularly scatter, while showing preference to the base of the spines.

The adambulacral spines are short. Three of them correspond to a ventral marginal. Each spine has two elongated, very sturdy cylindrical spine with the end swollen. They form two very regular series. Small straight pedicellariae are found within the furrow. The length varies between 0.15 and $0.2 \mathrm{~mm}$. The valves generally end in three unequal lobes. The median one is a little larger than the others. It intersects with the corresponding lobes of the other valve.

The spines on the second specimen from station 2 that is a little smaller than the preceding are comparatively larger, the pedicellariae more numerous, the popular areas larger and arranged in a more irregular manner.

The arrangement of the arms, always with three large and three small ones, indicates fissiparous reproduction. The small specimen from state 2 has three unequal arms $13 \mathrm{~mm}$ in length. The other three are barely apparent. One is $1.5 \mathrm{~mm}$ in length. The other two, still smaller, are scarcely $1 \mathrm{~mm}$.

Similarities and differences. - It is precisely this number and this inequality of arms that distinguishes $A$. incequalis and $A$. polyplax. They are separated also by the larger, thicker and less numerous arms. It resembles $A$. insignis in the general form of the body and arms that, as in this latter species, has six arms, three large and three small. But it is distinguished from A. insignis by its much less robust structure and by the narrower arms. For example, the arms are $6 \mathrm{~mm}$ at the base for a length of $30 \mathrm{~mm}$ in A. incequalis, while the width at the base 9 to $10 \mathrm{~mm}$ for $A$. insignis with the same length of arm. The spines are also much small, less dense, less numerous and with a comparatively less marked head than in A. insignis.

It is absolutely certain to me that the Allostichaster inaequalis that I just described is nothing other than the asteroid that Loriol has given, in 1904 under the name of Asterias fernandensis, a detailed description with some photographs (p. 41, Pl. III, fig. 7 and 8) of individuals from the coast of Patagonia, $40^{\circ} 45^{\prime}$ S., a location consequently very near to that where the "Swedish Antarctic Expedition" collected its specimens. I have, moreover, been able to compare my specimens with those Loriol studied, which had been lacking formerly. The others are found in the Museum of Geneva. The identity of the specimens is without doubt. Only the specimens of Loriol have arms thicker at the base paper more rapidly than my specimens. I show moreover two photographs of two individuals found in the Museum of Geneva (Pl. I, fig. 7 and 8).

The asteroid from Gulf of San Mathai named Asterias fernandensis by Loriol should thus be transferred to the genus Allostichaster. There is no doubt that Loriol made an error. If, moreover, we compare the description that Meissner gave to the true Asterias fernandensis to the description and figures of Loriol, we establish very important differences.

The Polyasterias fernandensis from Juan Fernandez established by Meissner is a species to be conserved, but as the author has not studied the skeleton, it is impossible to decide into which genus it should be placed at the present because the genus Polyasterias no longer exists. In any case, it cannot be placed in the family of stichasterids chiefly because of the arrangement of the crossed pedicellaria that form collars around the spines and cannot be confused with Allostichaster incequalis. 


\section{Granaster nutrix (Studer)}

(Pl. I, fig. 4, 5 and 6.)

Stichaster nutrix Studer. (1885), p. 1554, fig. 5, a.

Granaster nutrix Perrier (1894), p. 12.

Granaster biseriatus Kœhler (1906), p. 11; Pl. I, fig. 6; P1. IV, fig. 42.

Granaster biseriatus Kœhler (1908), p. $3 \mathrm{i} 7$.

Granaster biseriatus Kœhler (1912), p. 29; P1. III, fig.2; P1. VI, fig.1.

Hemiasterias biseriata Verrill (1914, p. 362.

All the specimens come from South Georgia and, except those from station 20, all also are from Cumberland Bay.

Station 19. 23 April 1902.Jason Port, 54 14' S.; 36 31'W. 10-15 m. Small stones and clay. Five specimens.

Station 20. 6 May 1902. Antarctic Bay (to the east of Possession Bay). 54 ${ }^{\circ}$ 12' S.; $36^{\circ} 50^{\prime}$ W. $250 \mathrm{~m}$. Small stones. One specimen.

Station 22. 14 May 1902. Outside the Bay of May, 54 ${ }^{\circ} 17^{\prime}$ S.; $36^{\circ} 28^{\prime}$ W. 75 m. Clay with some algae. Two specimens.

Station 26. 24 May 1902. Outside Marmite Bay, 54 22' S.; $36^{\circ} 27^{\prime}$ W. 30 m. Rocky bottom with algae. One specimen.

Station 30. 26 May 1902. Moraines Fiord, 54² 24' S.; 36 26’ W. 125 m. Clay with rare rocks. One specimen.

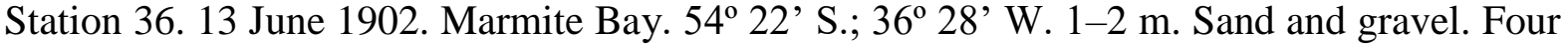
specimens.

Cumberland By, 5 May 1902. One specimen.

Marmite Bay. 24 May 1902. Four specimens.

One of the specimens from Marmite Bay was noted "red above" and another from Cumberland Bay was noted "yellow orange".

I established G. biseriatus in 1906 from a specimen collected by Charcot and in which the tube feet were always regularly biserial. Since then, I have found the same form with the same characaters also in the collections of the "Scotia" and those of "Pourquoi Pas?". I had thus believed it necessary to distinguish this species that I characterized by the very regular arrangement of the two feet in two series that appeared very constant, in contrast to the arrangement indicated by Studer in Stichaster nutrix, where the tube feet are arranged irregularly in three or four rows. One can suppose that the specimens having this latter character of restricted to the regions near South Georgia while the individuals having biserial tube feet were found in other regions. This biserial arrangement of the tube feet had even appeared important to Verrill for the justification of a special genus he called Hemiasterias.

But I found among the specimens collected by the "Swedish Antarctic Expedition" to South Georgia, some individuals with biserial tube feet and others in which the tube feet are arranged in three or four more less regular rows. Even better, I observed in one specimen at least that on certain arms the tube feet are arranged in several rows while in two other arms the tube feet form two very 
regular rows. One can moreover follow the variations shown in the specimens in the three examples that I show here in photographs (Pl. I, fig. 4, 5 and 6, from stations 30 and 36).

Under these conditions, it does not appear to me possible to conserve the distinction I had believed to establish in 1906 and I think that Granaster biseriatus must disappear, this term must be considered as synonymous with G. nutrix. The tube feet can be arranged in two or three or even four rows, without doubt according to the state of contraction of the ambulacral furrows. As far as the third adambulacral spine that I had reported as occurring sometimes at the base of the arms, I have found it in some individuals from the present collection but it is very inconstant and it does not constitute a specific character. I have already remarked, in studying the Granaster collected by the "Scotia" in the South Orkney Islands, and in which the adambulacral spines are regularly biserial, that the arrangement of the adambulacral spines by three is rare and inconstant.

The quadiaserial arrangement is moreover the exaggeration of the alternation that can occur in the tube feet. One can also see that the tube feet with the clearest quadriserial condition are in reality an alternation between them. Moreover, removing the tube feet arranged in two, three or four rows, I can establish the arrangement of the pores always remains the same. These pores are very wide transversely and the alternation of the tube feet is not determined by the position of the pores themselves but by the extension of the tube feet to the right or to the left. The ambulacral ampullae are, in principle, arrange in a single row, but sometimes at the base of the arms they take an alternating arrangement.

Just as Granaster biseriaatus must disappear, the same also, and with greater reason, the genus Hemiasterias must equally disappear.

The respective dimensions of the disk and the arms vary very notably in G. nutrix. Individuals most ordinarily have the form near that I gave in 1906 (Pl. I, fig. 6) and the $R / r$ ratio oscillates around 2. The stocky form that Studer has figured in 1885 (fig. 5a) and in which $R / r$ is less than 2 is rarer. To the contrary, the arms are elongated sometimes in relation to the disk. In the same individual that came to me from Studer, in which the arms are unequal, the largest has a length of $17 \mathrm{~mm}, r$ being only $5 \mathrm{~mm}$ so that in the smallest arms, the $R / r$ ratio equals 3.4 . In this individual the tube feet are clearly arranged in four rows but some adambulacral plates have three spines.

I will recall that I showed in 1908 (Pl. V, fig. 48), a form of straight pedicellariae a little different from that which Studer showed in individuals collected from South Georgia. In the specimens coming from the same locality that I have before me, the straight pedicellariae always have a form identical to that of the same figure of 1908, with the valves sometimes a little longer, sometimes a little shorter, but their external surface is always convex.

Asterina fimbriata Perrier

(Pl. IX, fig. 2 and 5 to 8.)

Asterina fimbriata Perrier (1875), p. 307.

Asterina fimbriata Perrrier (1891), p. 111, Pl. XII, fig. 5 and 5 b.

Asterina fimbriata Leitpoldt (1895), p. 594.

Asterina Perrieri Loriol (194), p. 27, Pl. II, fig. 6.

Asterina fimbriata Ludwig (1905), p. 59, Pl. Vi, fig. 10-13; Pl. VI, fig. 4, 5.

Non: Asterina fimbriata Benham (1909), p. 295, fig. 1.

Station 8. 11 February 1902. Graham region, 64 3'S; 56 37' W. 360 m (?). Clay not compact. Two specimens. 
All the other specimens come from the Falkland Islands.

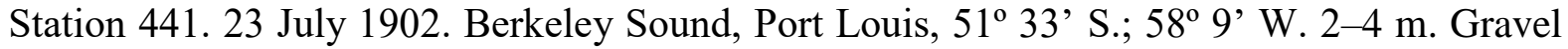
and mud. Two specimens.

Station 44. 28 July 1902. Port Louis, Greenpatch, near the bridge, $51^{\circ} 33^{\prime}$ S.; $58^{\circ} 10^{\prime}$ W. 7 m. Mud and gravel with algae. Two specimens.

Station 50. 12 August 1902. Port Louis, 51 $31^{\circ}$ ' S.; 58 9' W. 7 m. Mud. Two specimens.

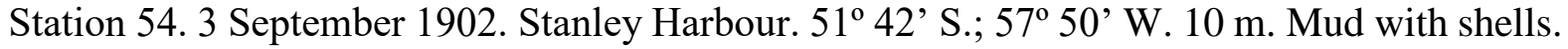
Three specimens.

Port Louis. 3 July 1902. Three specimens.

I had the opportunity to speak quite recently on A. fimbriata (1920, p. 135), comparing it to a new species from Macquarie Island, A. Hamiltoni. The descriptions of A. fimbriata that Perrier gave in 1875 (p. 107) and in 1891 (p. 111) are very exact and permit easy recognition of this species. I have explained that the Asterina from the Auckland Islands described recently by Benham under the name of A. fimbriata is not at all related to this species.

The photographs of A. fimbriata Ludwig published are very small. Perrier gave in 1891 a slightly larger figure of the ventral surface in 1891 that shows very well the characters of this surface. However, the oral pieces are not shown in a perfectly exact manner, because the ventral surface of each tooth has a spine that Perrier does not show. As the individuals of the "Swedish Antarctic Expedition" are all very small, I believe it is necessary to add to the photographs that I give those of individuals collected by Nordenskjöld (Pl. IX, fig. 2, 6 and 7) two photographs (fig. 5 and 8) of an individual from the coasts of Chile that is a little larger $(R=13 \mathrm{~mm})$.

The individuals from stations 8 and 54 have a nearly pentagonal body with slightly hollowed out sides (fig. 2 and 5), while those from stations 41 and 44 have more distinct arms and sides that are more profoundly hollowed out (fig. 7). In the first, $R$ measures 10 and $16 \mathrm{~mm}$. In the second, these values are 11 and $6.5 \mathrm{~mm}$. The body of these latter is covered with a tegument that is thicker than on the other specimens. The small spines of the plates, that are moreover a little less numerous, are somewhat hidden by the tegument. But they appear clearly in dried specimens. As regards the spines of the ventral surface of the teeth, these are very variable. They are more developed in some individuals than in others. They are more distinct for example in the specimen I show in fig. 2 than in those in fig. 6 . In the slightly larger specimen in fig.2, these spines are missing in most of the teeth.

A. fimbriata is very widespread in the Falkland Islands and the Strait of Magellan. In a general manner, it occurs on the two coast of the extreme south of South America. It appears again in the north off the coasts of Chile near Calbuco. One notes that the "Swedish Antarctic Expedition" has encountered this species at Graham Land at $64^{\circ} \mathrm{S}$. This is the most southern station that it is known presently. I am able to state that the individuals coming from it are completely identical to those from Chili and Patagonia.

The species from Port San Antonio that Loriol described in 1904 as A. Perrieri is nothing other than A. fimbriata. I have in fact been able to compare recently the specimens described by Loriol that are found in the Museum of Geneva with A. fimbriata from the "Swedish Antarctic Expedition" and the Mission of Cape Horn. I am able to state their perfect identity. The differences that Loriol used are either inconstant or have only little value, or they conform a little insufficiently to the description of Perrier. For example, the spines of the plates of the dorsal surface of the body are nearly always more numerous than Perrier indicated. This is less than I have found in nearly all the specimens I have had at hand. The spines of the ventral plates vary in number and there is 
sometimes only one, sometimes two or even three on each plate. The specimens in alcohol have a more or less thick tegument that partly hides the subjacent plates. This tegument shows very extended folds that one cannot find any trace in the dried specimens that Loriol studied. I have already spoken above of the spine that is usually found on the ventral surface of the tooth, which would have been mentioned and figured by Perrier. It is understood that this spine is sometimes absent, but it generally exists and I have usually found it in the specimens from Cape Horn that were precisely studied by Perrier and are conserved in the Jardin des Plantes. It also occurs in general on the specimens of the "Swedish Antarctic Expedition" but however it is sometimes lacking. There are variations even in the same specimen and it can happen that the spine is found on one side and not the other.

Perrier described A. fimbriata in 1875 from specimens in the Jardin des Plantes. The label of one indicates "Reunion Island, Maillard 1862" and the other "Chiloe, Gay 1843" All these individuals are perfectly identical and Perrier added that, as he greatly doubted that the same species of asteroid could be found both at Chiloe and Reunion Island, he thought that one of the geographical indications was in error. Since that time, Perrier himself found A. fimbriata among the asteroids of the Mission of Cape Horn and then by Ludwig, Leitpoldt, Meissner, Loriol and myself in numerous localities of the coasts of Chile and Patagonia. It thus appears certain that the species is essentially subantactic and that the reference to Reunion Island in the Jardin des Plantes if surely erroneous.

\section{Echinaster diffidens nov. sp.}

\section{(Pl. VIII, fig. 1 and 2; Pl. IX, fig 9 and 10)}

Station 5. 16 January 1902. Graham Land, southeast of Seymour Island. 64²0’ S; 56³8; W, 150 meter. Sand and gravel. One specimen.

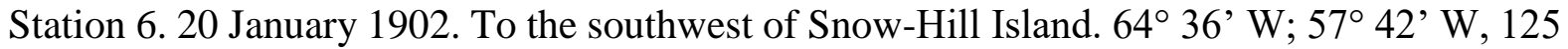
meters. Stone and gravel. Two specimen.

Station 22. 14 May 1902. South Georgia, Cumberland, outside the Bay of May. $54^{\circ} 17^{\prime} \mathrm{S} ; 36^{\circ}$ 28 ' W. 75 meters. Claywith some algae. Two specimens.

Here are the principal dimensions of thee five individuals.

$\begin{array}{llll} & R & r & \text { Width of arms at the base } \\ \text { Station 5 } & 25 \mathrm{~mm} & 8 \mathrm{~mm} & 7.5-8 \mathrm{~mm}-8 \mathrm{~mm} \\ \text { Station 6 } & 24 \mathrm{~mm} & 7 \mathrm{~mm} & 6 \mathrm{~mm} \\ & 20 \mathrm{~mm} & 4 \mathrm{~mm} & 4 \mathrm{~mm} \\ \text { Station } 22 & 13 \mathrm{~mm} & 3 \mathrm{~mm} & 3-4 \mathrm{~mm} \\ & 18 \mathrm{~mm} & 4 \mathrm{~mm} & 4 \mathrm{~mm}\end{array}$

The specimens from Graham Land are larger than those of South Georgia, but they are certainly identical.

The form of the bodies varies with size. In the specimens of Station 5 (Pl. IX, fig. 9) and 22, the arms are thick, relatively short, swollen at the base and decrease more rapidly in the first half than in the second. The end is still very large and founded. In the specimens of station 6 (Pl. VIII, fig 1 and 2), the arms are narrower although still very swollen at the base and decrease more rapidly 
and progressively towards the end that is more pointed. Finally, in the other individuals, the basal part of the arm is slightly swollen and regularly decrease.

The dorsal surface of the disc is not very convex and the interradial spaces are more or less depressed. The arms are nearly cylindrical with the ventral surface more are less flat.

The calcareous network of the dorsal surface of the disc and the arms is irregular very projecting, without having the least tendency of forming longitudinal or transverse series. The spaces limited by the network are comparatively large in the two specimens of station 6 than those of station 5, and each of the spaces has a perfectly distinct large papula. From the calcareous network are raised small, very short, cylindrical spines articulated on a small mamelon and ended by an obtuse end, filled with many fine, dense spinules. These spines form small erect rows that follow the curves of the calcareous network. The characters of the skeleton and spines are completely identical on the dorsal surface of the disc and arms. The anus is very apparent. It is surrounded by some small spines. The madreporite plate is very small, indistinct and slightly sunken. It is oval, nearer the center and has only a small number of broad grooves and irregularities on its surface. It is surrounded by some very close spines

Going to the ventral surface of the arms, the calcareous network becomes more regular and the spines, especially in the individual from station 5, has small transverse rows that abut to a row of adambulacral spines. These spine even have some traces of longitudinal arrangement. This very regular arrangement is scarcely apparent in individuals from station 6 . These spines are identical to those of the dorsal surface. There is no naked interval between the adambulacral spines and the spines of the ventral surface.

Each adambulacaral plate has at least five spines. The first internal one is very short, hidden in the groove and not curved. The three following ones are larger and unqual. Finally, the fifth is small, often with another, still smaller spine outside. All these spines are very thick and cylindrical, with the obtuse extremity filled with very stout spinules. They are notably stouter than the adjacent spines.

Each tooth has on their free border four spines identical to the adjacent adambulacral spines. They also have on the ventral surface a more or less regular row of three spine similar to the preceding.

The color of the individuals in alcohol is white or clear grey. The specimen from station 5 if grayish-pink.

Similarities and differences. - Echinaster diffidens is particularly close to E. smilax that I recently described (1920, p. 111, pl. XXV, fig. 1, 2 amd 6) from the pecimens collecged by the "Australian Antaractic Expedition" near $66^{\circ} \mathrm{S}$ and $145^{\circ} \mathrm{E}$ and near $64-66^{\circ} \mathrm{S}$ and $94-97^{\circ} \mathrm{E}$, between 110 and $318 \mathrm{fms}$ The new species is distinguished by the shorter arms, the smaller spines of the body and more spinulose at the end, and especially by the number of adambulacra spines that is five or even six. The number of adambjulacral spines separates also $E$. diffidens from $E$. Smthii and spinulifer, whose form is moreover different, the arms being shorter conical and pointed in the latter that is restricted to Kergueleln and to the contrary thinner and more elongated in $E$. Smithii, whose skeletal network has a very regular arrangement. 


\section{Henricia Pagenstecheri (Studer)}

See the bibliography:

Cribella Pagenstecheri Studer (1885), p. 158.

Cribella Hyadesi Perrier (1891), p. 100.

Cribella Hyadesi Meissner (1896), p. 99.

Cribella Studeri Meissner (1896), p. 102.

Cribella Hyadesi Leitpoldt (1895), p. 578.

Cribella Pagenstecheri Meissner (1904), p.13.

Cribella Pagenstecheri Ludwig (1905), p. 68.

Cribella Pagenstecheri Kœhler (1908), p. 556.

Station 17. 19 April 1902. Shag Rock Bank, between the Falkland Islands and South Georgia. $53^{\circ} 34^{\prime}$ S.; 43 $23^{\prime}$ 'W. 160 m. Gravel and sand. Two specimens.

Station 58. 11 September 1902. South of West Falkland. 52 29' S.; 60 36' W. 197 m. Sand and gravel. One small specimen. $(R=13 \mathrm{~mm})$

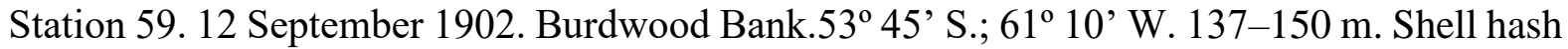
with algae. One very small specimen $(R=10 \mathrm{~mm})$.

I have already had the opportunity to say in my memoir of 1908 that I was of the opinion of combining into a single species Henricia (Cribrella), Pagenstecheri, Hyadesi, Studeri and obesi that had been distinguished by authors. The Henricia (Cribrella) of the present collection are identical to those that the "Scotia" has reported from Burdwood Bank and correspond to the form that Perrier called Hyadesi. Moreover they come from the same locality.

Cycethra verrucosa (Philippi).

(Pl. VII, fig.5, 11, 12 and 13; Pl. VIII, fig. 3 to 9.)

Cyethra electilis Sladen (1889), p. 377.

Cyethra nitida Sladen (1889), p. 379.

Cyethra pinguis Sladen (1889), p. 380.

Cyethra simplex Sladen (1889), p.377.

Cyethra simplex Perrier (1891), p.122 and 170.

Cyethra electilis Leipoldt (1895), p. 606.

Cyethra nitida Leitpoldt (1895), p. 602.

Cyethra simplex Bell (1902), p. 215.

Cyethra verrucosa Meissner (1904), p. 14.

Cyethra electilis Loriol (1904), p. 23.

Cyethra simplex Loriol (1904), p. 21.

Cyethra verrucosa Kœhler (1908), p. 557.

Cyethra verrucosa Kœhler (1912), p. 64.

Non Cyethra verrucosa Bell (1908), p. 10, Pl. V, fig. 1 b.

Cyethra verrucosa Bell (1917), p. 4, Pl. I, fig. 1 to 6.

Falkland Islands 
Station 39. 4 July 1902 . Port William. $51^{\circ} 40^{\prime}$ S.; $57^{\circ} 41^{\prime}$ W. 40 m. Sand, small stones with algae. One small specimen.

Station 44. 28 July 1902. Port Louis, Greenpatch. $51^{\circ} 33^{\prime}$ S.; $58^{\circ} 10^{\prime}$ W. 7 m. Mud and gravel with algae. Several specimens, one with four arms.

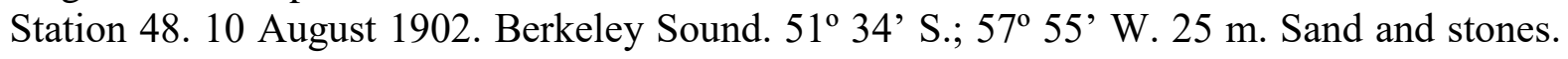
Two specimens.

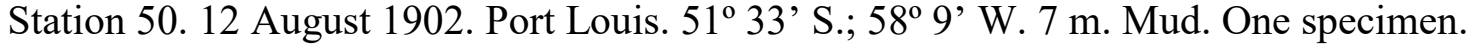

Station 52. 3 September 1902. Port William.51 ${ }^{\circ} 40^{\prime}$ S.; $57^{\circ} 44^{\prime}$ W. 17 m. Sand. Several specimens, one with four arms.

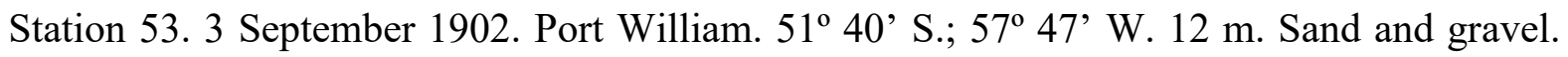
Three specimens.

Station 54. 3 September 1902. Stanley Harbour. $51^{\circ}$ 42' S.; 57 50’ W. 10 m. mud and shells. Two specimens.

Station 59. 12 September 1902. Burdwood Bank, to the south of West Falkland. $53^{\circ} 45^{\prime}$ S.; $61^{\circ}$ 10' W. 137-150 m. Shell hash and stones. One specimen.

Swedish Magellan Expedition 1907-09. Station 8. 5 December 1907. West Point Island, West Falkland, 0 m. Rocks. One specimen.

It is useless to recall the difficulties in the identification of the different forms that belong to the genus Cycethra. Various authors, Meissner, Ludwig and I have unreservedly considered the various described species, notably by Sladen, and most of the forms distinguished by Perrier, as only varieties of one and the same very polymorphic species. Perrier described with care the most important variations that he encountered in the Cycethra collected by the Expedition of Cape Horn and believed he was able to apply a name to each of the principal forms. Bell reproached him for the creation of numerous species and he added even that this point of view "can only be regarded as a piece of gallic gaiety". Bell was wrong. Perrier defended himself to the contrary of having created species and said it strongly (1891, p.187 and 188): "Also it does not appear established that the species distinguished by Mr. Percy Sladen are really different. We must in this hypothesis distinguish up to nine. We have moved back from this extreme and we have thought it was preferable to consider Cycethra simplex simply as an eminently variable species." There is no place in this memoir of mistaking the sense of these last words. Perrier has simply wanted to clarify by different names the diverse variations that he described. This naturalist believed he had to distinguish the types ganèroïdes and the types pentagonastérö̈des, and, among these principal types, forms with short, medium or long arms. In summary, he sought to fix, for the convenience of the language and of the exposition, the different states of the individuals that he studied. To use, in my turn, the terms that served Bell, I say that this author has given, himself, an example of the good English gaiety by describing recently, under the name Cycethra verrucosa, an asteroid collected by "Discovery" that does not belong at all to the genus Cycethra. Judging from the figure he gives (1908, Pl. 5, fig.1b) where is shown on each dental pair, in a manner most clear, a backwards tilted spine, is this is nothing else than a Gnathaster? I will not say it because this is no longer gaiety, this is an error, and with recidivism because the photographs that Bell published most recently (1917, Pl. I, fig. 1-6) in his work on the echinoderms of the "British Antarctic (Terra Nova) Expedition" in 1910 under the name of Cycethra verrucosa are also of Gnathaster.

As I wrote in 1908 (p. 557), I am of the opinion that the diverse Cycethra called by authors verrucosa, simplex, nitida, electilis, pinguis, etc. should be considered as variations of an extremely polymorphic species, and according to the law of priory, this species should have the 
name of C. verrucosa (Philippi) and not of simplex Bell. But I think, on the other hand, that one should not, on principle, throw into $C$. verrucosa, without an examination in depth, all asteroids recognized as belonging to the genus Cycethra. The process truly would be too convenient. Thus, I have had the opportunity to describe recently in my memoir on the asteroids of the "Australian Antarctic Expedition", a new Cycethra I named C. macquariensis (1920, p. 139, PL. XXXIV, fig. 1 to 4 and 6 to 7, and Plate LXVI, fig.5) from Macquary Island. I will give likewise later the reasons for which it seems to me necessary to specifically distinguish by the name $C$. cingulata another Cycethra collected by the "Swedish Antarctic Expedition" at station 10 and of separating it from very numerous individuals that I believe can be given the name $C$. verrucosa, while remarking that one can relate these individuals respectively to the two principal forms established by Sladen under the names electilis and nitida..

Whatever the ideas that one has on the respective value of species and varieties, I think that Perrier had much reason to distinguish in the genus Cycethra the ganérö̈des types with little developed or indistinct marginal plates from the pentagonastérö̈des types with very distinct marginal plates. It is a very interesting attempt that merits better than the pleasantries of Bell. But I differ from the French author relative to the attribution of the forms of these types. Thus it appears to me possible to better define the limits. Thus I propose to call ganérö̈des the forms with small and little developed marginal plates as Perrier indicated, but adding that these forms have more or less rounded arms and that the marginal plates, more specially limited to the sides of the arms, chiefly the dorsal marginal, are numerous, little apparent or even not visible when the asteroid is looked at from above. In pentagonastéroïdes the forms have a flat body, short arms, large marginal plates that are not numerous chiefly developed on the dorsal and ventral surfaces of the body to which they form a large border. It seems to me these forms must be separated specifically from the ganéroïdes. It is among these latter that are placed not only all those Perrier called ganéroïdes (and that for me are all $C$. verrucosa such as $C$. simplex Bell, electilis, nitida and pinguis of Sladen, in the same way $C$. elongata, media, and asterina of Perrier, but also most of the Cycethra of Cape Horn that Perrier called pentagonastéroïdes and to which he gave the names of nitida, electilis, subelectilis, calva and regularis. It is the same for some other forms not mentioned by Perrier in his memoir of 1891 and that however are conserved in the Jardin des Plantes where they are labeled under the name $C$. simplex. I have had the opportunity to study all the individuals collected by the Mission of Cape Horn. Most of them, I repeat it, merit being called ganéroïdes. The arms are more or less elongated and the marginal plates are more or less distinct, but they remain small, numerous, limited to the sides of the arms, little visible, chiefly at the beginning of the rows, when the asteroid is looked at from the dorsal surface or ventral surface. The middle plates of these rows are arranged obliquely in relation to the dorsal surface of the arms. The dorsal and ventral plates alternate for some length beyond the first. Finally, their covering is more or less paxilliform. It is this arrangement of the marginal plates and their position on the sides of the arms, less than their absolute dimension, that appear to me must characterize the numerous ganéroïde forms and that one can distinguish in $C$. verrucosa. Ganéroïde forms can be placed individuals with elongated arms and others having very short arms (as occurs for example in $C$. asterina) and I will establish a relation between the different states that can be observed from the point of view of the length of the arms in the genus Cycethra and the genus Henricia. It is known that W. K. Fisher found individuals with very long arms and others with very short arms with a nearly pentagonal form (Fisher 1911, Pl. LXIII, fig. 2). It is likewise to the same group of ganéroïde forms that belongs another species of Cycethra that I distinguished recently among the species collected by the 
"Swedish Antarctic Expedition", C. macquariensis, which I have made a distinct species after comparative examination with the Cycethra that I have now at hand.

As for the pentagonastéroïde type, I believe it necessary to restrict it as I have said above and include only those with a more or less pentagonal body form, indistinct or very short arms, with large marginal plates that are not numerous and that form a large, very apparent and greatly encroaching border on both surfaces of the body on both the dorsal and ventral surfaces. The free surface of these marginal plates is flat and covered with granules not making paxillar groups. This group seems to me to be less extended than the preceding. This is the group to which must belong the six specimens from Orange Bay that Perrier (p. 184) described under the name of Cycethra astericus. But all searches made at the Jardin des Plantes for these individuals have been in vain. In contrast, I have found several bottles, without label or labeled simply Cycethra that are quite pentagonal in form and that conform to the species that I will describe later under the name $C$. cingulata. Unfortunately, it is impossible for me to recognize from the brief description Perrier gave to this $C$. asteriscus, if it is or not identical to that I will describe under the name $C$. cingulata. For me, the latter, as also the pentagonal Cycethra I have found at the Jardin des Plantes and of which I will speak in describing $C$. cingulata, cannot be related to $C$. verrucosa. In fact it appears to me impossible Cycethra having the characters I enumerated above would be $C$. verrucosa and I think that they should be distinguished as species. Thus, except for this specimen that represents a new species, all the Cycethra collected by Nordenskjöld are ganéroïde forms. It is of interest to review them rapidly.

As regarding the structure of the skeleton, one can establish very important variations. In individuals such as those from stations 54 and 59 shown in Pl. VIII, fig.3 and 4, the skeleton absolute recalls that which Sladen described in $C$. nitida. It is very compact. The dense ossicles are projecting, very small, rounded and they are connected by an intercalary tissue that is crossed only by the small round papulae (Pl.VII, fig. 7). On the ventral surface, the ossicles are arranged in longitudinal and transverse rows and also solidly united with each other. In the other specimens that correspond to the $C$. nitida form, the skeleton is a little less dense. It remains however still very compact in the specimen with very long arms from station 50 and in that from station 54 shown in Pl. VII, fig. 5. But in the others, such as those from stations 44 and 45, the skeleton has a very loose network. The ossicles in the form of a cross are connected only by their extensions and have very large spaces between them by which pass two or three papulae (Pl. VII, fig. 12 and Pl. VII, fig. 5). However, one can find all intermediaries between these two extreme forms.

In order to look at the principal individuals collected by the "Swedish Antarctic Expedition", I separated them into two groups according to the structure of their skeleton, the characters of the electilis form or those of the nitida form. There will be considered also an individual with very short arms of which I have already spoken that that I will describe later as a new species.

I refer to the electilis form, first of all, three individuals from station 59, one of which is shown in Pl. VIII, fig. 4, a specimen from station 54 shown in Pl. VIII, fig. 3, and finally the individuals collected by the "Swedish Magellan Expedition" from station 8.

The specimen from station 54 is robust. The very elongated arms are large at the base and they taper gradually to the end that is rounded. The disk is not very large: $R=55$ and $r=21$. The ratio $R / r=2.6$. This individual agrees exactly to the description given by Sladen for $C$. electilis. The spines of the dorsal surface are very developed and they represent true spines. The individual from station 8 has a much larger disk and much shorter arms: $R=45$ and $r=20 \mathrm{~mm}$. The ratio $R / r$ is 2.25. The plates of the dorsal surface and the marginal plates have only elongated granules. The 
dorsal and ventral marginal plates are a little larger and more apparent than in the preceding individual.

In the individual from station 59 shown in Pl. VII, fig.13 and Pl. VIII, fig. $4, R=43$ and $r=$ 18. The ratio $R / r=2.4$. The marginal plates are quite apparent, chiefly in the second half of the arms. They are less developed in the first half where they are hardly apparent when the animal is looked at from the side. In the same way that often happens in the genus Cycethra, the ventral marginal plates alternate at first regularly with the dorsals. Then they correspond exactly. The specimen is remarkable by the tendency of the spines to arrange themselves on each other in a regular manner. This tendency is shown on the dorsal surface where the spines forming a marginal border surround a central group of spines that vary in number. But the arrangement becomes especially regular on the marginal plates (Pl. VII, fig, 13). It is the same on the ventral plates. On the marginal plates, that are taller than long, are two very regular lateral rows around central spines that also usually arranged in a regular manner, sometimes only one, sometimes in two vertical rows. On the ventral surface, the spines form two divergent rows on the border of the plates. Usually the central part lacks spines. These arrangements give the specimen an unusual appearance. All the spines are short. They have nearly the same size over the entire surface of the body. They have fine spinules at their end. The adambulacral plates have at first on their internal border two very sturdy, short spines that are rounded at the end. Sometimes they are more or less oblique. Behind, and on the ventral surface of the plate, is a group of three or four spines that are closer together. Sometimes they are irregular, sometimes they forming two successive pairs.

I refer to the form nitida the specimen of station 39, two from station 44, the two of station 48, those of station 50, on of station 54 (Pl. VII, fig. 12 and Pl. VIII, fig. 9) and finally the three from station 53.

All these individuals, except those of stations 50 and 54, have the same characters. They are all very small. In the largest, $R$ varies between 22 and $29 \mathrm{~mm}$ and $r$ between 9 and $10 \mathrm{~mm}$. In the smallest, $R=13$ and $r=5 \mathrm{~mm}$. The arms ordinarily are very narrow and long and the base is not very enlarged. The marginal plates are not very apparent and they are only a little larger than the adjacent ones, especially the dorsal marginal plates that have slightly longer spines. The spines of the surface of the body are very short, especially on the dorsal surface. The adambulacral spines are arranged as Sladen indicated. The is first two internal unequal spines arranged side by side nearly parallel to the furrow usually in a regular manner but sometimes a little obliqiue. These spines are very robust, elongated, ordinarily flattened at the end that is wide and truncate. Behind, on the ventral surface, there is at least a pair of small, very regularly arranged spines. Finally, following, some other very small and irregular spines.

The two other specimens from stations 50 and 54 are remarkable for their very long, narrow, nearly cylindrical arms that are not much enlarged at the base, and with a length much greater than the diameter of the disk. In the larger individual from station 54, $R=47, r=18 \mathrm{~mm}$ and the ratio $R / r=2.6$ (Pl. VII, fig. 5 and 11). In the smaller, $R=32, r=11 \mathrm{~mm}$ and the ratio $R / r=2.9$. In the first, the dorsal paxillae are very separated from each other and have small spinose spines that tend sometimes to have a regular arrangement with the marginal spines surrounding some central spines. This arrangement is clear on the first marginal plates that are very distinct, especially the dorsal marginals. The ventral marginals, which alternate at first with the preceding, are smaller but they soon reach the same size and even are a little larger at the end of the arm. The latero-ventrals have three to five small spines per plate. The adambulacral spines generally have six spines. The two internal ones are notably larger than the others and arranged in a very apparent pair parallel to the furrow. Sometimes the other smaller spines are arranged in an irregularly oblique row, or a 
second pair follows two irregularly arranged spines. The internal spines are very thin, cylindrical, often simply rounded at the end but sometimes however slight spatulate. I will remark that this individual from station 54 was accompanied by another example that I described above that had the characters of $C$. electilis whose photograph is given in Pl. VIII, fig. 3.

Regarding the other specimen from station 50, its dorsal plates are denser. They simply have very dense elongated granules. The dorsal and ventral plates are also small and indistinct. The adambulacral spines are arranged in three successive very regular groups, but the two internal spines are comparative small than in the preceding example and the external group is often reduced to a single spine.

Perrier identified as $C$. nitida a specimen from Cape Horn with elongated arms that I have been able to study in the Jardin des Plantes. The disk is comparatively larger and the arms are short and thicker than in the individual from station 54 shown in Pl. VII, fig. and ratio $R / r$ is 2.88 . The two internal adambulacral spines are unequal as Perrier indicated. The proximal spine is cylindrical and the smaller distal spine is spatulate. The two individuals are very similar. The dorsal and marginal plates are not much more distinct than those of Cape Horn and those of station 54. Now Perrier placed his specimen among the pentagonastéroïds. But for me, conforming to the distinction that I made above, it is a ganeroid because the marginal plates are small and little edeveloped. The individual from station 50 is also like the specimen from Cape Horn.

In contrast, Perrier correctly placed a Cycethra that he described under the name $C$. elongata in the ganeroids. It has relatively thin and elongated arms (the ratio $R / r=3.23$ ) and the marginal plates are not distinct. The plates on the dorsal surface are small and dense. This individual also has some resemblance to the specimen from station 50 that I referred to above but in the latter, the dorsal and ventral marginal plates are more marked that in the C. elongate of Perrier.

It seemed interesting to me to compare the two specimens with elongated arms that I referred to above to the $C$. Lahillei that Loriol described in 1904 (p. 73, Pl. V, fig. 2) and that I had been able two study and photograph thanks to the kindness of my excellent friend Bedot, Director of the Museum of Geneva, where the specimen is conserved. I show it here in Pl. VIII, fig. 10 and 11. It is essentially a ganeroid form but is very different from the other Cycethra that I have had the opportunity to examine or that the other authors have described. The spines of the dorsal surface as well as those of the ventral surface are very elongated. The adambulacral spines are also more developed than usual and most often they are arranged in four very regular rows, each with two spines. The tooth spines are also very developed, sturdy and elongate. I admit that I am disposed to see in $C$. Lahillei a special form that should be distinguished from $C$. verrucosa, perhaps even as a distinct species but in any case to the same standard at least as $C$. electilis and nitida. The two figures that Loriol gave of $C$. Lahillei are not very clear. I have thus believed it useful to give here two photographs of the type that remains unique to the present and that, although dried, is in a very good state of preservation.

I will add only a word on the subject of anatomical arrangements of the genus Cycethra. I have dissected one of the specimens from Port Louis. I have confirmed in particular that the ambulacral vesicles are in two rows (Pl. VIII, fig.6), that the gonads open onto the ventral surface of the body, and that the pyloric caecae extend to nearly mid-arm. 


\title{
Cycethra cingulata nov. sp.
}

\author{
(Pl. VII, fig. 6.)
}

Station 40. 19 July 1902. Falkland Islands, Berkeley Sound. 51³3' S.; 58º' W. 16 m. Gravel and shells with algae.

$R=17 \mathrm{~mm}, r=10 \mathrm{~mm}$. The arms have a width of $11 \mathrm{~m}$ at their base. Their length is only 10 $\mathrm{mm}$.

This Cycethra (Pl. VII, fig. 6 and 7) is completely different from the other specimens of the same genus included in the collection made by Nordenskjöld and all though that can be referred to $C$. verrucosa comprising in its broadest sense with its different forms, nitida, pinguis, electilis, etc. On the other hand, it is identical to some Cycethra collected elsewhere by the Expedition of Cape Horn and which are conserved in the Jardin des Plantes but which Perrier does not mention in his work. I have thus believed it necessary to give here the photographs of two of these specimens to which I shall return later (Pl. VII, fig. 8 and 9).

In the specimen from station 40, the arms are extremely short, triangular, very wide at the base so that they are continuous with the disk and a nearly as wide as long. The body is thin and the arms, like the disk, are flat. The margins are vertical and made up of a double row of very large marginal plates. They are not numerous and form a very apparent and important border between the dorsal and ventral surfaces. These plates, seen from above, are comparatively larger in the first half of the arm than in the second, although in some individuals from Cape Horn these plates are narrower at the base of the arms and enlarge slightly subsequently, whereas in specimen No. 395 (fig. 9), these plates have the same width nearly the entire length of the arms. They are even a little more developed and larger than in the specimen of Nordenskjöld.

The dorsal surface of the disk is filled with very small, unequal plates. Their borders are connected and produce a projecting principal region with an oval or circular form with a flat peripheral part. In the intervals between the projecting regions are isolated papulae that are arranged without order and extend to the area of the dorsal marginal plates. The madreporite plate has average dimensions and is near the center than the border. The terminal plate is small, triangular and slightly projecting. The dorsal lateral plates are covered with very short, cylindrical spines, 0.15 to $1.18 \mathrm{~mm}$ in length and $0.1 \mathrm{~mm}$ in diameter at the base. They narrow in the middle and widen at the end into a head with more or less numerous short, pointed spinules. These spines are different from those I have observed in diverse varieties of $C$. verrucosa. They are very much longer, cylindrical and easily reach $0.4 \mathrm{~mm}$ in height and $0.1 \mathrm{~mm}$ in with at the base and have at the head simply some short spinules.

The ventral interradial areas are large. They are covered with connected plates into a continuous pavement from which emerge rounded or slightly oval projections corresponding respectively to the plates and a quincuncial arrangement or, if one prefers, forming longitudinal and transverse rows The longitudinal rows are very apparent, at least the first three. There are twenty four plates in the first row next to the adambulacrals. Each of them corresponds to an adambulacral plate. The second row stops at the fourteenth adambulacral plate and the third at the twelfth. The first transverse rows are not very apparent. Two of these rows correspond to a ventral marginal. Each plate in the first row has a bundle of five or six very short, cylindrical small spines. They become smaller in the following plates. 
There are twelve dorsal marginal plates on each side. Seen from above, they are rectangular, wider than long. The last five are very much shorter than the preceding. Their surface is strongly convex. These plates have nearly the same development on their dorsal and lateral parts. They are separated by very wide, slightly oblique transverse furrows. They are covered with small spines similar to those of the dorsal surface, but a little larger and likewise a narrowing towards the middle with a head with spines. The ventral marginal plates do not correspond exactly with the dorsals at the beginning of the row but then establish correspondence. These plates have characters analogous to those of the dorsal plates. However they are a little less developed on the sides of the arms and slightly less tall than the corresponding dorsal plates when seen from the side. In contrast, the ventral marginal plates are developed more on the ventral surface of the body where they are least two times wider than long in the first half of the row. The antepenultimate plate is still very large. Only the two last are abruptly narrowed. The nearly square adambulacral plates have two spines on their internal border, placed nearly obliquely. The proximal spine is smaller than the other. These spines are cylindrical and very short. On the ventral surface of the plates is a group of generally three spines arranged obliquely to the first plates. Each tooth has three very short spines on their free edge. Towards the end are two very large spines, especially the last. Generally there are two small short spines on their ventral surface. Behind these are one or two extremely reduced spines.

As I have said above, I found in the Jardin des Plantes, among the Cycethra collected by the Mission of Cape Horn, various examples not mentioned by Perrier that appear to me should be referred to $C$. cingulate. In a specimen labeled $394 \mathrm{~g}, R=24$ and $r=12 \mathrm{~mm}$. In another labeled $395 \mathrm{c}$, Orange Bay, $R=23$ and $r=12.5$. Other samples also from Orange Bay and labeled 395 are smaller. In the largest, the respective values of $R$ and $r$ are from 15 and $8.5 \mathrm{~mm}$. Finally, other smaller specimens are labeled numbers $395 \mathrm{f}, 395 \mathrm{p}$, etc. In these difference individuals, the marginal plates are larger and wider, but often the dorsal marginals are narrower in the first half of the arms than in the second half. This is the situation for example in the individual shown in Pl. VII, fig. 8 that was labeled 395c. In that in fig. 9, the extremely wide dorsal marginal decrease in width towards the extremity of the arms. In the two last specimens, there are twelve marginal plates each side and seventeen in the first. In the other specimens of the same number, the marginal plates are slightly narrower. In the smallest individuals, they are to the contrary comparatively wider.

Similarities and differences. $-C$. cingulate is a species essentially pentagonal. It is clearly distinguished from all the known varieties of $C$. verrucosa by its nearly pentagonal form with a relatively large disc, very short arms, as long as wide, or barely a little longer than wide in various specimens of Cape Horn; by the great development of the ventral interradial areas; by the spines of the dorsal surface and marginal plates that are very short and slightly swollen at the end in a spinulose head; and especially by the great development of the marginal plates that form a wide, very apparent belt to the body not only when viewed laterally but also when it is viewed, either by the dorsal surface or the ventral surface. It does not appear possible for me to place, even with the title of variety, this Cycethra into $C$. verrucosa whatever is the extent of variations that this latter can offer. 


\section{Ganeria falklandica (Gray).}

Ganeria falklandica Sladen (1889) p. 383, Pl. LS, fig. 1 and 2; Pl. LXII, fig. 6 and 7.

Ganeria falklandica Perrier (1891) p. 9.

Swedish Magelanic Expedition 1907-09, Station 17. 18 April 1908. Fitzgeral Channel, between Otway and Skyring Waters, southern Patagonia. Large gravel, rapid current. 13-14 m. One specimen.

$R=16, r=14 \mathrm{~mm}$. The specimen conforms completely to the description and figures of Sladen.

\section{Ganeria Hahni Perrier}

(Pl. IX, fig. 3 and 4)

Ganeria Hahni Perrier (1891), p. 118, Pl. XI, fig.3a and3b.

Station 44. 28 July 1902. Falkland Island, Port Louis, Greenpatch, near the bridge. 51' 33'S.; $58^{\circ} 10^{\prime}$ W. 7 m. Mud and gravel. Four specimens.

The specimens are smaller than the type described by Perrier. In the largest, $R$ measures 38 and $r$ $11 \mathrm{~mm}$. In the next, $R$ equals 22 and $r 9 \mathrm{~mm}$. The two other individuals are much smaller. In one, $R=11$ and only $4 \mathrm{~mm}$ in the other.

By their exterior appearance, these individuals conform very well to the type of Perrier preserved in the Jardin des Plantes and to which I was able to compare them. However the largest differs by the arrangement of the adambulacrala spines. Perrior said, that which is moreover true, that the plates have on their internal border a long conical spine, sometimes flanked by a second smaller spine. In the specimen from the Swedish Antarctic Expedition, there are two very regular unequal spines. Nevertheless some spines have only one as occurs in the type where it is rarer to find two spines on the same plate. In the second smaller individual, there is never only a single internal adambulacral spine. I do not think that this difference is sufficient to permit a specific separation, especially with the small number of specimens known for the species.

I have believed it necessary to dry the largest specimen in order to study the form and armature of the plates on the two surfaces of the body. It is easy to recognize in my photographs the form of the dorsal plates with their very small spines and the large popular areas that they limit. The contours of the ventral plates are not very apparent. Nearly all have a spine. However, sometimes two are found in the area of the ventral marginal plates. The plates of the ventral interradial areas form especially, as Perrier said, transverse series in which the number of plates, six in the first row, decreases rapidly. 


\title{
Perknaster aurantiacus Kohler.
}

\author{
Perknaster aurantiacus Kœhler (1912), p. 36, Pl. III, fig. 9; Pl. IV, fig. 1.
}

Station 17. 19 April 1902. Shag Rock Bank, between the Falkland Islands and South Georgia. $53^{\circ} 34^{\prime}$ S.; 43 ${ }^{\circ} 23^{\prime}$ W. 160 m. Gravel and sand. Temp. + 2.05'. One specimen.

Station 22. 14 May 1902. South Georgia, Cumberland Bay, outside May Bay. 54 $17^{\prime} \mathrm{S}$; $36^{\circ}$ $28^{\prime}$ W. 75 m. Clay, some algae. Temp. + 1.5'. One specimen.

In the larger individual, from station $22, R=31-32$ and $r=11 \mathrm{~mm}$. The arms are very wide at their base that measures $11 \mathrm{~mm}$. They narrow gradually to the end that is not very narrow. The type, according to which I have established the species, was a little small ( $R$ measures 25 and $r 6 \mathrm{~mm}$ ). It was collected by the Charcot Expedition in Peltier Channel, between Goetschy Island and Doumer Island. In the individual from the Swedish Antarctic Expedition, the spines of the body are a little longer and more elongated that is without the result of the difference in the size of the subject, more than in the specimen from station 17 in which $R=18$ and $r=5 \mathrm{~mm}$. The spines themselves are small and the individual is completely comparable to that of the Charcot Expedition.

\section{Cryaster Auroræ Kœhler}

Cryaster Aurorce Kohler (1920), p. 120-126, Pl. XXVII, fig.1 to3 , 5 and 6; Pl. XXVIII, fig. 1 to 11 ; Pl. XXIX, fig. 2 to 6, Pl. XXX, fig. 2 to 5; Pl. LXXV, fig.1.

Station 5. 16 January 1902. Graham Land, to the southeast of Seymour Island. $64^{\circ} 20^{\prime} \mathrm{S} ; 56^{\circ}$ 38 ' W. 150 m. Sand and gravel. One specimen.

Station 17. 19 April 1902. Shag Rock Bank, to the west of South Georgia. 53 34' S.; 43 23' W. $160 \mathrm{~m}$. Graveland sand. One specimen.

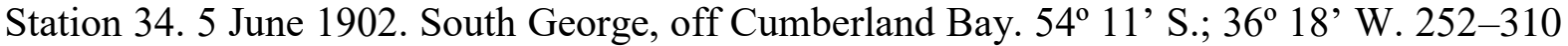
m. Gray clay with stones. One specimen.

The specimen from station 17, that is the largest, $R=40$ and $r=19 \mathrm{~mm}$, is completely typical and conforms absolutely with specimens of the same size collected by the "Australian Antarctic Expedition". It notably resembles the specimen that I have described under the letter G. The very large internal adamabulacral spine is great widened at the end. It has the form of a spatula. The two other individuals are smaller and measure respectively $R, 17$ and $22 \mathrm{~mm}, r, 5$ and $9 \mathrm{~mm}$. Their internal adambulacral spines are only a little flattened with noticeably widening at the end. In the three individuals, the dorsal surface of the body has dense spines, arranged exactly as in the specimens from the "Australian Antarctic Expedition".

I recall that the specimen was found by the "Aurora" in the locality of Adélie Land and in various Antarctic regions between $92^{\circ}--141^{\circ} \mathrm{E}$. and $64^{\circ}--66^{\circ} \mathrm{S}$. It thus has a very great geographical distribution in the Antarctic sea, as it also is found in the regions between $53^{\circ}--64^{\circ} \mathrm{S}$. and $35^{\circ}--56^{\circ}$ W. 


\section{Porania antarctica Smith}

See:

Porania antarctica Kœhler (1911), p. 27.

Porania antarctica Kœhler (1912), p. 66.

Porania antarctica Kœhler (1920), p. 178, P1. XXXIII, fig. 6 and 7.

Station 6. 20 January 1902. Graham Land, to the southwest of Snow Hill Island. $64^{\circ} 36^{\prime}$ S.; $57^{\circ} 42^{\prime}$ W. 125 m. Stones and gravel. Three large specimens.

South Georgia, Cumberland Bay

Station 22. 14 May 1902. Outside May Bay. 54 $17^{\prime}$ ' S.; $36^{\circ} 28^{\prime}$ W. 75 m. Two very small specimens, both with small spines on the dorsal surface.

Station 28. 24 May 1902. Entrance to the Marmite Bay. $44^{\circ} 22^{\prime}$ S; $36^{\circ} 28^{\prime}$ W.; $12-15$ m. Sand and algae. One specimen of average size.

Station 30. 26 May 1902. Moraine Fiord. 54' 24' S.; 36 26' W. 125 m. Clay, some stones. A very large specimen.

Station 33. 30 May 1902. Marmite Bay. 54 $22^{\prime}$ ' S.; $36^{\circ} 28^{\prime}$ W. 22 m. Clay and algae. Four specimens of average size.

23 May 1902. Marmite Bay, in kelp holdfasts. One specimen of average size.

Station 59. 12 September 1902. Burdwood Bank, to the south of the Falkland Islands. 53 $45^{\prime}$ S.; 61 $10^{\circ}$ 'W. 137-150 m. Three large specimens and one small one.

In the three large specimens from station $59, R$ varies between 46 and $40 \mathrm{~mm}$. The fourth is very much smaller and $R$ measures $7 \mathrm{~mm}$. All four are notable by the existence of very apparent conical tubercles on the nodes of the calcareous network. These tubercles that are nearly completely lacking in the specimens from station 22 and in the individual from station 30 that is very large. Likewise, the three large specimens from station 6, in which $R$ varies between 55 and $47 \mathrm{~mm}$, have a dorsal surface completely spineless. The marginal spines are not distinct. They are short, included in the thick tegument where there contours cannot be seen. They only form very marked lobes arranged in groups correspond to each plate. Even in the largest individual, these lobes remain indistinct.

\section{Lophaster antarcticus Kœhler}

Lophaster antarcticus Kœhler (1912), p. 46, Pl. II, fig. 4 and 5.

Lophaster antarcticus Kohler (1920), p. 144, Pl. XXXII, fig. 8 to 11; Pl. XXXIII, fig. 3 and 4; Pl. LXVII, fig. 1-5; Pl. LXVIII, fig. 1 and 2.

Station 26. 20 January 1902. Graham Land, to the southwest of Snow Hill Island. 64', 36' S.; $57^{\circ} 42^{\prime}$ W. 125 m. Stones and gravel. Two specimens.

$R=48$ and 23. 
The individuals are not in very good state of preservation, especially the larger. Nevertheless, I found the forms of the spines of the paxillae so characteristic of the species that I have described in detail in my memoir (1920), notably the very curious spines that end in thick, unequal lobes.

\section{Cuenotaster involutus (Kœhler)}

Leucaster involutus Kœhler (1912), p.54, Pl. V, fig.1, 2, 3, 6, 7, 10 and 11.

Cuenotaster involutus Kœhler (1920), p. 159-161, Pl. XXXIII, fig. 5; Pl. LXV, fig.5.

Station 17. 19 April 1902. Shag Rock Bank, to the west of South Georgia.53 $34^{\prime}$ S.; $43^{\circ} 23^{\prime}$ W. $160 \mathrm{~m}$. Gravel and sand. One specimen. $R=46 \mathrm{~mm}$.

The color of the specimen in alcohol is yellowish It absolutely conforms to the specimen of nearly the same size collected by the Australian Antarctic Expedition.

\section{Remaster Gourdoni Kœhler}

(Pl. IX, fig. I)

Remaster Gourdoni Kœhler (1912), p. 60, Pl. V, fig. 4, 5, 9, and 12; Pl. VIII, fig. 7.

Station 5. 16 January 1902. Graham Land, to the southeast of Seymour Island. $64^{\circ} 20^{\prime}$ S.; $56^{\circ}$ 38 ' W. $150 \mathrm{~m}$. Sand and gravel. One specimen.

Station 15. 31 March 1902. Falkland Islands, Port William. $51^{\circ} 40^{\prime}$ S.; $57^{\circ} 49^{\prime}$ W. 10 m. Macrocystis bed. One specimen.

Station 17. 19 April 1902. Shag Rock Bank. 53 34' S.; 43 23' W. 160 m. Gravel and sand. Four specimens.

South Georgia, Cumberland Bay:

Station 22. 14 May 1902. Outside May Bay. 54 ${ }^{\circ} 7^{\prime}$ S.; $36^{\circ} 28^{\prime}$ W. 75 m. Clay, some algae. One specimen.

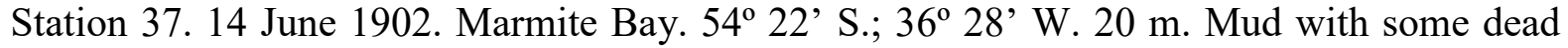
algae. One specimen.

South Georgia, Cumberland Bay. Gift of E. Sorling.

The individuals are rather smaller than those that have been collection by the Charcot Expedition and $R$ scarcely reaches $10 \mathrm{~mm}$. The diameter, measured between the end of the arm and the opposite interarm arc is 15 to $16 \mathrm{~mm}$. In the specimen from station 17 this diameter is only $11 \mathrm{~mm}$. All the specimens conform perfectly to the type. 


\section{Diplopteraster verrucosus (Sladen)}

(Pl. XI, fig.5; Pl. XII, fig. 1)

Retaster verrucosus Sladen (1889), p. 278; Pl.LXXVI, fig. 1 and 2 ; Pl. LXXVII, fig. 9 and 10. Diplopteraster verrucosus Fisher (1911), p.371.

Station 16. 11 April 1902. Between the Falkland Islands and South Georgia. 51 $40^{\prime}$ S.; $57^{\circ}$ $25^{\prime}$ W. 150 m. Sand. One specimen. The color noted in the living specimen was yellow above.

$$
R=28, r=17 \mathrm{~mm} \text {; the ratio } R / r=1.64 \text {. }
$$

I believe I can place this specimen in the species that Sladen has described under the name Retater verrucosus that was transferred into the genus Diplopteraster because of the characteristics of the tube feet and the adambulacral spines. My specimen is noticeably smaller than the type of Sladen in which $R$ was 47 and $r 28 \mathrm{~mm}$. It is evidently this difference in size that there are some differences that I will indicate later all that concern principally the adambulacral spines.

The general form is the same as I the type described and illustrated by Sladen. The dorsal paxillae have the same regularity shown in his figure (1889, Pl. LXXVI, fig. 1) with a central spine much larger and projecting than the others. There are about a dozen arranged very regularly around this central spine to which they are connected by fibrous bands. They form a very regular ensemble as can be seen in my photograph (Pl. XI, fig. 5). The spiracles, about a dozen around the central spine, are small, unequal and arranged very regularly

There are four teeth. The external one is much shorter than the others that are sturdy and elongated. There is, in addition, a very short, vertical spine on the ventral surface of each tooth. The adambulacral spines have an arrangement a little different from that indicated by Sladen. The combs these spines form are alternatively long and short. The longest, found nearer the furrow, has sometimes five sometimes four spines. The number five is found only at the beginning of the arms and the internal spine is notably small than the others that are unequal. The shorter combs ordinarily have only three unequal spines, but sometimes there is an extremely small internal spine. All these spines are united by a thick membrane forming a sac at the end of each spine. Sladen indicated a constant number of five spines in the longest combs as in the shortest. The number I have given above for my specimens, which are two times smaller than those of Sladen, should certainly change with age.

\section{Diplopteraster Nordenskjöldi nov. sp.}

$$
\text { (Pl. X, fig.4 to 8) }
$$

Station 59. 12 September 1902.Burdwood Bank, to the south of the Falkland Islands. $53^{\circ} 45$

S.; 61 ${ }^{\circ} 10^{\prime}$ W. 137-150 m. Stones, shell hash. Two specimens: one with seven and the other with six arms.

In the larger individual with seven arms, the total diameter is about $80 \mathrm{~mm}$ and in the other, with six arms, the diameter is only $54 \mathrm{~mm}$. The specimens have a very firm consistency and their thickness is $23 \mathrm{~mm}$. in the larger and 14 in the smaller. The arms are comparatively shorter in the larger individual. Their form is also very variable. Most of them have their end turned up on the 
dorsal surface. One of them that is best exposed has the form of a triangle whose height measures approximately $25 \mathrm{~mm}$ and whose base is a little less large. But it is impossible to give the exact dimensions because of the deformation of the arms. It is easy to judge their form in the photograph I reproduce here $\mathrm{Pl}$. X, fig. 4 . In the small specimen, the arms are equally triangular, short and thick, with the end very thin, turned up and flat on the dorsal surface. The ventral surface of the body is convex.

I have dried the individual with seven arms in order to be able to study the skeleton. It is from this dried specimen that the photographs were made fig. 4, 5, 6 .

The presence of six or seven arms in the Antarctic species immediately recalls Pteraster obscurus of boreal seas, but a simple glance makes it possible to recognize it is not a Pteraster but certainly a Diplopteraster and I believe it must be considered as new.

The dorsal covering, very thick and opaque, is crossed by the ends of the spines of the paxillae and these ends remain free and naked. These paxillae are each constituted of about a dozen spines, a central one the others peripheral and divergent. These spines are cylindrical with the end blunt and their surface has very fine longitudinal grooves, just as the truncated end has very fine rugosities. The stalk of the paxillae is elongated, very thick, nearly as long as the spines at its end. These spines are in general arranged in a symmetrical and regular manner. But in some regions, the spines are more or less flat and their regular arrangement is lost. The central spine has the same length or a little longer than the others.

The small conical projections, usually with a free end that determine the spines in supporting the dorsal membrane sometimes take, in the smaller specimen, a very regular arrangement in transverse or longitudinal rows that is very apparent especially on some arms. The fibrous bands that are extended between the central and peripheral spines of the paxillae are not very projecting. The spiracles are very numerous and close, but they are disposed irregularly and very unequally. In general, they are very fine but some of them are much more developed than others.

The osculum is small and its valves are each supported by seven or eight spines that are cylindrical, very thick, short and unequal.

The dorsal membrane remains very uniform for its entire extent and does not have very marked interradial furrows. I have not found the least indication of eggs or young in the incubatory chambers they form.

The ambulacral furrows are notable for their considerable width. They end in a very vast mouth and the tube feet are arranged regularly in four rows. These tube feet are large and wide. They end in a very large sucker. They are not very numerous. I have counted about twenty pairs on each size in the largest specimen and fifteen or sixteen in the smallest.

The combs formed by the adambulacral plates are very developed. The individual spines are cylindrical, stout and elongated, except for the first. As in the other species of Diplopteraster, the combs are alternatively with and narrow. The widest borders inside the narrowest whose first spine is placed more outside. The largest comb usually encloses six spines whose length increases from the first to the last, especially from the first to the second. The shortest combs enclose only five spines each and the first spine is notably smaller than the following and notably smaller than the first spine of the large combs. In the smallest combs, the small spine is not always placed exactly in alignment with the other but is inserted a little obliquely to the outside or even distally at the base of the second spine. The alternation between the spines is not always perfectly regular but is however, generally, preserved nearly the entire length of the arms. This is more in the photograph of the dried specimen than in the other (fig. 5 and 8). The adambulacral spines are cylindrical and their ksurface has fine longitudinal grooves. Their truncated end has small radiating channels that 
correspond to the grooves of their surface. The membrane that connects them is thick, especially at the end where it is more or less swollen, without forming however very regular and rounded saccules.

The free edge of each tooth has a comb of five spines. The first external one is more than two times smaller than the others that are unequal, south, cylindrical and longitudinally striated like the adambulacral spines. There is in addition on the ventral surface of each tooth and towards its middle, but nearer the suture, a single erect spine that is much shorter than the preceding ones.

The very large and oval segmented openings along the length of their oral border have an elongated, narrow papilla that is not prominent.

The successive combs formed by the adambulacral spines and the membrane that unite them are quite distinct from the neighboring interradial areas. The spaces that separate them are not continued in these areas in deep grooves as sometimes happens. The laterao-ventral spines are not visible in the small specimen where they are completely hidden by the tegument. Iin the largest, they are about twenty five in number. The first three or four are short. Then the length increase rapid in the three or four following spines. This length reaches $6 \mathrm{~mm}$. They are now maintained up to the eighteenth or twentieth spine. Then they decrease progressively. The five or six spines scarcely reach the interradial median and the others remain more elongated.

The border of the body has in the interradial spaces only a very short, unimportant fringe.

Similarities and differences. - The species discovered by Nordenskjöld fits well the genus Diplopteraster because the tube feet are arranged in four rows and the constant alternation in the development of successive adambulacral combs. They are distinguished from other species by having more than five arms, sometimes six, sometimes seven. It is probable that the normal number of arms should be, in D. Nordenskjöld, more than five, although in the three other known species of the genera this number is in principle five (however a quite exceptional D. multipes with six arms was encountered).

The type of the genus Diploteraster is D. multipes of boreal seas. The genus created by Verrill is completely justified and should be conserved. Fisher has shown (1911, p. 371) there is reason to combine Retaster verrucosus and peregrinator from the southern seas described by Sladen. The first was found at the Atlantic entrance of the Strait of Magellan at $55 \mathrm{fm}$ and the second at Kerguelen at $127 \mathrm{fm}$.

In addition to the number of arms, the species from the Swedish Antarctic Expedition is distinguished by the more numerous paxillar spines and by the very unequal and irregularly arranged spiracles. The tube feet, to judge by the figures of Sladen and by the arrangement that I see in the specimen describe above of D. verrucosus collected by the Swedish Antarctic Expedition, seems thicker and stronger than in this last species as in D. peregrinator and they recall especially those of $D$. multipes. On the other hand, the arrangement of the adambulacral spines recalls less those of $D$. multipes and verrucosus than those of $D$. peregrinator where the small combs have a number of weaker spines. But the number of these spines is generally greater in D. Nordenskjöld although they can reach six in the largest combs. These spines appear comparatively stronger than in the three other species.

I have indicated above the existence in the collections made by Nordenskjöld of a specimen with five arms in D. verrucosus. It is smaller than the type of Sladen, but the dorsal surface shows well the characters of the species, notably the very regular arrangement of the paxillae that does not exist in D. Nordenskjöldi. The appearance of the dorsal surface in the two species is quite 
different as can be convincingly shown by comparing the photographs I reproduce in Pl. X, fig. 7 and Pl. XI, fig. 5.

\section{Pteraster Hunteri Kœhler.}

Pteraster Hunteri Kœhler (1920) p. 165, Pl. XXXVII, fig. 4 to 10; Pl. XXXVIII, fig. 8; Pl. LXV, fig. 8.

Station 16. 11 April 1902. Between the Falkland Islands and South Georgia. 51 $40^{\prime} \mathrm{S} ; 57^{\circ} 25^{\prime}$ W. $150 \mathrm{~m}$. Sand. One specimen.

$R=13-14 \mathrm{~mm}, r=9 \mathrm{~mm}$.

The body is pentagonal with the sides sunken and the end of the arms turned upward. It completely conforms to the type I described from specimens collected by the Australian Antarctic Expedition, one at $66^{\circ} 50^{\prime} \mathrm{S}$. and $142^{\circ} 6^{\circ} \mathrm{E}$ at $254 \mathrm{fms}$, and the other at $64-65^{\circ} \mathrm{S}$. and $96-97^{\circ} \mathrm{E}(110-358 \mathrm{fms})$. These specimens were a little larger than those of Nordenskjöld, $R$ varying in them between 22 and $13 \mathrm{~mm}$, but I can find no difference between them. In particular, the paxillar spines show well the same characteristic structure that I described and figured.

\section{Acodontaster elongatus Sladen var. abbreviatus var. nov.}

(Pl. X, fig. 1 to 3 )

Station 25. 21 May 1902. South Georgia, Cumberland Bay, outside Marmite Bay. 54 $22^{\prime}$ S; $36^{\circ} 27^{\prime}$ W. 24-52 m. Gray clay, some algae. One specimen.

$R=22, r=9.5 \mathrm{~mm}$; the ratio $R / r$ is 2.3 .

The form from South Georgia seems to me very close to the A. elongatus that the "Challenger" collected in the region of the Kergulen Islands, Marion and Heard at 50-150 fms that I believe myself justified to consider it as a simple variety of the latter. There exists, in fact, some differences that appear important to note and that, until more amply informed, can justify the creation of a variety, although there is only a single specimen.

The arms are very much shorter than in the type, widened basally, and narrow rapidly in their first half, less rapidly in the second and end in an obtuse and rounded tip.

In the "Challenger" specimens, the respective measurements given by Sladen are $R, 56$ and 62 $\mathrm{mm}$, for $r, 16.5$ and $17 \mathrm{~mm}$; the ratio $R / r$ is about 3.3. However, Sladen notes that some individuals from Kergulen have shorter arms and a more triangular form than others.

The plates of the dorsal surface have the same characters as in A. elongatus. They are small, numerous, irregularly arranged and generally rounded in form in the central part of the disk and in the middle of the arms. But towards the margin, these plates are arranged in successive, regular transverse rows. They take at the same time a rectangular form. They become more and more long and narrower in the immediate area of the marginal plates. Each of these rows regularly abuts a dorsal marginal in the first third of the arm. But, further, the rows are a little more numerous than the marginals. The edges of these plates appear very clearly under the covering of granules. These granules, as in the type of $A$. elongates, are made polyhedric by reciprocal pressure and have the 
form of very short base of a cone with a convex free surface. The madreporite plate, nearer the center than the border, is larger than the adjacent plates. It is a little wider than long and has a slightly trapezoidal form. It has fine, numerous furrows. Within it is accompanied by a plate very much larger than those nearby. It is semi-circular, strongly convex and covered with larger granules than the others.

There are twenty three to twenty four dorsal marginal plates in each plate outside the unpaired triangular plate. These plates are wider than long in the form of a parallelogram separated by very oblique grooves that make the two internal angles of the plate narrower from the end of the arm than the opposite angle. The granules, a little larger than on the nearby plates of the dorsal surface, are very dense. The grooves that separate the successive plates, while being very fine, are quite apparent in the first half of the arm. The edges of these plates then become indistinct. At the end of the arm, the granules of the marginal plates pass onto the terminal plate.

The ventral marginal plates correspond exactly to the dorsals. They are separated by a very apparent groove. They have exactly the same characters and the same covering as the latter. The granules that cover them are a little larger than the granules of the adjacent latero-ventral plates.

The plates that cover the ventral interradial areas have, in the proximal region of these areas, small, very scattered spines that form a marginal border to the plates that surrounds one or two central spines. Thanks to this regular arrangement, the edges of the plates are easily seen and it is possible to clearly recognize the beginning of two rows parallel to the adambulacrals. But the spines soon shorten and at the same time become denser and a little thicker. They are transformed into granules in the form of a truncated cone identical to those of the dorsal surface. They form a very dense covering at the surface of the plates that in fact hides the contours.

Each short and very large adambulacral plate has four successive pairs of plates. The length decreases from the two internal ones to the two external ones, which are very short. To the contrary, the internal spines are very developed. They are first cylindrical, then flatten rapidly while widening to take a very characteristic spatula form. Their truncated end is two times wider than the base of the spine. This spatula form persists in all the spines of the internal row and it appears still very clearly on some spines of the second row. The spines of the two external rows are cylindrical. This arrangement of the adambulacral spines is very different from that which Sladen indicates in the individual types coming from the region of Kergulen, where the two larger internal spines are pointed while the shorter followings ones are thick and have an obtuse end. This is, in short, completely the inverse that is formed in the variety from South Georgia in which the internal spines have moreover a spatulate form.

The teeth are small. On each side of the large spine, they have four spines nearly identical to the adambulacral spines that they continue. Then, on the ventral surface of the tooth, are three successive smaller spines.

The variety from South Georgia is remarkable by the presence of pedicellariae that belong to two different types. There is first, at the summit of each of the interradial ventral areas, a fasiculated pedicellaria constituted by the joining of four convergent spines that form a conical group. This arrangement conforms to that which Sladen reported in A. elongatus, but here there is only a single fasciculated pedicellaria at the top of each area and there is not the least trace on the lateral ventral plates adjacent to the adambulacrals. In contrast, there are some flat pedicellariae resembling the type I have called "trivalve" in my memoir of 1920 (p. 185). On the dorsal surface, there is one of these pedicellaria in each interradius but one at a short distance from the center. These pedicellariae have three flat valves in two of them and only two values in the two others (Pl. X, fig. 2 and 3). In addition, these same pedicellariae are found on some dorsal marginal plates: On each side, the first 
three marginals in one row each have one of them and in the two other rows there is also one on each of the first plates (fig. 2 and 3). In addition, these same pedicellariae are found on some dorsal marginal plates: on one of the sides, each of the three first marginal plates of a row have one of them and in two other rows there are likewise one on each of the first plates (fig. 2 and 3). On the ventral surface, four analogous pedicellariae are found on some marginal plates, always very separated from the unpaired plate. All have three valves. These pedicellariae do not exist in the type of A. elongatuos and they still have not been found in the genus Acodontaster.

For these various reasons, it appears necessary to me to distinguish the Acodontaster from South Georgia from the type coming from the region of Kerguelen, but it naturally will be necessary to examine numerous individuals to determine the exact value of the differences I just noted.

\section{Asterodon singularis (Müller and Troschel)}

See for the bibliography:

Asterodon singularis Perrier (1890), p. qer, Pl. XIII, fig. 3.

Asterodon singularis Leitpoldt 1895), p. 614.

Asterodon singularis Ludwig (1903), p. 19.

Odontaster singularis Meissner (1904), p. 19.

Asterodon singularis Meissner (1905), p. 40, Pl. VI, fig. 5 and 6.

Odontaster singularis H.L. Clark (1910), p. 332, Pl. II, fig. 4.

Swedish Magellan Expedition 1907-09. Station 17, 18 April 1908. Fitzroy Canal, between Otway and Skyring Waters, South Patagonia. Larger gravel. 13-14 meters. Rapid current. One specimen.

$R=30, r=19 \mathrm{~mm}$. There is not the least trace of pedicellariae.

The specimen with arms slightly shorter and more obtuse than the individuals shown by Perrier (1891, Pl. XIII, fig. 3 and 3 b) and by Meissner (1905, Pl. VI, fig 5 and 6). In the former, that came from Cape Horn and is preserved in the Jardin des Plantes, $R=39, r=22 \mathrm{~mm}$. My specimen perfectly conforms to it, except that the arms are slightly shorter. There are fifteen marginal plates on each side outside the unpaired plate.

\section{Gnathaster validus (Kœhler)}

Odontaster validus Kœhler (1906), p. y, Pl. III, fig 22 to 26.

Odontaster validus Kœhler (1911), p. 27.

Odontaster validus Kohler (1912), P. 68, Pl. VII, fig. 1, 2, 3, 4, and 12.

Gnathaster validus Kœhler (1920), p. 228, Pl. XXXIV, fig. 10; Pl. LX, fig 4, 5 and 7; Pl. XLI, fig. 2 and 3; Pl. LX, fig. 3.

(I have already had the occasion to make remarks above that the individuals reported by Bell in 1908 regarding Cycethra verrucosa (p. 10, Pl. V, fig. 1 b) and in 1917 (Pl. I, fig. 1 to 6) actually belong to the genus Gnathaster and appear to me to be G. validus.) 
Station 17; 19 April 1902. Shag Rock Bank, east of South Georgia, 53 34' S' $36^{\circ} 28^{\prime}$ W. 75meters. Gravel and sand. One specimen.

The other specimens come from South Georgia, Cumberland Bay:

Station 22. 14 May 1902. Outside the Bay of May. 54¹7' S, 36²8' W. 75 meters. Clay, algae. One small specimen.

Station 25. 21 May 1902. Outside the Bay of Marmite. $54^{\circ} 22^{\prime}$ ' S. 36 $27^{\circ}$ ' W. 24-52 meters. Gray clay, some algae. Two specimens.

Station 28. 24 May 1902. Entrance of the Bay of Marmite. $54^{\circ} 22^{\prime}$ S, 36 $28^{\circ}$ W; $12-15$ meters. Sand and algae. One specimen.

South Georgia. 14 June 19092. Outside the Bay of Marmite. 15-25 meters. Stones and algae. One specimen.

South Georgia. Cumberland Bay. 4 May 1905. Gift E. Sörling. One specimen.

South Georgia. Swedish Magellan Expedition. 1907-09. 2 February 1909. Bay of Marmite. 10 meters. Stone. One specimen.

I have given in my memoir of 1920 the limits and characters of Gnaathaster validus and the value I gave them in establishing the species in 1906. The specimens collected by Nordenskjöld conform well with those of $G$. validus so understood. In the largest, $R$ varies between 35 and $28 \mathrm{~mm}$.

Gnathaster elegans (Kœhler)

Odontaster elegans Kœhler (1912), p. 72, P1. VII, fig. 5 to 11.

Gnathaster elegans Kœhler (1920), p. 227 Pl. XLL, fig. 7 and 8; Pl. LXXI, fig. 4.

Station 5. 16 January 1902. Region of Graham, southeast of Seymour Island. 64²0’ S; 56 38' W. 15 meters. Sand and gravel. Three specimens in which $R$ is 40, 35 and $25 \mathrm{~mm}$.

Station 22. 14 May 1902. South Georgia, Cumberland Bay, outside the Bay of May. 54¹7' S, $36^{\circ} 28^{\prime}$ W. 75 meters. Clay, some algae. One specimen.

Peridontaster Grayi (Bell)

(Pl. XI, fig. 1 to 4; Pl. XII, fig. 9 and 10)

See for bibliography:

Asterodon pedicellaris Perrier (1891), p. 135, Pl. XIII, fig 1

Odontaster Grayi Ludwig (1905) p. 44 and 48.

And add:

Peridontaster Grayi Kœhler (1920), p. 194-195, Pl. XLIX, fig. 5 and 6.

Station 59. 12 September 1902. Burdwood Bank, south of the Falkland Islands. $53^{\circ} 45^{\prime} \mathrm{S}$; $61^{\circ} 10^{\prime}$ W. 137-150 meters. Five specimens. Broken shells with stones. 
Here are the measurements taken from the specimens that I have designated by the letter A, B, C, $\mathrm{D}$ and $\mathrm{E}$.

$\begin{array}{llrr}\text { Specimen } & R & r & \begin{array}{r}\text { Numb } \\ \text { the }\end{array} \\ \text { A } & & & \\ \text { B } & 46 \mathrm{~mm} & 27 \mathrm{~mm} & 17 \\ \text { C } & 44-45 \mathrm{~mm} & 26 \mathrm{~mm} & 17 \\ \text { D } & 27 \mathrm{~mm} & 14 \mathrm{~mm} & 15 \\ \text { E } & 23.5 \mathrm{~mm} & 15 \mathrm{~mm} & 11 \\ & 14 \mathrm{~mm} & 9 \mathrm{~mm} & 8\end{array}$

Pentangonal body with the arms more or less excavated. The tops of the pentagon are extended and the true arms very short but distinct in the specimens A, B and C (Pl. XI, fig. 1 to 3). But in specimens D and E, small and where the sides are a little less incurved with the marginal plates comparatively less numerous, these tops are simply pointed (Pl. XII, fig. 9 and 10). They are like the figures of Perrier (1891, Pl. XII, fig. 1). The body is very thin. The dorsal surface is flat and the ventral surface is a little arced, especially in specimen $\mathrm{B}$. The dorsal and ventral marginal plates form a very apparent border.

Perrier gave in 1891 a very good description of $P$. Grayi under the name Asterodon pedicdllaris. I have compared the specimens of the "Swedish Antarctic Expedition" to those of the Mission of Cape Horn and I have been able to assure myself it was the same species. The two larger species of Nordenskjöld have nearly the dimensions of the largest individuals studied by Perrier in which $R=47$ and $44-45 \mathrm{~mm}, r=29$ and $26 \mathrm{~mm}$. The ratio $L$ is slightly larger than those of the first.

It is in individual A that the arms are better marked and more pointed. It is completely typical. Specimen B has a slightly more robust appearance and the body is thicker. The arms are slightly less elongated and more rounded at the end. The plates of the dorsal surface are larger and denser than in the preceding individual. The ventral plates are also slightly larger and their spines a little thicker. In specimen $\mathrm{C}$ that I dried, the spines of the dorsal paxillae are a little finer and longer. This is not the result of drying or size because in specimen D, these spines are a little less elongated. One see easily in the photograph of individual C (PI XI, fig. 4) the form of the paxilae whose central stem is erect, thick short and rounded. The teeth has the simple structure characteristic of the genus. The large unpaired backwards tilted spine does not have another backwards tilted spine on the sides as it ends in a hyaline point as in the genera Tridontaster and Epidontaster. The dorsal and ventral marginal plates are covered with contiguous granules that scarcely reach the border of the plates in specimens A, D and E. They are slightly more elongated in individual B and a little thicker in individual $\mathrm{C}$, especially on the ventral marginal plates.

The pedicellariae are very variable. In individual A, they are on many plates of the lateroventral row that touch the adambulacrals, but with some spaces. Some can be seen in my photograph Pl. XI, fig. 1 where however they are not very easy to distinguish. They are very developed in individual $\mathrm{C}$ especially at the top of the ventral interradial areas. Some can also be found on individual D (Pl. II, fig. 10). In specimen C, they are scarcely recognizable. These pedicellariae do not exist in individual B whose ventral spines are, as I said above, a little larger than in the others. The presence of these pedicellariae is seen more easily in dried and brushed individuals, their presence indicated by the small pit where they were partly sunken. Thus one can 
easily recognize the location of pedicellariae on the individual (which comes from the Mission of Cape Horn) that I have shown in my memoir of 1920 (PL. XXXIX, fig. 5 and 6) where the characteristic pits are seen on the plates of the two first rows parallel to the adambulacrals, and even sometimes on those of the third. In this specimen, the pedicellariae are particularly clear in spite its small size ( $R$ measures only $30 \mathrm{~mm}$ ). I note also in the central region of the dorsal surfaced of the disc characteristic pits but much smaller than those of the ventral surface and must certainly correspond to rudimentary pedicellariae.

Pseudontaster conspicuus Kœhler

(Pl. XIII, fig. 4-6)

Pseudontaster conspicuus Kœhler, 1920, p. 202, P1. XLII, fig 1 to 7; XLIII, fig. 1 to 10; LXX, fig. 1.

Station 5. 16 January 1902. Region of Graham, southeast of Seymour Island, 64 29' S; 56 $38^{\prime} \mathrm{W}$. Sand and gravel. 150 meters. One specimen

$R=120 \mathrm{~mm}, r=53-55 \mathrm{~mm}$.

The specimen is in excellent condition and perfectly characterized.

I have established quite recently the Ps. conspicuus according to some individuals collected by the "Australian Antarctic Expedition" and those that Nordenskjöld encountered is intermediate by its characters between the individuals that I have called A and B in the memoir cited above and that I have reproduced the photographs pl. XLII, fig. 2 and 7, pl. XLIII, fig. 4, 5, 8, 9 and 10, firstly and pl. XLII, fig. 3 and 4, pl. XLIII, fig.2, secondly. However, there is never complete correspondence in these examples as concerns notably the arrangement of the pedicellariae that I called trivalve. As I have had the occasion to report, these pedicellariae can have some variations either in their form or their distribution. It seems useful to me to say some words of this example and reproduce here some photographs.

The trivalve pedicellariae are found on the dorsal surface of the disk and arms but they show less exact limits in the area of the carinal line than in specimen of the "Australian Antarctic Expedition". They are dispersed in a median band a little wider from the dorsal surface of the arms. But they are always lacking on the sides. Some of them have four valves and have an oval icontour. Their large axis is moreover directed irregularly in relation to that of the arm. Each dorsal and ventral marginal plate in a very regular manner a trivalve pedicellaria that is constant in form located very near the internal border of the plate. These pedicellariae disappear in the terminal part of the arms. The valves of these pedicellariae sometimes are four. They are barely larger than the adjacent granules that cover the plate and are not more projecting than them (one can see these pedicellariae under the microscope in my photograph Pl. XIII, fig. 6).

Each lateral ventral plate of the first row parallel to the adambulacrals has a trivalve pedicellaria, slightly larger but more projecting that those of the other plates of the body. These pedicellariae follow each other very regularly but the series they form does not quite reach the middle of the length of the ambulacral grooves. Towards the top of the ventral interradial areas, the first three or four pedicellariae are much more projecting than the following and their valves instead of being simply convex, are clearly elongated. One can see even that on the first pedicellariae, that have generally four valves, they are made up of true small spines forming a 
dense convergent and erect network. Some other pedicellariae occur in the median region of the interradial areas and towards the tope of these areas. These pedicellariae, usually seven or eight in number, are also formed by short, projecting spines. They are also found in a region where the plates have small spines instead of granules.

The large unpaired backwards tilted tooth spine is relatively short, but it is very thick at the base and its form is clearly conical. This unpaired spine is conspicuously shorter in specimen B collected by the "Australian Antarctic Expedition" that I have shown in pl. XLII, fig.2 of my memoir of 1920. It has nearly the same length, but it is much thicker at the base than in specimen C shown as fig. 4 of the same plate.

The specimens of Ps. conspicuus collected by the "Australian Antarctic Expedition" have been found. Some at $66^{\circ} 142^{\prime} \mathrm{E}$ and others at $64^{\circ} 97^{\prime} \mathrm{E}$. and other finally off the coasts of Adélie Land at depths varying from 25 to $350 \mathrm{fm}$.

Pseudontaster moderatus sp. nov.

(Pl. XI, fig. 6 and 7)

Station 17. 19 April 1902. Shag Bank Rock, east of South Georgia. 53 34' S' 4323' W. 160 meters. Gravel and sand. A single specimen.

$$
R=66, r=23 \mathrm{~mm} \text {. The arms are } 26 \mathrm{~mm} \text { in width at their base and their length is } 52 \mathrm{~mm} \text {. }
$$

The disc is large and the arms, although very enlarged at the base, are quite distinct. These arms have the form of very elongated triangles and they decrease very rapidly until the end that is pointed that is a small triangular end plate with a rounded distal base and without spines. The body is not thick and the dorsal surface is a little arched. The ventral surface is nearly flat. The border formed by the dorsal and ventral marginal plates is not as thin as in the other species of the genus Pseudontaster, and they remain rounded.

The body is covered with plates that have an arrangement like that I described and figured in my memoir of 1920 in Pseudonaster conspicuus and stellatus (See Pl. XLII, XLIII and L), and the species seems to me should be placed in the genus Pseudontaster.

One recognizes very easily the limit of the dorsal plate of the body, under the cover of granule with which they are well supplied. These plates are small, unequal with an average diameter a little more than $1 \mathrm{~mm}$. They are irregularly arranged on the disc. In the middle of the arm the plates form some inconspicuous longitudinal rows, four or five at the bae of the arm. Among these, one cannot distinguish carinal plates larger or better aligned than the adjacent ones. The plates on each side of this median band have a regular arrangement in transverse rows that touch the dorsal marginals. One can distinguish a dozen of these marginal rows to the base of the arms. The size of the plates decrease progressively as they approach the dorsal marginals. The successive rows are narrower than thee later plates and seven of them correspond in general to four dorsal marginals. The anus is indistinct. The very small madreporite is a little enlarged transversally. It measures 35 by $2.5 \mathrm{~mm}$. It very numerous fine grooves on its surface. It is nearer the center than the border. The papular openings are numerous and fine, sometimes isolated, sometime united by small groups of three to four. They disappear on the sides of the arms having reached the dorsal marginals.

All the dorsal plates are covered by very dense granules. They are small, a little polygonal and number from ten to fifteen per plate. They are covered with very dense granules but however it is possible to distinguish the borders of adjacent plates. These granules have a truncated cone form, 
not much taller than wide. The width of the large base is $0.25 \mathrm{~mm}$ in average. The small ones are only 0.15 . The large base is clearly convex and the surface is free of granules and rounded, with extremely fine, short, little developed spinules.

The dorsal marginal plates are small, about one and a half wider than long. They are separated, as in the other species of the genus Pseudontaster, by oblique grooves, the internal angles being nearer the end of the arms than the outer angles. These plates are covered with granules identical to those of the dorsal pates and the granules of each plate are absolutely contiguous to those of the two neighboring plate. However, the edge remains very apparent, which is especially due to the fact that the rows of the edge of each plate are very regularly arranged. The edge of the separation between the rows of the dorsal and ventral plates is more apparent and it is between them a narrow, very marked groove.

As I said above, the dorsal and ventral marginal plates remain relatively very thick, and the borders of the body are not sharp. They are round and their height, i.e., the thickness of the two rows of combined plate exceeds $3 \mathrm{~mm}$.

The ventral marginal plates correspond exactly to the dorsals. They have, like them, a rectangular form and are one and a half times wider than long with the adjacent oblique borders, covered with granules that pass to the granules of adjacent ventral plate. The edges of successive are a little less apparent than those of the dorsal plates.

The ventral interradial areas are large, covred by a large number of plates arranged in regular rows. The transverse rows are much more marked than the longitudinal rows. One recognizes especially two longitudinal rows parallel to the adambulacrals but, outside of these ranges, the plate are no longer longitudinally arranged. The transverse rows remain to the contrary very apparent on most of the arms. The first rows of each side of the median interradial line contain fifteen plates that become smaller and smaller towards the ventral margin. The ventral plates are first transversely elongated in the interradial direction they are triangular with the founded angles, nearly two times wide as long. Then they become as wide as long and finally, when their size is greatly decreased, they are longer than wide. In the proximal half of the ventral areas, the plates have small spines with rounded end forming a peripheral border of the plate. They have some central spines. This arrangement make the contours of the plate very apparent. In the outer region of the rea, the spines decrease little by little their length and finally become polyhedral granules in the form of truncated cones identical to those that cover the adjacent marginal plate. The contour of the plates appear nearly complete under this covering of granules. However the transverse edges of the rows still remain distinct. The transverse rows correspond respectively to the adambulacral plates but they do not correspond to the ventral marginals and most often two adjacent rows touch the same ventral marginal plate.

The adambulacral plates are short and much wider than long. The adambulacrals spines are large and elongated, much more developed than the adjacent spines of the latero-ventrals. One observes first two internal unequal spines, very thin and pointed. Then outside, two other spines a little smaller, always thin and pointed and sometimes, only one. Following are two other spines a little smaller forming a third row, never very distinct. Finally, outside are one or two very short spines.

The teeth are notable by the size of the dental unpaired backwards tilted dental spine. This spine reaches in fact nearly $6 \mathrm{~mm}$ in length and 1.6 in width at the base. It becomes thinner very rapidly, especially in it outer half that is hyaline. It ends in an extremely fine and sharp point. It occupies thus a good part of the free surface of each dental pair. From each side of the unpaired spine are some spines of variable size. The two spines closest to the unpaired large spine are much 
more developed than the others. They are directly obliquely towards the unpaired spine and even are found a little hidden on the ventral surface. But they are not strictly speaking vertical and still less are they tilted backwards. Their end is truncate and do not end in a hyaline point (Pl. XI, fig. 6 ). The other spines, four or five in number, are much smaller. There is on the free border of the two a very narrow space with only four or five little developed spines, smaller than the adambulacral spine.

The pedicellariae are not very important. I found at the top of each ventral interradial area only one fasciculate pedicellaria formed by the union of four convergent spines and the same size as the adjacent ones. Even this pedicelleria is lacking in one of the areas.

Similarities and differences - The arrangement of the dental spines is such that one could perhaps hesitate to place the new species in the genus Tridontaster or in the genus Pseudontaster. I characterized the genus Tridontaster in 1920 (p. 193) by the presence, on each side of the larger unpaired backwards tilted spine, of another smaller spine but likewise tilted backwards and ended like it in a transparent point. Now the case is not the same here. In fact, in the new Pseudontaster, one clearly sees on each side of the unpaired spine, not another smaller spine, but two other spines smaller than it and larger than the other adjacent spines of the ventral surface of the tooth. But these two unequal spines are erect and not backwards tilted. They have a truncated end and they never have a hyaline point.

I established the genus Pseudontaster to include a species collected by the "Pourquois Pas?" near $68^{\circ} \mathrm{S}$ and $70^{\circ} \mathrm{W}$ at 250 meters of depth, Ps. marginatus, remarkable for the presence of marginal spines. Two other species of Pseudontaster, Ps. conspicuus and stellatus, have been reported by the "Australian Antarctic Expedition". These two species both lack marginal spines. Pseudontaster moderatus comes closer to it than Ps. marginatus. They are distinguished immediately from each other and outside their structure, by the form of the bodies that is very flat with long arms in the first species, very tall to the contrary with short, triangular arms in the second. Ps. moderatus recalls Ps. conspicuus by its exterior form and by its rounded and blunt arms. But it separated by several characters. First, it has no trace of trivalve pedicellaria, but this is not sufficient in absolute manner because, among the speciemens form the "Australian Antarctic Expedition" I have found two where the pedicellariae are completely lacking. One cannot take into account the form of the body and the length of the arms.

They are very thin and pointed in Ps. moderatus from station 17, while they are short and thick at the base in Ps. conspicuus from station 5. But I have reported analogous variation in the form of the body in various specimens of the "Australian Antarctic Expedition". Other clearer characters separate the two species. First, the adambulacral spines are fine and pointed in Ps. moderatus instead of being thick and often slightly flat at the end as one can see in the photograph that I reproduce Pl. XII, fig. 5 of Ps. conspicuus from station 5. On the other hand, the teeth always have several spines on the ventral surface and, in the first species. Two of them near the large unpaired backwards tilted dental spine, are particularly developed and much larger than the others. To the contrary, in Ps. conspicuus, the ventral dental spines are unequal. I do not speak of the dimensions of the large unpaired dental spine itself that can vary. In fact thee spines are generally very spindly in the specimens of the "Australian Antarctic Expedition" whie they are a littler shorter and more enlarged at the base in the specimen collected by Nordenskjöld at atation 5. But another difference that one can appreciate easily in comparing Ps. moderatus shown n Pl. XI, fig, 5 to Ps. conspicuus in Pl. XIII, fig. 5 and 6 is that, in the first species, the large unpaired dental spines leaves exactly from the proximal end of the teeth, while in Ps. conspiciuus there is a row of spines separating the 
mouth from the base of the unpaired dental spine. I will add that the ventral interradial areas of PS. moderatus have small sines on half their length, while in Ps. conspicuus the greatest part of these areas has only by granules and the spines occur only at the tip of the areas (compare Pl. XI, fig 6 and 7 to Pl. XIII, fig. 4 and 56). The difference is all the more remarkable as Ps. conspicuus shown is much larger than Ps. moderatus. Finally, in the latter the plates of the dorsal surface of the disc and arms are much more separated from each other than in $P$. conspicuus.

Ps. moderatus, which is separated from Ps. stellatus by its low form and by the more elongated arm, it to the contrary is closer to the latter by the spines of the of it ventral interradial arms and by the tendency of them to form fasciculate pedicelariae recalling those I described in Ps. selllatus, and finaly by the presence on the ventral surface of each tooth outside the large tilted backwards unpaired tooth of two large spines that are moreover much larger and more apparent in Ps. moderatus than in Ps. stellatus. But the rest of the characters of the two species are very different.

Ps. moderatus is separated still more from Ps. marginatus by the presence of marginal spines, by the development of the spines of the ventral interradial areas and by the smallness of the backwards tilting unpaired dental spine.

\section{Ceramaster patagonicus (Sladen)}

Pentagonaster patagonicus Sladen (1889), p. 269, Pl. XLVI, fig. 3and 4; and Pl. XLIX, fig 3 and 4.

Mediaster patagonicus Verrill (1889), p. 145.

Ceramaster patagonicus Fisher (1911), p. 214, Pl. XXXVII, fig. 4; Pl. XXXVIII, fig 1 and 2; Pl. LX, fig. 3.

Station 59. 12 September 1902. Burdwood Bank, south of the Falkland Islands. 53 $45^{\prime} \mathrm{S}$; $61^{\circ} 10^{\prime}$ W. 137-150 meters. Broken shells with tones. One specimen. $R=60, r=40 \mathrm{~mm}$.

Ceramaster patagonicus was described well by Sladen from specimens coming from the Strait of Magellan the Strait of Smyth (50 and $245 \mathrm{fms}$ ). Fisher has completed the description from specimens from diverse localities of the boreal seas (California, Aleutian Islands, Behring Sea, etc.), in general from very shallow water.

The individual reported by the "Swedish Antarctic Expedition" is near that Fisher represented in 1911, Pl. XXVIII, fig. 2. However, the side of the body are a little more arched in the figure of Fisher, but a little less than that of Sladen (1889, Pl. XLVI, fig. 3) and the arms are less pointed at the end than in the latter. Sladen described the variations the pedicellariae of the ventral surface can show, principally in the plates adjacent to the adambulacrals. I found in my specimens pedicdellariae with two, three and four vales. When there are three or four, the valves can take all position.

The geographical extension of $C$. patagonicus is very vast because they are found in the arctic seas and in the southern sea, but its presence in the Gulf of California (Carmen Island) is very unexpected. C. patagonicus appears to be littoral and its greatest depth ( $245 \mathrm{fms}$.) is in the Smyth Canal. In boreal seas, it has been dredged between 41 and $134 \mathrm{fm}$. 


\section{Astropecten cingulatus Sladen}

(Pl. XII, fig. 2)

Astropecten cingulatus Sladen (1889), p. 218, Pl. XXXV, fig. 5 and 7, Pl. XLVii, fig. 1to 3. Astropecten cingulatus Döderlein (1917), p. 103, Pl. II, fig. 7-8; Pl. IX, fig. 5-8

Station 1. 12 December 1901. Coast of Uruguay. $33^{\circ} 0^{\prime} \mathrm{S} ; 51^{\circ} 10^{\prime}$ W. 80 meters. Several specimens.

The type was collected off the coast of Brazil, southeast of Pernambuco, at $9^{\circ} 34^{\prime} S^{\prime}$ at depths between 32 and $400 \mathrm{fms}$. The dimensions given by Sladen were $R=28 \mathrm{~mm}$, and $r, 9 \mathrm{~mm}$.

The specimens collected by the "Swedish Antarctic Expedition" are larger in general than the type of Sladen, and $R$ varies between 40 and $45 \mathrm{~mm}$. In a specimen in which $R$ is $45 \mathrm{~mm}$, I count twenty eight marginal plates. The arms are always very narrow at their base. In all their characters, the specimens conform very well with the type of Sladen.

\section{Ripaster longispinus Kœhler}

(Pl. XII, fig. 6, 7 and 8)

Ripaser longispinus Kœhler (1920), p. 260, Pl. LI, fig. 5 to 8; Pl. LII, fig. 2 to 4; P1. LXXII, fig. 2.

Station 17. 19 April 1922. Shag Rock Bank. 53 34' S; 43 23' W. 160 meters. Gravel and sand. One small specimen.

South Georgia

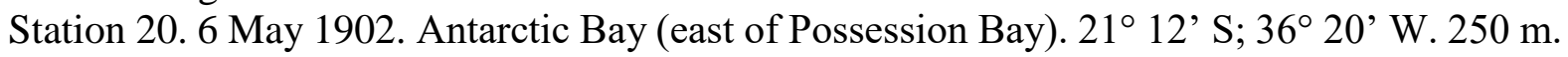
Small stones. Three large specimens.

Station 22. 14 May 1902. Cumberland Bay, outside the Bay of May. 54 ${ }^{\circ} 17^{\prime} \mathrm{S} ; 36^{\circ} 28^{\prime}$ W. 75 meters. Clay, some algae. One small specimen.

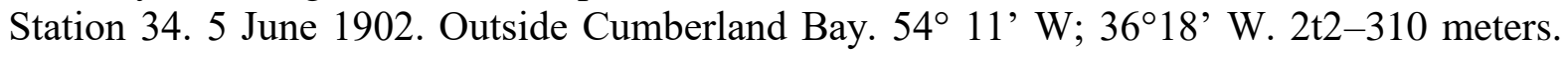
Gray clay with some stones. Eleven specimens, all of large size in excellent state of preservation.

In the small specimen, from Staton 17, $R$ varies between 17 and $18 \mathrm{~mm}$.

Here are the principal dimensions that I measured of some individuals from Station 34.

$\begin{array}{ccc}R & r & \text { Width of arm at the base } \\ 135-138 \mathrm{~mm} & 26 \mathrm{~mm} & 31 \mathrm{~mm} \\ 130 \mathrm{~mm} & 25 \mathrm{~mm} & 28 \mathrm{~mm} \\ 120 \mathrm{~mm} & 23 \mathrm{~mm} & 24 \mathrm{~mm} \\ 105 \mathrm{~mm} & 21 \mathrm{~mm} & 24 \mathrm{~mm} \\ 85 \mathrm{~mm} & 18 \mathrm{~mm} & 19 \mathrm{~mm} \\ 70 \mathrm{~mm} & 19 \mathrm{~mm} & 19 \mathrm{~mm}\end{array}$


I established Ripaster longispinus from individuals collected by the "Australian Antarctic Expedition", at $66^{\circ} \mathrm{S}$ and $141^{\prime} \mathrm{W}$ for one part and $65^{\circ} \mathrm{S}$ and $92-96^{\prime} \mathrm{E}$. In the large individuals, $R$ measured 142, 140 and $120 \mathrm{~mm}$. These dimensions are very near those of the larger individuals of Nordenskjöld that had absolutely the same characters as the first.

As I have had the occasion to say, the species is remarkable for the size of the spines of the dorsal and marginal plates. The ventral marginal spines especially have a very great development. The dorsal marginal spines are often a little less numerous than in the specimens of the "Australian Antarctic Expedition: where the number four dominates and often falls to three, while here the spines nearly always number five per plate and sometime six. The dimensions of these spines increase from the first dorsal to the second and to the third. The last ventral spine is a little smaller than the preceding. From the second or third, the spines are a little longer than the corresponding plate. In the smaller specimens, in which $R$ is less than $85 \mathrm{~mm}$, these spines usually number four, but sometimes reach five per plate, and are comparatively a little smaller. The first dorsal is ordinarily smaller than the plate but the third always surpasses it a little. In the smallest specimen, in which $R$ is $70 \mathrm{~mm}$, these spines are sometimes even smaller than the plate or they hardly equal it. They then take character analogous to those I have shown in my memoir of 1920 (Pl. LI, fig. 7). These small variations in the number and dimensions of the spines are evidently individual.

I was not able to correct the proofs of the work that I just cited on the asteroids of the "Australian Antarctic Expedition" and I realized, too late to correct, that in my description of $R$. longispinus the paragraph relative to the characters of the ventral marginal plates and their spines was omitted. Here is what I wrote on this subject that should be added to p. 261 of my memoir.

"Regarding the ventral marginal plates, they generally have five spines whose sizes increase from the first ventral that is near the plate. The second, third and fourth spines are subequal and their length is equal to one and a half that of the plate. The last spine is a little shorter. These spines are flat, pointed, lay on the plate and very thick. In spite of their size, they are rather fragile and they are very often broken. These are the like the characters that I see in the specimens of Nordenskjöld

In all the individuals, the terminal part of the arm, about a fourth or a fifth of the total length, is particularly thin as I observed already in the individuals of the "Australian Antarctic Expedition".

The specimens from station 20 were noted to be either yellow of pale yellow. The specimens in alcohol are gray or yellow-gray.

In the specimens from stations 22 and 17, which are much smaller than the preceding, $R$ measures 25, 19 and $10 \mathrm{~mm}$, respectively. In some of them the dorsal marginal plates have very distinct spines. The ventral marginal plates alone have only one per plate in the smallest individual, two in the middle, and three in the largest. In this latter, the last two upper spine, and in the preceding individual the upper spine exceed the length of the plate.

The specimens collected by the "Swedish Antarctic Expedition" being relatively numerous, I took the opportunity to remove from one of them the dorsal surface of the arms in order to study the arrangement of the ambulacral vesicles. I reproduce here the photograph of a portion of this arm that shows in the most evident manner the arrangement of these ampoules which form two very regular rows on each side of the median line and are very close together.

The specimens of the "Swedish Antarctic Expedition" were collected at South Georgia in a locality consequently very far from that where the "Australian Antarctic Expedition" discovered the species. 


\title{
Leptoptychaster accrescens Kohler
}

\author{
(Pl. XIII, fig. 3)
}

Leptoptychaster accrescens Kœhler, 1920. P 246, P1. LII, fig. 5; LIII, fig. 1 to 3; LIV, fig. 2 to o9; LV, fig. 1; LXXIV, fig. 1.

Station 34. 5 June 1902. South Georgia, outside Cumberland Bay. 54 $11^{\prime}$ ' S' $36^{\circ} 18^{\prime}$ W, 252 319 meters. Gray clay with some stones. Only one specimen. $R=140-145 \mathrm{~mm}, r=50 \mathrm{~mm}$.

I described $L$. accrescens from very numerous species of a wide range of sizes collected by the "Australian Antarctic Expedition", some from $66^{\circ} \mathrm{S}$ and $142^{\circ} \mathrm{E}$, the others from $65^{\circ} \mathrm{S}$ and 92 $97^{\circ} \mathrm{E}$ at depths varying from 60 to $354 \mathrm{fms}$.

The specimen collected by Nordenskjöld is in a perfect state of preservation and is of very large size It recalls the specimens collected of the "Australian Antarctic Expedition" that I designated in my memoir of 1920 by the letters $\mathrm{C}$ and $\mathrm{D}$ and in which the dimensions were, for $R$, 140 and $110 \mathrm{~mm}$, and for $r, 30$ and $40 \mathrm{~mm}$.

I believe it is necessary to reproduce here Pl. XIII, fig 3, a photograph of this specimen that will not duplicate with those included in my work of 1920.

The discovery of $L$. accrescens at South Georgia, i.e., at a station very far from those where the "Australian Antarctic Expedition" collected it, is very interesting and extends considerably the area of geographic distribution of this remarkable form.

Leptoptychaster mendosus nov. sp.

(Pl.XII, fig. 3, 4, and 5)

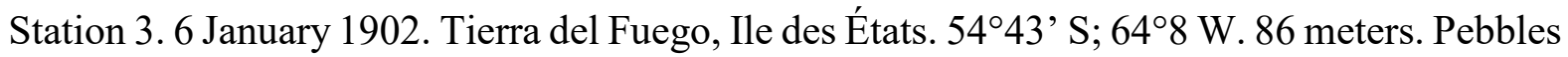
and gravel. One specimen.

$R=40$, and $r=11 \mathrm{~mm}$. The arms are $11 \mathrm{~mm}$ in width at the base and 8.5 towards the middle; the ration $R / r=3.6$.

The single specimen is unfortunately not in an excellent state of preservation. One of the arms is broken and another is partly detached but it is nevertheless preserved.

The arms are relatively short but they are not at all enlarged at their insertion to the disc and their width scarcely decreases for the greater part of their length. They decrease mostly in their fourth or fifth terminal, their end forming a blunt tip. This form with rather short arms is very different from that of L. kerguelenis, type of the genu, where the very long arms go to thin very progressively and become very narrow in their distal part. As well it differs also from that which Sladen indicated in L. antarcticus where the arms are short and triangular (See Sladen 1889, p. 190, Pl. XXXI, fig. 3 and 4, and XXXII, fig. 7 and 8; Kohler 1917, Pl. VI, fig 1, 2, 7 and 12).

The disc is not very large and the arms are very distinct from it at the base. The dorsal surface of the disc is covered with small paxillae, very dense and nearly confluent, becoming a little larger towards the base of the arm. On these, the paxillae of the median region are small, dense, and equal, but they become larger towards the borders. They are then separated from the oblique transverse rows. Each row has seven to eight paxillae. The dorsal marginal paxillae form a regular row but are not much larger than the adjacent ones. These paxillae are formed by a bouquet of 
spines having the structure that I indicated in the genus Leptoptychaster. I.e., each spine is surrounded by a thin transparent tegument whose length is between 0.25 and $0.3 \mathrm{~mm}$. It has a basal region that is about a third of the total length. It is formed by a compact tissue and a terminal region filled with conical and pointed lateral teeth, more or less numerous. This is somewhat little enlarged and whose borders are made up of a hyaline tissue. The two regions often form together a very obtuse angle. The terminal plate is small. The madreporite plate is nearly completely hidden by the paxillae.

The ventral marginal paxillae are very developed and correspond exactly to the dorsals. I counted about fifty of them on each arm. They are very tall and very short, taller than long, especially at the beginning of the arms. They are visible for a large part of the arm length when the asteroid is seen from above. Each plate is covered with spines arranged irregularly in vertical series, three or four per plate. There are moreover other small spines on the adjacent border that intertwine with the analogous spines on the adjacent plate. The spines of the ventral marginal plate are stouter than those of the dorsal surface. They measure an average of $0.7 \mathrm{~mm}$ in length. The increase slightly in their terminal part and have large conical, pointed, transparent and very separate teeth on the borders.

The ventral interradial areas are little developed and are covered with plates forming small transverse series. The first ones have only three plates. This number decreases rapidly to two and then to one. The spines that cover them are longer than those of the ventral marginal plates and exceed $1 \mathrm{~mm}$. They have however the same structure as these latter.

The ambulacral grooves are very wide and the tube feet, regularly biserial, have a conical and rounded end. The adambulacral plates are rectangular and very projecting. Each generally has seven spines. First is an internal spine, followed by two others directed obliquely and often combined to form a small dense group. These three spines are equal in size. They are followed by two scarcely smaller spines. Following these are two other spines, a little smaller, to which is sometimes one or two other small spines. There is not a great difference in sizes of these spines, at least between the first five, and the internal spine is not notably elongated. It is sometimes slightly fattened and enlarged at the end. All the spines are straight.

The teeth are not very large. Each has six to seven spines on their border that continue the adjacent adambulacral borders. They become a little larger towards the mouth. One sees, moreover, four or five spines on the ventral surface of the teeth that are irregularly arranged.

Similarities and differences. $-L$. mendosus is characterized by the form of the arms that, as I have said above, separates it from L. kerguelensis and antarcticus. I recently described a new Leptoptychaster discovered by the "Australian Antarctic Expedition", L. accrescens, which can reach a very considerable size. A specimen was collected by Nordenskjöld. Our species is distinguished from it by the arrangement of the adambulacral spines, whsoe size increases slightly in going from the external spines to the internal spines. In L. accrescents the internal adambulaacral spines are shorter and their size increases progressively. L. mendosus cannot be confused with the Leptoptychaster known in the boreal regions of the Pacific and Atlantic. 


\section{Bathybiaster Liouvillei Kœhler}

Bathybiaster Liouvillei Kœhler (1902), p. 96, Pl. VI, fig. 2, 3, 4, and 12; Pl. VIII, fig. 5 and 6. Bathybiaster Liouvillei Kohler (1920), p. 263, P1. LXXIII, fig. 1.

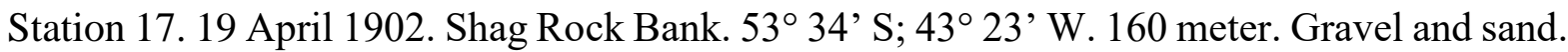
One very young specimen $(R=12 \mathrm{~mm})$.

South Georgia

Station 18. 22 April 1902. Cumberland Bay, entrance to the Fiord de l'Ouest. 54 $4^{\circ} 15^{\prime}$ 'W. 250 meters. Slightly compacted clay. One specimen.

Station 34. 5 June 1902. Outside Cumberland Bay. 54 11 s' 36 $18^{\prime}$ W. 253-310 meters. Gray clay with some stones. Four specimens, and a fifth very small one.

The specimens perfectly conform to those that were collected by the "Expedition Charcot" to the South Shetland that I used to establish this species in 1912. Most of them have dimensions very near the example I used as the type in which $R=70$ and $r=16 \mathrm{~mm}$. In the specimens of the "Swedish Antarctic Expedition", $R$ varies between 80 and $63 \mathrm{~mm}$. The exterior form is the same.

The "Australian Antarctic Expedition" encountered B. Liouvillei at $66^{\circ} 32^{\prime} \mathrm{S}$ and $141^{\circ} 39^{\prime} \mathrm{E}$. The two specimens collected also conform to the type of Charcot but are of larger size. In the largest individual, in fact, $R$ exceeds $103 \mathrm{~mm}$.

In the small specimen from station $34, R$ is only $20 \mathrm{~mm}$ and the marginal plates have not the least indication of spines or quamules.

\section{Ophiuroids}

\section{Gorgonocephalus chilensis (Philippi)}

(Pl. XIV, fig. 1)

Astrophyton chilensis Philippi (1858) p. 268.

Gorgonocephalus chilensis Lyman (1882), p. 261.

Astrophyton Pourtalesii Lyman (1875), p. 25, Pl. IV, fig. 42-43.

Gorgonocephalus Pourtalesii Lyman. (1882), p.258, Pl. XLV, fig. 2-5.

Astrophyton Lymani Studer. ((1885). p. 145.

Gorgonocephalus chilensis Ludwig (1898). p. 775.

Gorgonocephalus chilensis Ludwig (1899), p. 16.

Gorgonocephalus chilensis Bell (1905), p 259.

Gorgonocephalus chilensis Kohler (1908), p. 614.

Gorgonocephalus chilensis Döderlein (1911), p. 30 and 105, Pl. V, fig 5; Pl. VIII, fig. 1 and $1 \mathrm{a}$.

Gorgonocephalus chilensis H. L. Clark (1915), p. 185.

Station 58. 11 September 1902. South of West Falkland. 52 ${ }^{\circ} 29^{\prime}$ S; 60 36' W. 197 meters. Sand and gravel. Two specimens. 
Gorgonocephalus chilensis was studied in detail by Ludwig in 1898 and I have nothing to add to his description. Döderlein published in 1911 three photographs in which the granules of the dorsal surface are all uniformly rounded although the radial side are indistinct. I observe on one of my dried specimens that the granules, very fine, rounded and a little unequal in the interradial spaces, are elongated on the radial sides and extremely marked and projecting. They become clearly conical with a spiulose point. I reproduce her, Pl. XIII, fig. I, the photograph of a portion of the dorsal surface of this specimen. In the second specimen, that remains in alcohol and whose radial sides are likewise very apparent, the granules of these sides are shorter and less rounded than in the first specimen, all remaining clearly conical.

G. chilensis occurs the length of Chile, from Calbuco to Cape Horn. It occurs off the coast of Patagonia up to $45^{\circ} \mathrm{S}$ and is also found at the Falkland Islands. Lyman has reported it at the Kerguelen and Heard Islands and Bell reported it at the Cape. It can reach a depth of 100-320 meters, but it is often captured at littoral stations between 22 and 55 meters.

\section{Astrotoma Agassizii Lyman}

Astrotoma Agasssizii Lyman (1875), p. 24, Pl. IV, fig. 57 and 58.

Astrotoma Agassizii Lyman (1882), p. 272.

Astrotoma Agassizii Kœhler (1907), p. 344.

Astrotoma Agassizii Kœhler (1908), p. 614, Pl. XIII, fig. 120.

Astrotoma Agassizii Bell (1908), p. 15.

Astrotoma Agassizii H.L. Clark (1915), p. 181.

Astrotoma Agassizii Bell (1917), p. 5.

Astrotoma Agassizii Kohler (1922), p. 9, Pl. I, fig. 1 to 10.

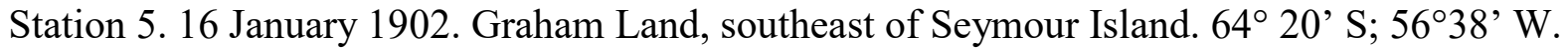
150 meters. Sand and gravel. Two specimens.

Station 6. 20 January 1902. Graham Land, southeast of Snow Hill Island. 64 $36^{\prime}$ S; 57 $42^{\prime}$ W. 125 meters. Stones and gravel. One specimen.

Station 17. 19 April 1902. Shag Rock Bank, west of South Georgia. 53 34' S' 43' 23' W. 160 meters. Gravel and sand. One specimen.

Station 58. 11 September 1902. South of West Falkland. 52 29' S; 60 36' W. 197 meters. Two specimens of average size and three small.

Station 59. 12 September 1902. Burdwood Bank, south of West Falkland. 53 ${ }^{\circ} 45^{\prime}$ W. 137-150 meters. Broken shell with stones. Two specimens of average size and four small.

The diameter of the disc varies between 38 and $20 \mathrm{~mm}$ in the average-sized individuals and between 10 and $5 \mathrm{~mm}$ in the small ones. All are in very good condition. I have had the occasion to speak of this species in my recent memoir of 1922 and I have given some photographs of it. I refer the reader to this work. 


\section{Astrochlamys bruneus Kœhler}

Astrochlamys bruneus Kœhler (1912), p. 143, Pl. XI, fig. 3, 4,6, 7, 14 and 15.

Astrochlamys bruneus H. L. Clark (1915), p. 189.

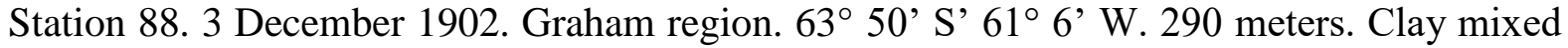
with sand. One specimen.

The specimen conforms well with the type that I described after the specimen collected by the "Pourquoi Pas?" at Marguerite Bay, but it is smaller The diameter of disc measures only $5 \mathrm{~mm}$.

\section{Ophiochondrus falklandicus nov. sp.}

(Pl. XIV, fig. 2 and 3)

Station 58. 11 September 1902. South of West Falkland. 52 29' S'; 60 36' W. 197 meters. Sand and gravel. Five specimens.

The specimens are all of small size. The largest, which I reproduce here the photograph (Pl. XIV, fig. 2 and 3), the diameter of the disc is $4.5 \mathrm{~mm}$, the length of the arms are 12 to $15 \mathrm{~mm}$. The others are smaller and the diameter of the disc is not greater than $3 \mathrm{~mm}$. The arms are coiled vertically and more or less twisted.

The disc is pentagonal strongly concave in the interradial spaces and the radial regions are projecting. The dorsal surface has ten prominent radial sides that extend from the border up to a distance from the center to less than half the radius of the disc. The entire dorsal surface is uniformly covered with round, dense and equal granules. However, some have a tendency to rise a little more than the adjacent ones. Seen with the microscope, the surface of these granules seems slightly rugose. The ventral surface of the disc is covered with granules that are continuous to the borders of the genital slit and up to the oral shield. These granules are a little less dense and slightly larger than on the dorsal surface. The genital slits are very large but not very elongated and do not extend much more than half the radius of the disc.

The oral shields, of average size, are triangular, a little wider than long, with a very open proximal angle. The right lateral borders come together at rounded angles at the distal border that is very convex and that can have in its middle an enlarged more or less apparent lobe. The adoral plates have nearly parallel borders. They are however a little shrunken and contiguous on the median line. They are enlarged outside and send a small lobe that separates the first lateral arm from the oral shield. The oral plates are low and triangular. There are three lateral papillae. The external one is a little enlarged and rectangular. The following is a little smaller and the internal one more pointed. The free border of these papillae is finely denticulated. The terminal unpaired papilla is larger than the adjacent one.

The dorsal arm plates, of average size, are triangular with a very narrow proximal angle limited by straight sides and a convex distal border. They are widely separated. The first ventral arm plate is small and pentagonal with a very small distal border and divergent lateral sides. The following plates, of average size, are triangular, with a very open proximal angle limited by straight sides joined at rounded corners at the distal edge, which is almost straight on the first plates. They then have a very slight median notch. 
The lateral plates slightly prominent, have the subequal spines small and shorter than the article. These spines are cylindrical with an obtuse end. Their surface is rugose their entire length.

The tube foot scale is spiniform very small with a blunt end.

The color of specimen in alcohol is gray of whitish.

Similarities and differences. - It appears to me this species should be placed in the genus Ophiochondrus rather than in the genus Ophiolebes because its arms are more or less contorted. It is moreover very close to Ophiocondrus stelliger that the "Challenger" found in the southern seas $\left(37^{\circ} \mathrm{S}, 55^{\circ} \mathrm{W}\right)$ at a depth of 1098 meters. But the species of the "Swedish Antarctic Expedition" is distinguished from it immediately by its three subequal and small arm spines, while $O$. stelliger have four arm spines, the last dorsal much larger than the others. Moreover, the oral shields are larger and shorter.

\section{Ophiacantha vivipara Ljungman}

See:

Ophiacantha vivipara Kœhler (1908), p. 612.

Ophiacantha vivipara Bell (1908), p. 13.

Ophiacantha vivipara Kœhler (1912), p. 138, P1. XI, fig. 1, 2 and 10).

Ophiacantha vivipara H. L. Clark (1915), p. 105.

Ophiacantha vivipara Kœhler (1922), p. 12.

Station 7. 22 January 1902 . Graham region. $65^{\circ} 56^{\prime} ; 5^{\circ} 353^{\prime}$ W. 920 meters. Mud mixed with stones. One specimen with seven arms.

Station 16. 11 April 1902. Between the Falkland Islands and South Georgia. 51 $40^{\prime} \mathrm{W} ; 57^{\circ}$ $25^{\prime}$ W. 150 meters. Sand. Several specimens, nearly all with seven arms, and of which some have young on the disc. Three specimens have six arms and one has nine.

Station 22. 14 May 1902. South Georgia, outside the Bay of May. $54^{\circ} 17^{\prime}$ S; $36^{\circ} 28^{\prime}$ W, 75 meters. Clay, some algae. Some specimens with six arms of which only one has a young, and an individual with nine arms with two young.

Falkland Islands

Station 34. 5 June 1902. Outside Cumberland Bay. 54 11' S; 36 $18^{\prime}$ 'W. 252-310 meters. Gray clay, some stones. Two specimens, one with six arms, the other with five.

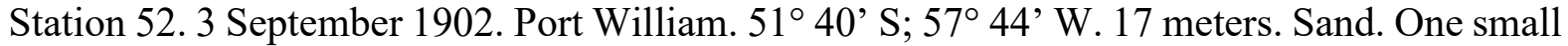
specimen with six arms.

Station 55. 8 September 1902. Port Albermarle. 52 ${ }^{\circ} 11^{\prime} ; 60^{\circ} 26^{\prime}$ W. 40 meters. Sand with some algae. Some specimens with six arms.

Station 58. 11 September 1902. South of West Falkland. 52 29’ S; 60 36’ W. 197 meters. Sand and gravel. Two small specimens with seven arms.

I studied this species in detail in my work of 1912 and I have nothing to add to it. I shall content myself to make the remark that in an individual from station 22, with a disc diameter of $3 \mathrm{~mm}$, the number of arms is seven. Thus the number of arms is already acquired from the youngest age. I likewise call attention to the depth of Station 7. 


\section{Ophiodiplax disjuncta Kœhler}

Ophiodiplax disjuncta Kœhlerl (1911), p. 48, PL VI, fig. 9 to 11; Pl. VII, fig. 13.

Ophiodiplax disjuncta Kœhler (1912), p. 142.

Ophiodiplax disjuncta H. L. Clark (1915), p. 222.

Ophiodiplax disjuncta Kœhler (1922), p. 15, P1. III, fig. 4, 5, 9 and 12.

Station 34. 5 June 1902. South Georgia, outside Cumberland Bay. 54 $11^{\prime}$ S; 36 $18^{\prime}$ W. $252-$ 310 meters. Gray clay, stones. Some specimens.

I found in these individuals variation in the length of the rods of the dorsal surface of the disk and those of the dorsal arm plates, analogous to those I have observed in specimens collected by the "Australian Antarctic Expedition".

Ophioripa ingrata (Kœhler)

(Pl. XIV, fig. 4, 5, and 6)

Station 55. 8 September 1902. Falkland Islands, Port Albermarle. 52 ${ }^{\circ} 11^{\prime} \mathrm{S} ; 60^{\circ} 26^{\prime} \mathrm{W} .40$ meters. Sand wih some algae. A very small specimen.

Station 58. 11 September 1902. South of West Falkland. 52 29' S; 60³6’ W. 197 meters. Sand and gravel. Three specimens.

Station 5912 September 1902. Burwood Bank, south of West Falkland. 53 45' S; 61 ${ }^{\circ} 10^{\prime}$ W. 137-150 meters. Broken shells with some stones. Two very small specimens, one with six arms.

Station 60. 15 September 1902. Tierra del Fuego, east opening of the Beagle Channel. 55 $10^{\circ}$ S; $60^{\circ} 15^{\prime}$ W. 100 meters. Broken shells. One specimen.

I described $O$. ingrata from a specimen encountered by the "Scotia" at Gough Island at $100 \mathrm{fms}$ depth, with a disc diameter less than $4 \mathrm{~mm}$. In most of the individuals collected by the "Swedish Antarctic Expedition" the size is near this or even smaller. However, two individuals of station 58 had a disc diameter of $6 \mathrm{~mm}$ and arms $10 \mathrm{~mm}$ in length. I show in Pl. XIII, fig. 5 and 6, two photographs of one of the species that differs only from that collected by the "Scotia" by the presence of six arm spines at the base of the arms and the larger oral shield with rounded external angles.

One of the specimens from station 59 has six arms (fig. 4). It differs in no way from the others that have only five.

I first placed this species in the genus Ophiomitrella, but it seems to me to be better placed in the genus Ophioripa that I recently established from specimens found by the "Albatross" in the Philippines and in which I believed I could distinguish two different species. This genus is characterized from others by the large size of the dorsal plates of disc and the small dimensions of the dorsal and ventral arm plates, which are found in the ophiuroid collected by the "Swedish Antarctic Expedition". O. ingrata differs from these two species from the Philippines by the large tubercles on the dorsal plates of the disc that are regularly arranged on each plate. In O. nugator, there are only some very large spines in the central region with a few simple elongated granules at the periphery of the disc. In $O$. marginata, the dorsal plates of the disc are nearly completely lacking in spines or granules. These latter occur only towards the periphery. 


\title{
Amphiura alternans nov. sp.
}

\author{
(Pl. XV, fig 1 to 4$)$
}

South Georgia, Cumberland Bay:

Station 22. 14 May 1902. Outside the Bay of May. 54 $17^{\prime}$ W; $36^{\circ} 28^{\prime}$ W. 75 meters. Clay, some algae. One specimen.

Station 33. 30 May 1902. Bay of Marmite. $54^{\circ} 22^{\prime} \mathrm{S} ; 36^{\circ} 28^{\prime} \mathrm{W}$. Clay and algae. Three specimens.

Station 34. 5 June 1902. Outside Cumberland Bay. 54 $11^{\prime}$ S; $36^{\circ} 18^{\prime}$ W. 252-310 meters. Gray clay, some stones. One specimen.

Station 37. 14 June 1902. Bay of Marmite. 54 22' S; 36² $28^{\prime} \mathrm{W}$; 20 meteres. Mud with dead algae. Six specimens.

The diameter of the largest specimen is $8 \mathrm{~mm}$ and the arms are 30 to $32 \mathrm{~mm}$ in length. The dorsal surface of the disc is a little convex. It contour is rounded or sub-pentagonal with slight indentations at the origin of the arms. This dorsal surface is covered with plates of average size, subequal and imbricated, larger in the central region and becoming small towards the periphery. One cannot distinguish the least indication of primary plates. The radial shields are small, two times longer than wide and their length is nearly three times the radius of the disc. The internal side is straight, the external side is convex. The two shields of each pair are slightly divergent but they are separated their entire light first by a single plate and then by two or three plates. The ventral surface is completely cover with very small plates, equal, imbricated, with wide and very short. In the large individuals, one can recognize, however, outside the oral shields, a space generally inconspicuous and naked. This space is not seen in small specimens and I think the species can be placed among those whose ventral surface of the disc is covered with plates. Their absence towards the oral shields results from a secondary resorption. The genital slits are very narrow.

The oral shields, of average size, are nearly as long as wide, and even a little longer than wide because of the presence of a median distal lobe. They have a very acute proximal angle connected by rounded angles to the lateral sides that are straight. The adoral plates are triangular, narrow on the inside and separated from each other on the median interradial line where they end in a round angle. They are to the contrary very enlarged on the ouside and separate greatly the first arm lateral plate of the oral shield. The oral plates are small and short. There are three lateral oral papilla. The internal one is stout, thick and squat with a rounded end. It is not much longer than wide. The external papilla is stout, cylindrical and erect, nearly spiniform, with a rounded end, a little flat and slightly spinulose. The intermediate papilla is triangular with an obtuse point and likewise slightly spinulose.

The two or three first dorsal arm plates are much smaller than the others ad the fourth equal to the following. Thee plates are large, mostly oval, much wider than large with a proximal border narrower than the distal border that is very wide and very convex with rounded sides.. All the plates are contiguous.

The first ventral arm plate is slightly trapezoidal or pentagonal with a short distal border and an obtuse proximal angle. The two following are o pentagonal but with a truncated proximal angle. The adjacent angles are very rounded. These two plates are a little longer than wide. The following 
plate is quadrangular, a little longer than wide, with rounded angles. The proximal side is shorter than the distal side. All thee plates are contiguous.

The lateral plates have four spines, very stout, conical with a rounded end, subequal and longer than the article. The length of the first ventral exceeds however those of the others, especially the last dorsal. The number of the spines then decreases to three.

The arrangement of the tube feet scales is very variable. In the individuals I consider typical, there is a tube foot scale on each pore at the beginning of the arms. Then, at some distance from the disc, the scales begin to disappear with, however, some alternating of pores with or without a scale. Finally this scale disappears completely. In the specimen in Pl. XV, fig. 2, the tube foot scale persists up to the fifteenth or eighteenth arm article. In other individuals, the first pores can have no trace of the tube foot scale although the following ones have hem and there is still an irregular alternating of pore with and without scales. Finally, the tube foot scale is rare. In principle, there is not the least trace of them in some articles. Then they are isolated from place to place and at irregular spaces. All this indicates the most irregular manner. Most specimens of station 33 lack scales, all being perfectly identical to other individuals. One of them however has some. This scale is small, conical, with a rounded point and a slightly rugose surface.

Similarities and differences. - A. alternatus can be placed into the section of the genus Amphiura where the ventral surface is covered with plates and where there is a tube foot scale (which, I repeat, can moreover disappear in a more or less great number of articles). I do not see many species of this section to compare with it. Among the southern species with plates on both surfaces of the disc and having four to five arm spines, I can cite only A. algida in which the tube foot pore is very stout and constant, the oral shields are elongated and the plate of the disc very developed; A. angularis, whose tube foot scale is well developed and whose oral shields have a different form, and finally A magellanica which has a very large tube foot scale, a very developed ventral arm spine and oral pieces of a very different form. As for A. breispina, it has five arm spines and, according to Marktanner, the plates of the ventral surface of the disc are completely indistinct, characters that do not accord with those of our species. Finally, A. tomentosa of Kerguelen always has tube foot pores and very regularly lacks a scale. The external oral papilla is small, the oral shields are triangular and as wide as long. The two species cannot be confused. I see no species whose ventral surface is more of less naked and has a tube foot scale with which $A$. alternans can be confused. There cannot be any confusion between A. alternans and the new Antarctic species discovered by the "Australian Antarctic Expedition" that I recently described under the names A. proposita, deficiens and destinata.

\section{Amphiura complanata Ljungman}

Amphiura complanata Ljungman (1866), p. 319.

Amphiura complanata Ljungman (1871), p. 642.

Amphiura complanata Lyman (1882), p. 123 and 142.

Amphiura complanata Kœhler (1914), p. 59, Pl. V, fig. 3 to 6.

Amphiura complanata H.L. Clark (1915), p. 234.

Station 1. 12 December 1901. Coast of Uruguay. $33^{\circ}$ 0' S; $51^{\circ} 10 \mathrm{~W} .80$ meters. Gray-blackish clay. One specimen. 
The individual is very well characterized and the second ventral spine has a terminal hyaline hook that characterizes the species.

One knows that $A$. complanata is especially known off the coast of Brazil. I described it in 1914 after individuals in the U. S. National Museum, found at $23^{\circ} \mathrm{S}$ and $41^{\prime} \mathrm{W}$ at a depth of 59 meters.

\section{Amphiura Eugeniæ Ljungman}

(Pl. XIV, fig. 7)

See for bibliography:

Amphiura Eugenice Kohler (1917), p. 63, Pl. VIII, fig. 1 to 9.

Falkland Islands:

Station 39. 4 July 1902 . Port William. $51^{\circ} 40^{\prime}$ S; $57^{\circ} 41^{\prime}$ W. 40 meters. Sand and small stones with algae. One specimen.

Station 41. 23 July 1902. Port Louis, Berkeley Sound. 51 $33^{\circ}$ S; 58 9' W. 8 meters. Gravel and mud with some shells. Three specimens.

Station 42. 26 July 1902. Port Louis, Greenpatch, near the bridge. $51^{\circ} 33^{\prime}$ W; $58^{\circ} 10^{\prime}$ W. 7 meters. Mud and gravel with some algae. Three specimens.

I have recently described A. Eugenice after specimens collected by Rallier du Baty at Kerguelen. The individuals of the "Swedish Antarctic Expedition" from all the Falkland Islands are more constant in their characters and seem to me closer than those studied by Ljungman, Lyman and Ludwig, and all of which come from the extreme south of South America. I believe that it is good to say a few words.

In all the specimens coming from Kerguelen, I have observed only one external oral papilla, except in a single specimen where there of two of them on a single side of the oral slit. The more eternal papilla being smaller than the other. According to Ludwig, there is in adult A. Eugenia, outside of the externa papilla, a second small papilla that does not occur in youg individuals and that Lyman called a rudimentary papilla. In the photographs that H. L. Clark published ini 1915 (Pl. IV, fig 10), although the plates are not very clear, it seems that there are also two external papillae. Now, in all the specimens collected by the "Swedish Antarctic Expedition", I found two oral papillae, the external small and that even among the specimens whose disc was only $3 \mathrm{~mm}$ in diameter. The second papilla is more or less separated from the preceding. It is smaller than it and rounded, although the first is squamiform, widened and projecting. One can see the two papilla in the photograph that I reproduce here (Pl. XIV, fig. 7). The two radial shields of each pair are slightly divergent. They are separated sometimes by a single plate, sometimes by several plates as in the specimens from Kerguelen. In the latter, there are two tube foot scales, in principle, at the beginning of the arms. The scale of the ventral arm plate disappears more or less rapidly. I have indicated in detail the variations that can occur in the tube foot scales. Here, the scales remain two in number for nearly the entire length of the arm and the internal scale disappears only near the very end, even in individuals with a disc diameter of only $3 \mathrm{~mm}$. Ludwig has said, to the contrary, that in small specimens this tube foot scale disappears in the first arm articles The oral shields are always longer than wide with rounded angles and an apparent distal lobe. Their form is analogous to that one can see in the photograph given by H. L. Clark. 
It seems thus that the specimens from Kerguelen differ a little from specimens coming from South America in regards notably the absence of the external oral papilla and the disappearance of the internal tube foot scale. The rest of the characters remain in conformity and it is the same species as I established it in 1917. However, one could ask if the form of Kerguelen is not a variety of A. Eugenice and does not represent consequently A. Antarctica of Studer. I recall in this regard that H. L. Clark in 1915 conserved the two species, A. Eugenice and A. Antarctica. He maintains the name A. antiarctica that Lyman had once proposed to be replaced by A. Studeri to avoid confusion with Ophiophragmus antarcticus Ljungman, placed by Lyman in the genus Amphiura. But this is now placed in the genus Amphiodia where it is considered synonymous with $A$. chilensis, as Ludwig established, so much so that the confusion Lyman sought to avoid is no longer to be feared.

\section{Amphiura magellanica Ljungman}

Amphiura magellanica Ljungman (1867), p. 320.

Amphiura magellanica Lyman (1882), p. 124 and 143.

Amphiura magellanica Studer (1885), p. 146.

Amphiura magellanica Ludwig (1898), p. 10.

Amphiura magellanica Ludwig (1905), p. 75.

Amphiura magellanica Kohler (1908), p. 607, Pl. XI, fig. 104.

Amphiura magellanica Kohler 1912), p. 212.

Amphiura magellanica H. L. Clark (1915), p. 228.

Station 3. 6 January 1902. Tierra del Fuego, Ile des États. 54 43’ S; 64 8' W. 36 meters. Pebbles and gravel. Two specimens in bad condition.

Falkland Islands:

Station 39. 4 July 1902 . Port William. 51 $41^{\circ}$ ' S; $57^{\circ} 41^{\prime}$ W. 40 meters. Sand, small stones with algae. Two specimens.

Station 49. 10 August 1902. Berkeley Sound. 51 ${ }^{\circ} 35^{\prime}$ S; 57 56' W. 25-30 meters. Shells and stones. One specimen.

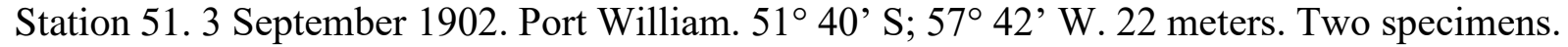

Station 52. 3 September 1902. Port William. 51 $40^{\circ}$ S; $57^{\circ} 44^{\prime}$ W. 17 meters. Several specimens.

The diameter of the disc varies between 3 and $5.5 \mathrm{~mm}$. I gave in 1908 a figure of the ventral surface of this species that is essentially characterized by the development of the first arm spine.

A. magellanica is well known at the extreme point of Soutoh America, at Tierra del Fuego and in the Strait of Magellan. The "Scottish Antarctic Expedition" found it at Gough Island and it was not known at the Falkland Islands where the "Swedish Antarctic Expedition" collected it. 


\section{Amphiura Mortenseni Kohler}

Amphiura Mortenseni Kœhler (1908), p. 604, Pl. XIV, fig. 121 and 122.

Amphiura Mortenseni Køhler (1912), p. 134, Pl. XII, fig. 2.

Amphiura Mortenseni H. L. Clark (1915), p. 325.

Amphiura Mortenseni Kohler (1922), p. 31, Pl. LXXX, fig. 5-8.

Station 5. 16 January 1902, Graham Land, southeast of Seymour Island. 64² 20' S; $56^{\circ} 38^{\prime}$ W. 150 meter. Sand and gravel. Several specimens.

Station 22. 14 May 1902. South Georgia, outside the Bay of May. $54^{\circ} 17^{\prime} \mathrm{S} ; 36^{\circ} 28^{\prime} \mathrm{W}$. Clay with some algae. Several specimens.

In my memoir on the ophiuroids of the "Australian Antarctic Expedition", I made several additional remarks on the number of tube foot scales of this species. I found again analogous variations in the specimens collected by Nordenskjöld.

\section{Amphipholis patagonica Ljungman}

(Pl. XIV, fig. 11 and 12.

Amphiphholis patagonica Lungman (1871), p. 646.

Amphiphholis patagonica Lyman (1882), p. 145.

Amphiphholis patagonica Studer (1885), p. 140.

Amphiphholis patagonica Ludwig (1898), p. 764.

Amphiphholis patagonica Ludwig (1899), p. 11.

Amphiphholis patagonica H. L. Clark (1915), p. 243.

Station 55. 8 September 1902. Falkland Islands, Port Albemarle. 52 ${ }^{\circ} 11 \mathrm{~S} ; 60^{\circ} \mathrm{S}, 26^{\prime}$ W. 40 meters. Sand with algae. A very small specimen, in very bad condition, in which a good part of the dorsal surface of the disk is missing. The diameter of the disk is less than $2 \mathrm{~mm}$.

The A. patagonica studied by authors are all of very small size and the diameter of the disc is generally between 1.5 and $2.5 \mathrm{~mm}$. They type of Ljungman had $2.75 \mathrm{~mm}$.

The species is known in the Strait of Magellan and was reported by Ludwig at Cap Blanco ( $47^{\circ} \mathrm{S}$ and $71^{\circ} \mathrm{W}$ ). It has also been reported at Juan Fernandez Island. It is often littoral. However it was collected at Cape Blanco at 146 meter depth.

At the same time as the collection made by the "Swedish Antarctic Expedition", I received from the Museum of Stockholm some ophiuroids collected by the expedition of Professor Skottserg to Juan Fernandez Island in 1916-1917. Among some specimens with the label "Masatierra, 28 March 1917", I found three specimens of a Amphipholis whose disc diameter was less than $2 \mathrm{~mm}$ with arms only 8 to $9 \mathrm{~mm}$ in length and which I consider A. patagonica. As this species had never been represented, I believed I should reproduce here two photographs (Pl. SIC, fig 11 and 12). Despite the very small sizes of these individuals, the two firs arm articles sometimes have four spines The dorsal surface of the disc is cover with very coarse, irregularly polygonal plates. Some of the central pates are a little larger than the others. All these plates are slightly imbricate. The radial shields are very large and the length exceeds a third of the disc radius. The two shields of each pair are contiguous their entire length, and it is difficult to separate them easily from each 
other at their proximal angle in order to see the end of one of the adjacent plates. Their external border is very convex. The ventral surface of the disc has very small scales, short, numerous and covering its full extent. The adoral plates are extremely wide and the oral plaes are to the contrary very small. The external oral papilla is very large, squamiform, with a convex free border. The two others are very small. The dorsal arm plates, very large, cover nearly all the width of the dorsal surface of the arms. They are as long as wide. They are sometimes pentagonal with a very open proximal angle, straight sides and a convex distal border. They sometimes take a bell-shaped form. They ae always separated by a very narrow interval. The ventral arm plates are triangular, with an obtuse proximal angle and a distal, slightly convex side. The usually have here spines of average size, very stout and pointed.

A. patagonica appears to me very different from the close forms of the genus Amphipholis by the dimensions of the plate that cover the dorsal surface of the disc.

\section{Amphiodia chilensis (Müller and Troschel)}

Ophiolepis chilensis (Müller and Troschel) (1843), p. 120.

Ophiophragmus antarcticus Lungman (1867), p. 315.

Ophiolepis chilensis Lyman (1875), p. 5, Pl. V, fig. 77.

Ophiolepis chilensis Lyman (1882), p. 125.

Amphiura antartica Lyman (1882), p. 146.

Amphiura chilensis Ludwig (1898), p. 760.

Amphiura chilensis Ludwig (1899), p. 12.

Amphiodia chilensis Verrill (1899), p. 313

Amphiodia chilensis H. L. Clark (1910), p. 341, Pl. IX, fig. 1.

Amphiodia chilensis H. L. Clark (1915), p. 245.

Falkland Islands

Station 39. 4 July 1902 . Port William. 51 $40^{\prime}$ S; $57^{\circ} 41^{\prime}$ W. 40 meters. Sand and small stones with some algae. One specimen.

Station 40. 19 July 1902. Berkeley Sound. 51³3' S; 58 0' W. 16 meters. Gravel and shells with some algae. One specimen.

In the individual from station 39, the diameter of the disc is $5 \mathrm{~mm}$. The disc completely lacks spines at its periphery. The arms are broken a short distance from their base.

The specimen from station 40 is much larger and the arms exceed $80 \mathrm{~mm}$ in length. They are wide and stout, but the dorsal surface of the disc is missing. The arms have irregular cross bands on their dorsal surface. Some are clearer and the others deeper in color, forming thus an annulation that is more marked in the second half of these arms than in the first half.

The species is identical that that which Ljungman and Studer call Ophiophragmus antarcticus and Amphiura antarctica, respectively. A detailed description has been published by Ludwig in 1898.

Oone knows that $A$. chilensis goes up the coast of Chile to $36^{\circ} \mathrm{S}$ and down to the south to the Strait of Magellan.

Because of the arrangement of the oral papilla, this species should be placed in the genus Amphiodia as done by Verrill and H. L. Clark. 


\section{Amphioplus affinis (Studer)}

Amphiura affinis Studer (1885), P. 162, Pl. II fig. 9a and b.

Amphioplus affinis Kohler (1917), p.. 69, Pl. VIII, fig. 10 and 11.

South Georgia, Cumberland Bay:

Station 19. 23 April 1902. Port Jason. 54 ${ }^{\circ} 14^{\prime}$ S; $36^{\circ} 31^{\prime}$ W. $10-15$ meters. Small stones and clay. Several specimens.

Station 28. 24 May 1902. Entrance to Marmite Bay. 54 22'; 36 28' W. 12-15 meters; Sand and algae. One specimen.

The diameter of the disc rarely exceeds $4.5 \mathrm{~mm}$ and the arms have on average $15 \mathrm{~mm}$ in length.

I have described and figured recently this species after specimens coming from Kerguelen, remarking that these species absolutely conform to those of the "Swedish Antarctic Expedition". I refer the reader to my memoir of 1917 and to the two photographs there.

The type of A. affinish comes from South Georgia. The specimens from Nordensskjöld likewise come from this locality.

\section{Amphioplus peregrinator (Kœhler)}

Amphiura peregrinator Kœhler (1912), p. 135, Pl. XI, fig 5, 11 and12.

Amphiura peregrinator H. L. Clark (1915), p. 234.

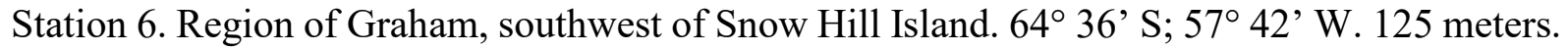
Stones and gravel. One specimen.

The specimen is very near the type that I established in 1912, for that I believe necessary to place it in the same species. The oral shields are only a little larger, but the species was created from a single specimen and as that of the "Swedish Antarctic Expedition" is also one, one can accept variation is possible. Moreover, because all the other character conform very well to that which was collected by the "Expedition Charcot": in particular the arms are thin and relatively very long.

The type of Charcot was found at $64^{\circ} \mathrm{S}$ and $65^{\circ} \mathrm{W}$, and that of the "Swedish Antarctic Expedition" comes from a very near region.

As there are two external oral papillae and four sometimes even five lateral papillae on each side, thereby doubling the most external papillae, I believe it necessary to place the species in the genus Amphioplus, rather than in the genus Amphiura where I first placed it.

\section{Ophiactis asperula (Philippi)}

See for the bibliography:

Ophiactis asperula Ludwig (1899), p. 6.

Ophiactis asperula de Loriol (1904), p. 43.

Ophiactis asperula Kœhler (1908), p. 608.

Ophiactis asperula H. L. Clark (1914), p. 259, Pl. X, fig. 11 and 12.

Ophiactis asperula Kohle (1922), p. 36, P1. LXXXI, fig. 8-9. 
Station 2. 23 December 1901. Southern coast of Argentina. $37^{\circ} 50^{\prime} \mathrm{W} ; 56^{\circ} 11^{\prime} \mathrm{W} .100$ meters. Gravel mixed with sand. One very small specimen.

Station 13. 15 March 1902. Tierra del Fuego, outside Ushuaia. 54 50' S; 68 $16^{\prime}$ W. 8 meters. Shells, gravel and pebbles. Two specimen.

Station 14. 19 March 1902. Tierra del Fuego, east of Ushuaia. 54 49’ S; 68 17’ W. 10 meters. Gravel and pebbles with some algae. One specimen.

Station 16. 11 April 1902. Between the Falkland Islands and South Georgia. 51 ${ }^{\circ} 10^{\prime} \mathrm{S} ; 57^{\circ} 25^{\prime}$ W. 150 meters. Sand. Several specimens.

Station 33. 30 May 1902. South Georgia, Cumberland Bay, Marmite Bay. 54² $22^{\prime}$ S; $36^{\circ} 28^{\prime}$ W. 22 meters. Clay and algae. One small specimen.

Falkland Islands

Station 39. 4 July 1902 . Port William. $51^{\circ} 40^{\prime} \mathrm{S} ; 57^{\circ} 41$ W. 40 meters. Sand and small stones with algae. One very small specimen

Station 40. 19 July 1902 . Berkeley Sound. $51^{\circ} 33^{\prime}$ S; $58^{\circ} 0^{\prime}$ 'W. 16 meters. Gravel and shells with some algae. Several specimens.

Station 48. 10 August 1902. Same location. 51 ${ }^{\circ} 34^{\prime}$ S; 57 55' W; 25 meters. Sand and stones. One small specimen.

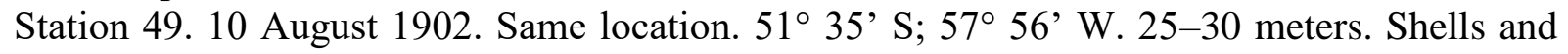
stones. One specimen.

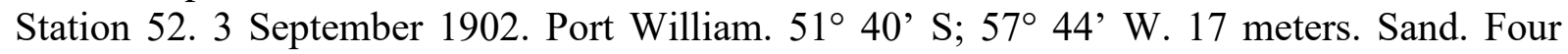
specimens.

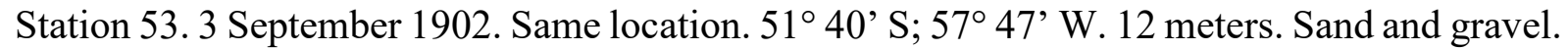
One specimen.

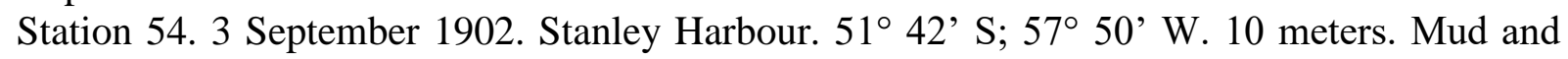
shells. One specimen.

Station 55. 8 September 1902. Port Albemarle. $52^{\circ} 11^{\prime} \mathrm{S} ; 60^{\circ} 26^{\prime}$ W. 40 meters. Sand with some algae. Two specimen.

Station 60. 15 September 1902. Tierra del Fuego, east mouth of the Beagle Channel. 55 $10^{\prime}$ S; $66^{\circ} 15^{\prime}$ W. 100 meters. Broken shells. Several specimens.

Station 62. 16 September 1902. Beagle Channel. 54 53' S; 67 56’ W. 140 meters. Clay mixed with sand. A very small specimen.

Although this species has been reported frequently, it was represented for the first time only in 1915 by H. L. Clark, who gave two photographs. One sees very great variation in the number and arrangement of spines of the dorsal surface of the disc. I refer the reader for all that concerns this specie to the information I gave and to the photographs that I reproduced in my memoir of 1922.

\section{Ophiomages nov. gen.}

Ophiolepididae in which the disc is very tall, forming a dome, and covered on the dorsal surface with large equal and polygonal spines, each with a large elongated and thick granule. The radial shields ae distinguished neither by their size nor by the form of the other dorsal plates of the disc. There is a radial comb whose papillae are continuous the length of the internal border of the genital slits. The arms, which leave from the ventral surface of the disc, are especially narrow. The dorsal arm plats are extremely tall, thick, vertically erect, forming many large, thick ridges. The tube foot pores of the first pairs are very developed and have scales on their two borders, especially thick 
and obliquely oriented. The ventral arm plates are small, a little longer than wide. The short arm spines have the same form as the adjacent tube foot scales.

The genus Ophiomages is distinguished clearly from all other known Ophiolepididae by the dorsal plates of the disc that are all equal and each armed with a large tubercle, by the radial shields scarcely larger and of the same form as the other dorsal plates, and finally by the form of the dorsal arm plates. The height of the disc recalls the genera Ophiopyrgus and Ophiomastus, and the form of the dorsal arm plates recall that known in Ophiosteira antarctica. But all the rest of the organization is very different.

\section{Ophiomages cristatus nov. sp.}

(Pl. XV, fig. 7 to 10$)$

Visokoi Island, South Sandwich. 13 November 1908. 48-60 meters. A single dried specimen. (gift of C. A. Larsen). Museum of Kristiania.

The diameter of the disc is $10 \mathrm{~mm}$. The arms are 35 to $36 \mathrm{~mm}$ in length and the height of the disc is $6 \mathrm{~mm}$. The arms have a height at their base of 4.5 while their width is only $2.5 \mathrm{~mm}$. The disc is circular and hemispherical. It dorsal surface is strongly convex and the ventral surface is flat. The arms are very thin and they decrease in size progressively to their end that is very narrow. The ensemble is very robust and the arms seem to be more or less rigid.

The dorsal surface of the disc is covered with large subequal plates, irregularly polygonal, with straight borders and very marked angles, forming together a sort of very resistant pavement. The plates are welded together at their borders and are not only imbricated but remain separated by narrow grooves. They are $15 \mathrm{~mm}$ in average width. Each plate has in its middle a large, elongated tubercle, round at the end, are rarely cylindrical but usually flattened in the radial direction. The tubercles are a little wider than long and become sometimes two times taller and wide. The radial shields are not much larger than the adjacent plate. They are pentagonal and have in their middle a smaller tubercle, shorter and narrower than the other pate. The two shields of each pair are separated by the adjacent dorsal plate and then by the first dorsal arm plate. The radial papillae are small, low and truncated, nearly as wide and long. One sees four to five of them when the animal is observe by its dorsal surface. The ventral interradial regions are narrow and, outside the oral shields, each has only some plates whose arrangement is not regular. One sometimes sees three plate in the same range, sometimes two larger plates and two other smaller. These plates are thick and their surface is rounded. Then, outside, are two or three other plates that are elevated in their center to form a strong projection, conical and rounded. The genital plates are very narrow and have, on the free border, a row of regular low papillae, rounded and truncated at the end.

The buccal shields are very large, longer than wide, triangular, with a strongly rounded distal border. The two sides have towards their first thirds a very slight notch corresponding to the base of the genital slit. The adoral plates are elongated. Three times longer than wide, contiguous on the median interradial line, with the large sides narly paralle. The oral plates are small, one and half taller than wide and the surface is curved. There are six lateral oral papillae. The three external ones are large, expanded, thick and erect, expecially the second and third. The others on the oral plate are smaller, conical and pointed. There generally are three and after them is the slighty larger unpaired terminal papilla. With these three ordinary papillae, at the end of the oral plate, are one 
or two other papillae that are found below and on each side of the terminal papilla. Finally, but on only one side of the mouth, I note towards the middle of the oral plate, an isolated papilla, smaller thn the preceding one.

The dorsal arm plates are very tall. At the beginning of the arms they are two and a half times taller than long. They at first are slightly wider than long. Then they become as long as wide, and finally they are longer than wide in the first part of the arms. The arm plates of the first half of the arms can be compared to a truncated cone whose small base is very rounded and that are flatted transversely in relation to the arm axis. The successive plates are separated from each other by a very large and deep space, but which decreases progresively and disappears towards the beginning of the last third of the arm. Thanks to the the height of the plate, the arms become, at their base, more than half taller than wide. As one goes towards the end of the arms, the plates become lower and they end by becoming completely flat in the terminal part, where they are a little wider than long, quadrangular,with a narrow proximal border, straight and very divergent lateral borders, and an enlarged and convex distal side. Then the proximal borders disappears little by little and it makaes a more or less acute angle. The three or four last plates are then simpy triangular.

The ventral arm plates are not very large and their size decreases progressively after the first. They are triangular with the proximal angle truncated. The very wide distal border has three sides of which the median is largest. The lateral angles are very sharp. The three following plates are quadrangular, a little wider than long with the distal border larger than the proximal border, and with lightly divergent sides. All these plate are contiguous. The fifth plate is still contiguous with the preceding one by a very small proximal side. But beyond the plates are separated by a larger and larger space and they become triangular with a wide and convex proximal angle and distal border. In the terminal part of the arms, they become a little longer than wide.

The lateral plates are vey projecting and tall, nearly three times taller than long. At the beginning of the arms, their height nearly equals that of the dorsal arm plate. Then, according to the subsiding of the dorsal plates, the relative height of the lateral plates increases little by little. These plates have the form of a very elongated triangle whose based is turned from the doral side. But the middle of this base responds a little to the space that eparae two successive dorsal plates. Thee lateral plate themselves are separate by a very deep groove, especially towards the ventral side.But it decreases progressively and disappears in the second half of the arm. On the ventral surface of the arms, the lateral plate leave on each side of the ventral arm plates a very large space. It is even larger than the ventral plates. They each have the form of a flat pentgagon with two large straight sides. The round distal side and a very pointed proximal angle penetrates between the successive ventral arm plates. Each lateral plate has five five small papilliform spines, dense, short, thick and flatted with a rounded end, a little longer than wide, applied against the lateral surface of the plate. The ensemble forms a small transverse comb whose length slightly exceeds a third of the article. The first ventral spine is a little shorter than the others

The tube foot pores of the first pair opens onto the ventral surface and are oblique. They generally have three proximal scales and two distal ones. The two following pairs of pores ordinarily have two proximal scales and two distals ones. These scales are very stout, cylindrical and erect. The pores of the third and fourth pairs have another proximal scale and a distal scale. But the latter is very small. It then disappears and the pores do not have more than one very flat proximal scale. It is sometimes a little enlarged and has absolutey the same form and size as the first adjacent arm spine. All the plates of the disc and arms have an extremely fine granultion like on the arm spines, the tube foot scales, the oral plates, etc.

The general color of the dried individual is pink. 
While I was writing this memoir, I received from A. Smith of the British Museum, with the request to identify it, a specimen of this same species that was collected at the South Orkney Islands (Scotia Bay). It is a little smaller than the type with a disc diameter of $9 \mathrm{~mm}$. The arms, slightly incomplete, is about $20 \mathrm{~mm}$. This specimen was in alcohol and is completely discolored.

\section{Ophioceres incipiens Kœhler}

Ophioceres incipiens Kœhler (1922), p. 48, Pl. IX, fig. 1 to 6 and 13-14.

Station 17. 19 April 1902. Shag Rock Bank, west of South Georgia. 53 34' S; 43 23' W; 160 meters. Gravel and sand. One specimen. Disc diameter, 4.5; arm length, $15 \mathrm{~mm}$.

Station 22. 14 May 1902. South Georgia, Cumberland Bay, outside the Bay of May. 54 $17^{\prime} \mathrm{S}$; $36^{\circ} 28^{\prime}$ W. 75 meters. Clay, some alge. One specimen. Disc diameter, 6; arms, 25 mm.

The specimens are absolutely identical to those discovered by the "Australian Antarctic Expedition" I used to describe the species. I refer the reader to the detailed description and to the photographs that I pubished in my memoir of 1922.

The discovery of $O$. incipiens at Shag Rock Bank and South Georgia greatly extends the geographical distribution of this species, whose type was collected at $60^{\circ} \mathrm{S}, 141^{\circ} \mathrm{E}$ and $64-65^{\circ} \mathrm{S}$, $92-97^{\circ} \mathrm{E}$.

\section{Ophiocten amitinum Lyman}

Ophiocten amitinum Lyman (1882), p. 79, Pl. IX, fig. 7-9.

Ophiocten amitinum Studer (1885), p. 16, Pl. II, fig. 8 a-g.

Ophiocten amitinum Ludwig (1899), p. 4.

Ophiocten amitinum Kœhler (1907), p 288.

Ophiocten amitinum H. L. Clark (1915), p. 328.

Station 16. 11 April 1902. Between Falkland Islands and South Georgia. 51 ${ }^{\circ} 40^{\prime} \mathrm{S} ; 5^{\circ} 25^{\prime} \mathrm{W}$. 150 meters. Sand. Several specimens.

Station 58. 11 September 1902. South of West Falkland. 52²9’ S; 60 36' W. 197 meters. Sand and gravel. Six specimens.

Station 61. 16 September 1902. Tierra del Fuego, Beagle Channel. 54 54' S; 67 52’ W. 125 meters. Gravel, small stonews. One specimen.

The disc diameter can reach $11 \mathrm{~mm}$ and varies most often between 6 and $9 \mathrm{~mm}$. The specimens of stations 16 and 58 are completely discolored in alcohol and a uniformly greyish white. That of station 61 has a very deep pigmentation, brownish on the edge of the plates of the dorsal surface of the disc. Its dorsal arm plates have a clear brown color with, in the middle, a clear patch. The ventral surface is completely colorless.

The species appears to extend to the southern point of South America, on the coast of Patagonia, in the Straits of Magellan and of Smyth, etc. One knows that it has been found by the "Challenger" at the Prince Edward Islands, Crozet and Kerguelen, and up to $108 \mathrm{E}$ longitude. It has not yet been encountered at the Falkland Islands or south of these islands. 


\section{Ophiomastus conveniens nov. sp.}

(P1. XV, fig. 5 and 6)

Station 8. Graham region. 11 February $1902.64^{\circ} 3^{\prime}$ S; 3'W, 360 meters? Little compacted clay. One specimen.

The specimen is very small. The diameter of the disc is only $4 \mathrm{~mm}$. The arms are $8.5 \mathrm{~mm}$ in length.

The disc is round with a very convex doral surface and a flat ventral surface. The dorsal surface of the arms is likewise round and convex. The dorsal suface of the disc is covered by a small number of large plate, among which one recognizes first a rosette of six primary plates that alone fill half of the disc. These plates are contiguous, subequal and round. Outside are, in the radial spaces, a very large oval plate, a little longer than wide and two much smaller plates that separate the two radial shields of each pair.In the interradial spaces is a series of three plates. The first and the third are large and round, the second smaller plate is widened transversally. The third plate extends to the edge of the disc and goes onto its sides. One can see the external border in looking at the ophiurid from the ventral surface. Some other very small plates complete the covering of the dorsal suface of the disc. The rdial shields are irregularly triangular, a little smaller than the primary plates. The two shields of each paire are separate along their entire length and diverging within where they are separated by the large radial plate reported above.

The ventral suface of the disc has, between the oral shield and the genital plaes, a very large plate, generally contiguous to the oral shield and which reaches to the border of the disc where there are two other very small plates. The genital plates are very large and wide. The genital slits are very narrow and scarcely visible. There is not the least trace of papillae.

The mouth shields are very large, pentagonal with a proximal roughy right angle with straight sides. The lateral borders converge towards the distal border that is shrunken. The lateral angles are a little rounded. The adoral plates are very elongated, narrow, three times longer than wide, with border a little sinuous. The oral plaes are a little wider than the adoral and one and half times longer than wide the lateral oral papillae are very small and welded into a nearly continuous fringe, in which however, one can recognize four papillae. The external ones are wider and the unpaired terminal papilla is very small.

The first two dorsal arm plates are small, round, a little wider than long. The third is longer than wide and separated from the preceding. It is triangular with a very convex distal border. The following plates are rather lozenge-shaped, a little longer than wide, always largely separated and becoming smaller and smaller. They even disappear on the last articles.

The first ventral arm plate is triangular, very large, nearly as wide as long, with a very narrow proximal area, straight sides and a convex distal border with rounded lateral angles. The second has nearly the same form as the first from which it is separated by a small space. The third is much smaller, and largely separated from the second. It is a little wider than long. The following plates become still much smaller. They always remaii wider than long and the space that separates them is more and more elongated The plates end by disappearing in the terminal part of the arms.

The later plates first have four small spines, thin and pointed and then three. These spines are on the distal border of the plates, equal distance from each other.

The arm pores of the first two pairs are very developed. Those of the first pair have two and even three spines on the proximal border and one or two on the distal border. The pores of the second pair have one or two scales on the proximal border and one on the distal border. The pores 
of the smaller third pair have a single small scale, shorter than the adjacent arm spines. Finally, the following pores completely lack scales.

All the plates of the body are covered with a very fine and very regular granulation.

Similarities and differences - $O$. conveniens recalls $O$. Ludwigi by the two first pairs of tube foot pores, lage and with some scale, bu it is separated from it by the arrangement of the dorsal plates of the disc and the small and non-projecting dorsal arm plates.

$O$. conveniens is separted from $O$. tegulitus whose tube foot pores, very large and with a elongated scale on each border, and has ony two arm spines. Moreover the centro-dorsal is much larger than the primarial radials. The other specis of the genus Ophiomastus have only a single oval scale on each tube foot pore

\section{.Ophionotus Victoriæ Bell}

Ophionotus Victoria Bell (1901), p. 216.

Ophionotus Victoriae Kœhler (1906), p. 29.

Ophionotus Victoria Bell (1906), p. 13.

Ophionotus Victoriae Kœhler (1912), p. 114, P1. X, fig. 2 to 4, 12 and 13; P1. XI, fig. 8.

Ophionotus Victorice H. L. Clark (1915), p. 327.

Graham region:

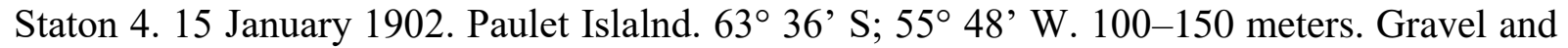
small stones. Six small specimens.

Station 10.12 February 1902 . Admiralty Strait. $64^{\circ} 20^{\prime}$ S; $57^{\circ} 0^{\prime}$ W. 6 meters. Little compacted clay. Several specimens.

Staton 11.18 February $1902.65^{\circ} 19^{\prime}$ S; $56^{\circ} 48^{\prime}$ W. 400 meters. Clay mixed with gravel A dozen specimens.

Station 22. 14 May $1902.5^{\circ} 17^{\prime} \mathrm{S} ; 36^{\circ} 28^{\prime}$ W. 75 meters. One specimen with seven arms.

10 November 1908. Zavodowski Island, South Sandwich. 56 7’ S; $27^{\circ} 30^{\prime}$ W. Six specimens. Gift of C. A. Larson. These six individuas, whose disc diameter varies between 24 and $28 \mathrm{~mm}$, have kept in alcohol a clear brownish red color.

I studied Ophionotus Victorice in detail in 1912 with specimens collected by the "Charcot Expedition”. I published photographs and I have nothing to add to what I said there.

\section{Ophionotus hexactis (Smith)}

(Pl. XIV, fig. 10)

See for bioliography:

Ophionotus hexactis Káhler (1917), p. 61.

Station 7. 22 January 1902 . Graham regon. $65^{\circ} 56^{\prime}$ S; $54^{\circ} 35^{\prime}$ W. 920 meters. Mud mixed with stones. Four specimens.

Station 17. 19 April 1902. Shag Rock Bank, west of South Georgia. 53 35’ S; 43 23'. 160 meters. Gravel and sand. Several specimens. 
South Georgia

Station 20. 6 May 1902. Antarctic Bay, east of Possesson Bay. 54 12' S; 36 50’ W. 250 meters. Small stones. Several specimens.

Station 21. 9 May 1902. Entrance to Possession Bay. 54 8' S; 37 3' W. 200 meters. Clay. One small specimen.

South Georgia, Cumberland Bay.

Station 22. 14 May 1902. Outside Bay of May. $54^{\circ} 17^{\prime} \mathrm{S} ; 36^{\circ} 28^{\prime} \mathrm{W} .75$ meters. Clay, some algae. Two specimens.

Station 23. 16 May 1902. Outside Moraine Fjord. 54 23' S; 36² 26' W. 64-74 meters. Gray clay with gravel and stones. One specimen.

Station 25. 21 May 1902. Outside Marmite Bay. 54 22' S; 36 $27^{\prime}$ W. 24-52 meters. Gray clay, some algae. One specimen.

Station 28. 24 May 1902. Entrance to Marmite Bay. $54^{\circ} 22^{\prime} \mathrm{S} ; 36^{\circ} 28^{\prime} \mathrm{W} .12-15$ meters. Sandand algae. Six specimens.

Station 29. 26 May 1902. Moraine Fjord. 54 24' S; $36^{\circ} 25^{\prime}$ W. 16 meters. Stones with some algae. Four small specimens.

Station 30. 26 May 1902. Same locality. 54 24' S; 36² 26' W. 125 meters. Clay with rare stones. One specimen.

Station 32. 29 May 1902. South Fjord, before Nordenskjöld Glacier. 54² 24’ S; 36² 22' W. 195 meters. Clay with some stones. One small specimen.

Satation 34. 5 June 1902. Outside Cumberland Bay. 54 $11^{\prime}$ ' S; 36 $6^{\circ} 18^{\prime}$ W. 252-310 meters. Gray clay with rare stones. One specimen.

I have had occasion to speak of Ophionotus hexactis on different occasions (See Kœhler 1911, p. 29; 1912, p. 122 and 1917, p. 61) and I have little to add to that I have already said. I already reported in 1917 the remarkable depth at which O. hexactis was encountered by the "Swedish Antarctic Expedition", 920 meters (station 7). Generallly O. hexactis is found at littoral stations with shallow depths. "Challenger" however collected it between 37 and 137 meters. Individuals reported by the "Swedish Antarctic Expedition" came from very different depths, 12-15 meters (station 28), 16 meters (station 29), 75 meters (station 22), 195 meters (station 32), 250-310 meters (station 34), and finaly 920 meters (station 7).

The sizes of the specimens varied greatly. The larget came from stations 20, 22 and 32 with a disc diameter reaching $33 \mathrm{~mm}$.

A specimen from station 22 had seven equal arms. The diameter of its disc was only $12 \mathrm{~mm}$. I show it here in Pl. XIV, fig. 10.

\section{Ophiura Lymani (Ljungman)}

See for the bibliography:

Ophiura Lymani Ludwig (1899), p. 5.

Ophioglypha Lymani Kœhler (1907), p. 295, Pl. X, fig. 11 and 12.

Ophioglypha Lymani Kœhler (1912), p. 201.

Ophioglypha Lymani Matsumoto (1915), p. 268.

Ophiura Lymani H. L. Clark (1915), p. 322. 
Station 59. 12 September 1902. Burdwood Bank, south of West Falkland. 53 45' S; 61 ${ }^{\circ} 10^{\prime} \mathrm{W}$. 137-150 meters. Broken shells with stones. One specimen.

\section{Ophiomaria Döderleini (Kœhler)}

Ophioglypha Döderleini Kœhler (1900), p. 19, Pl. V, fig 34-36.

Ophioglypha Döderleini Kœhler (1907), p 293.

Ophiura Döderleini H. L. Clark (1915), p. 325.

Ophiomaria Döderleini Austin Clark (1916), p. 384.

Station 7. 22 January 1902 . Graham region. $65^{\circ} 56^{\prime} \mathrm{S}$; $54^{\circ} 35^{\prime} \mathrm{W} .920$ meters. Mud mixed with sand. Two specimens.

I established this species after specimens collected by the "Belgica" near $70^{\circ} \mathrm{S}$ and $83-84^{\circ} \mathrm{W}$ at a depth of 475 to 500 meters.

The species was also fouond at the southern end of South America by the Mission of Cape Horn, but without indication of the locality or depth. It probably came from littoral stations. The "Swedish Antarctic Expedition" fouond it at Graham Land at a depth of 920 meters. The specimens completely conform to those collected by the Mission of Cape Horn.The genus Ophiomaria was recently established by Austin Clark for two ophiuroids dragged off the coast of Chili, O. tenella and rugose. The American naturalist scholar believes there is a need to place in this same genus O. carinifera and Döderleini Kœhler. I completely agree with this opinion.

\section{Ophioperla Ludwigi Kœhler}

Ophioperla Ludwigi Kœhler (1912), p. 126, Pl. X, fig 1, 5, 6 and 7.

Ophioperla Ludwigi H. L. Clark (1915), p. 348.

\section{South Georgia:}

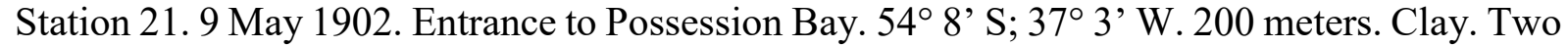
specimens.

Station 34. 5 June 1902. Outside Cumberland Bay. 54 $11^{\prime}$ S; $36^{\circ} 18^{\prime}$ W. 252-310 meters. Gray clay with rare stones. Five specimens.

The diameter of the disc varies between 18 and $24 \mathrm{~mm}$. The arms are nearly all incomplete. In a specimen with a disc diameter of $19.5 \mathrm{~mm}$, one of the arms with the end missing is $55 \mathrm{~mm}$ in length.

The smallest specimen preserved in alcohol has very week traces of a violet red color.

I have nothing to add about this species to my description of 1912. I shall recall only that it was found by Charcot in the area of Graham Land between 70 and 75 meters depth. It was found by the "Australian Antarctic Expedition" at greater depths (375 and $358 \mathrm{fms}$ ) near $64-65^{\circ} \mathrm{S}$ and $96-$ $97^{\circ} \mathrm{E}$. 


\section{Amphiophiura antarctica nov. sp.}

(Pl. XIV, fig. 8 and 9)

Station 38. 28 June 1902. Between the Falkland Islands and South Georgiga. 50 $19^{\prime} \mathrm{S} ; 50^{\circ}$ 50' W. 2,675 meters. Small stones. Two specimens.

In the largest, the disc diameter is $6 \mathrm{~mm}$ and the arms are not more than $9 \mathrm{~mm}$ in length. One of them is broken at the base. In the other specimen the disc diameter is only $4 \mathrm{~mm}$.

The disc is very thick and the dorsal surface is a little convex. It is covered with sparse, very large plates, among which one sees a pentagonal cenro-dorsal and five radials widened transvesally, one and a half times wider than long, quadrangular or hexagonal, with two small lateral, divergent sides, an external border strongly rounded and an internal border that touches the centro-dorsal. All these plates are contiguous and a little smaller than the centro-dorsal. Following each of them, the radial spaces enclose only the radial shields that are very large, nearly as wide as long or a little wider than long, nearly quadrangular, largely contiguous for most of their length. They separate only outside to touch the first dorsal arm plate. These shields are notably smaller than the primary plates.The radial papilla are low and short. Sometimes the first is very large and wide, squamiform, nearly as wide as long, but the following ones are narrower. They are first a little pointed, then they become clearly quadrangular and a little wider than long on the ventral surface along the genital slit. The interradial spaces enclose only two plates that are wider than long. The first is pentagonal and the second quadrngular. The sides of the disc are bordered by three lateral plates that are taller than wide.

The interradial spaces on the ventral surface of the disc have, outside the very large oral shields, only two small intercalated plates between the shields and the plates of the sides of the disc. The genital sis are narrow except in the proximal part where they are very widened.

The oral shields cover nearly all the interradial spaces. They generally have a triangular form. However their top is bordered by two small sides that go to the lateral borders by a very obtuse angle corresponding to the base of the genital slit. The distal side is strongly rounded and convex. The lateral angles are equaly very rounded. The adoral plates are very small, short and wide, scarcely longer than wide with straight sides. The oral plates are larger than the preceding and above all they are taller but a little less wide.

The first dorsal arm plate is small, triangular, and included in the angle formed by the two radial shields of each pair. The three following plates are large and quadrangular, with the distal size wide and convex and with divergent lateral borders. They are contiguous at first. Then the plates become triangular with a distal convex border. Their size decreases very rapidly at the same time that they are separated by a space that increases.

The first ventral arm plate is large, pentagonal, longer than wide, and with a proimal angle bordered by two very small sides. Then come two lateral borders, strongly excavated by the oral tube foot pore. The distal border is very wide and a little rounded. The lateral angles are equally rounded. The three or four following plates are quadrangular with a distal border larger thn the proxima border and a little rounded. All these plates are contiguous. The following ones tend to take a triangular form with a proximal angle, lateral borders a little excavated and a rounded distal side. They are separated by a space that becomes larger and larger. These plates are first longer than wide. Then they become as long as wide.

Each of the very projecting lateral plates have first three spines and then only two. These spines are excessively short and a little widened. They very often are lacking 
The tube foot pores are extremely wide, but the number of scales is not very great and it appears to vary as do the sizes of the scales. The pores of the first two of three pairs often has three scales on their proximal border and one or two on their distal border. But the proximal scales can be replaced by a single larger one. The scales of the following tube foot pores persist for some length of the arms and on the proximal border only where they are usually reduced to only while they disappear on the distal border.

Similarities and differences. - A. antarctica is very near $A$. convexa and coronata, particularly the arrangement of the dorsal plates of the disc recall those that are known in these two species, especially in the latter. But in A. convexa and coronata, the papillae of the radial comb are elongated and pointed. The new species is very near $A$. oedignata of Martinique, but the dorsal plates of the disc are more numerous in the latter species and the radial papillae are also finer.

\section{Ophiurolepis resistens (Kœhler)}

Ophioglypha resistens Kœhler (1911), p. 42, Pl. VII, fig. 9 to 12.

Amphiophiura resistens H. L. Clark (1915), p. 315.

Ophiurolepis resistens Kœhler (1922), p. 74, Pl. XI, fig 7, 8, 11, 17, and 18; Pl. XIII, fig. 8 to 10; Pl. XV, fig 7 to 12 and 14 to 22.

South Georgia, Cumberland Bay:

Station 22. 14 May 1902. Outside the Bay of May. $54^{\circ} 17^{\prime} \mathrm{S} ; 36^{\circ} 28^{\prime} \mathrm{W} .75$ meters. Clay some algae. Several specimens.

Station 32. 29 May 1902. Fjord of the South, before Nordenskjöld Glacier. 54 $24^{\prime}$ S; $36^{\circ} 22^{\prime}$ W. 195 meters. Clay with some stones. Four specimens.

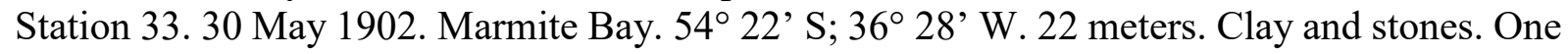
specimen.

Station 34. 5 June 1902. Outside Cumberland Bay. 54 $11^{\prime}$ S; 36 $18^{\prime}$ 'W. 252-310 meters. Gray clay with rare stones. Three specimens.

All the specimens are of small size. The diameter of the disc is between 6 and $7 \mathrm{~mm}$. The arms are extremely thin.

The type of the species was discovered by Shackleton at Cape Royds at 10-20 fms depth. Numerous specimens of the species were found by the "Australian Antarctic Expedition". I studied them in detail in my memoir of 1922. I refer the read to this work in which he will find seveal phtograaphs of $O$. resistens and where I also indicate the reasons that made me transfer this species in the genus Ophiurolepis.

The individuals collected by the "Swedish Antarctic Expedition" conform to the variety I call gracilior in the preceding memoir.

\section{Ophiurolepis gelida (Kœhler)}

Ophioglypha gelida Kœhler (1901), p. 17, P1. I, fig. 6 to 8.

Ophioglypha gelida Kœhler (1912), p. 102, Pl. IX, fig. 4-101; Pl. XIII, fig. 13-15.

Homalophiura gelida H. L. Clafrk (1915), p. 326. 
Ophiurolepis gelida Kœhler (1922), p. 79, Pl. XI, fig. 9 and 10, 12 ti 15; Pl. XIV, fig 1-14; Pl. $\mathrm{X}$, fig. 1 to 6; and XIII.

Station 8.11 February 1902 . Graham region. $64^{\circ} 3^{\prime}$ ' S; $56^{\circ} 37^{\prime}$ W. 360 meters. Little compacted clay. One specimen.

Station 34. 5 June 1902. South Georgia, outside Cumberland Bay. 54 $11^{\prime}$ S; 36 $16^{\circ}$ ' W. 252310 meters. Gray clay with rare stones. One specimen.

The specimens are very like those the "Pourquois Pas?" collected and that I represented in 1912 Pl. IX, fig. 4. The "Australian Antarctic Expedition" collected numerous speciens of $O$. gelida. In my memoir of 1922, I studied this species in some detail and I gave several photographs of various specimens. I also indicated the reasons I believed it necessary to transfer the species to the genus Ophiurolepis. I refer the reader to this memoir.

\section{Addenda and Corrections}

\section{Anasterias tenera}

Antarctic Bay is not located in Cumberland Bay, but is east of Possessoin Bay.

\section{Sporasterias antarctica}

The specimens mentioned on p 15, 16 and 18 as coming from Sparrow Cove, East Falkland (10. I. 1908), come actually from West Point Island, West Falkland, rocks, 0 meters (5. 12. 1907).

\section{Podasterias Brandti}

The two large specimens do onoto come from South Georgia, but from the Falkland Islands, Port Louis, Greenpatch, 7 meters (17. 7. 1902).

\section{Podasterias meridionalis}

The provenance of the two specimens from South Georgia is not at all certain. The small individuals (p. 35) were collected from stations 17, 20 and 22 (not 28).

\section{Allostichaster inæqualis}

It seems uncertain if the three specimens mentioned come from station 2 or station 17 (Shag Rock Bank, 160 meters) or perhaps both.

\section{Asterina fimbriata}

Station 4. 15 January 1902. Graham region, Paulet Island. 100-150 meters. Gravel. Two specimens.

Station 7. 22 January 1902 . Graham region. $65^{\circ} 56^{\prime}$ S; $54^{\circ} 35^{\prime}$ W. 920 meters. Mud mixed with sand. Three specimens. 


\section{Bemaster Gourdoni}

In the list of localities, the last specimens actually comes from the Bay of May, Cumberland Bay, 3 May 1902, on the holdfasts of Macrocystis.

\section{Luidia africana Sladen}

Luidia africana Sladen (1889), p. 256, Pl. XLIV, fig. 1-2; Pl. XLV, fig 1-2.

Luidia africana Döderlein (1920), p. 288, fig. 35.

Station 1. 12 December 1901. Coast of Uruguay. $33^{\circ} 0^{\prime} \mathrm{S} ; 51^{\circ} 0^{\prime} \mathrm{W} .80$ meters. One speciemen is not in very good condition, a single arm remains attached to the disc: $R=75 \mathrm{~mm}$ and $r=9 \mathrm{~mm}$; the arms are $9 \mathrm{~mm}$ in width at the base.

This individual, which was forgotten, seems to me to have been repored as L. africana Sladen. It differs however from the type that Sladen descried y the absence of didactyl pedicellaria between the adambulacral spines and the venral marginal plaes. This pedicellaria is replaced either by a very stout spine or by a group of two or three small spines. Sladen had also remarked, in the African individuals he had in his hand, the pedicellaria could be replaced here and there by a group of two or three spines. For the rest of the characers, the specimen conforms well to L. africana. I thus do not believe it necessary to separate it because I have only one specimen at my disposition. If it is confirmed he the individuals from South America always lack pedicellariae, it obviously would be necessary to make them a distinct variety of $L$. africana. One knows $L$. africana has been encountered in various localities of wesern Africa, from Marocco to the Cape of Good Hope. Likewise, L. senegalensis was found at Senegal, to the Antilles and along the coasts of Brazil to Destero, at about $27^{\circ} \mathrm{W}$.

\section{Astrothamnus tuberculatus nov. sp.}

(Fig. 1 a-f)

Station 5. 16 January 1902. Graham region, southeast of Seymour Island. 64 $20^{\prime} \mathrm{S} ; 56^{\circ} 38^{\prime}$ W. 150 meters. Sand and gravel. A single specimen.

The specimen was forgotten and was sent to me after printing of the memoir. Because it is neccessary to make a type of the new species, it seems to me useful to give here a description accompanied by some photographs (Fig. 1).

The disk is thick with a very convex dorsal surface. Its contour is subpentagonal $(a-c)$. There is a very marked indentation where the arms insert and it is slightly indened in the middle of each interradial space. Its diameter is 10.5 and its heighgt is $5 \mathrm{~mm}$. The arm are slender $(a)$, folded around the ventral surface of the disc and strongly coiled in a vertical plane. I have brought these arms into a horizonotal plane in order to photograph the ophiuroid. Their length is about $45 \mathrm{~mm}$ and their width at the insertion on the disc is $2.5 \mathrm{~mm}$. They gradually decrease up to the end that is very thin. 
The dorsal surface of the disc ( $a$ and $b$ ) is entirely covered with large, round, unequal projecting tubercles. The largest of these tubercles has a diameter of $0.8 \mathrm{~mm}$. The smallest is less tha $0.1 \mathrm{~mm}$. In the central region of the disc, they are nearly contiguous. But they remain separate from each on the rest of the dorsal surface and they are separated elsewhere by very unequal spaces. There is not the least indication of radial sides nor of radial shields. The surface of the tubercles is smooth. Examined with the microscope, they show only extremely fine and regular granulation.

The ventral surface of the disc $(c)$, in the interradial spaces, has the same tubercles as the dorsal surface. They are unequal like the latter and very near each other towards the periphery of the disc. Then they are progressively separated and leave a narrow interval between the two genital slits that is lacking in tubercles, within which they reppear in the area near the oral pieces where they remain separated by a narrow naked space. The genial slits are small, short and very narrow.

The oral pieces are covered with small tubercles much finer than those of the rest of the body and whose dimensions decrease slightly from outside to inside. There are some oral papillae, sometimes low and obtuse, sometimes more elongated and pointed. The oral angles have some teeth and stoutal dental papillae, conical and pointed. Arranged on each of them is a small pile containing two or three irregular rows.

The arms have successive rings $(a$ and $b$ ). The narrower ones have a more or less regular double row of small tubercles or rounded granules, slightly rugose. The others are formed of small hooks measuring 0.15 to $2.0 \mathrm{~mm}$ on average and ending in a long recurved hook $(d)$. The granules are flat on the lateral surfaces of the arms and still more on the ventral surface, between the tube foot scales where they ar a little projecting, separate from each other and completely smooth.

The tube foot pores are inconspicuous, small and rounded. Those of the first pair generally have only one scale, very small, sometimes a little elongated and conical, sometimes rounded. Those of the second pair have three scales and this continuies on all the following pairs $(c)$. These scales are stout, thick, a little flat and end in a variable number of spines, from one to three. Their size decreases a little from the most internal to the most external ( $e$ and $f$ ). The surface of these scales is first simpy rugose, but then as the arms decrease, the terminal ends are generally reduced to a single one per scaoe, widened and forming true hooks recurved as the scale becomes more slender. Its surface has a fine acute asperity. Exceptionally, one can find in the basal part of the arms four scales on one side on some articles.

The color of the specimen in alcohol is clear greyish yellow. 


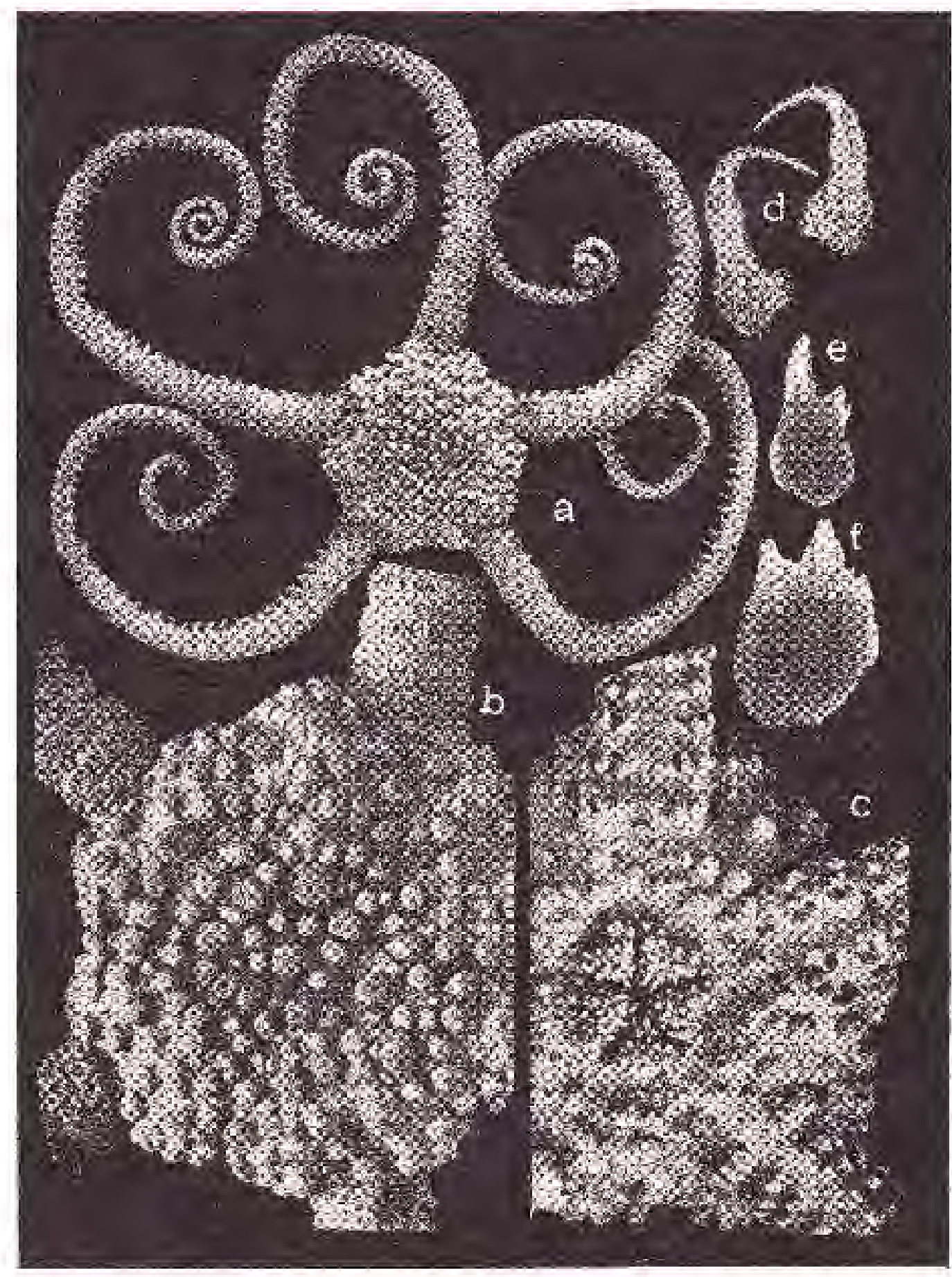

Fig. 1. Astrothamnus tuberculatus. $a$, Entire ophiuroid seen from the dorsal surface, X 2; $b$, dorsal surface more enlalrged, X 5; $c$, ventral surface; $d$, hooks of the arms, X 100; $e$ and $f$, two tube foot scales in the first quarter of the arms, $\mathrm{X} 30 ; e$, external scale, $f$, internal scale.

Similarities and differences. - The genus Astrothamnus was established by Matsumoto in 1915 for a Japonese species, A. echinaceus. The Japanese naturalist scholar included in the same genus 
three species that I had previously attributed to Astrotoma, A. bellator, rigens and vecors. In these last three species, the disc is uniformly covered with fine dense granules, rounded or pointed, on the dorsal surface. The aspect is much diferent from that of the Antarctic species. They are nearer A. echinaceus in which the disc is likewise covered with granues but these are larger, their dimensions remaining very uniform. They also are very dense on the dorsal surface as on the ventral surface. In addition, these granules end in small pointed spines. To the contrary, the antarctic species has very unequal granules, larger and less numerous. Their surface is smooth and they are much less dense, especially on the ventral surface. 


\section{List of cited works}

1842. Müller, J. and Troschel, F. H. Neue Beiträge zur Kenntnis der Astriden. Archiv. f. Naturgesch. 1842.

1858. Philippi, A. Beschreibung einiger neuen Seestern aus dem Meere von Chiloe. Archiv f. Naturgesch. 1858.

1866. Ljungman, A Ophiuroiden huc usque cognita. Öfvers. K. Vetesk. Acad. Förh. Ärg. 23. 1866.

1871. Ljungman, A. Förteckning öfver uti Vestindien af. Dr. Goës samlade Ophiurider Ib. Ärg. 28. 1871.

1875. Th. Ophiuridæand Astrophytidæ. Zoolog. Results of the "Hassler" Expedition. Cambridge 1875.

1875. Perrier, E. Révision de la collection des Stellérides du Museum. Arch. Zool. Expérim. Vol. IV et V. Paris 1875-76.

1879. Smith, E. Echinodermata, in Zoology of Kerguelen Island. Philosoph. Trans. Roy. Soc. London. Vol. CLXVIII. London 1882.

1882. Lyman, Th. Report of the Challenger. Ophiuroidea. London. 1882.

1882. Studer, Th. Verzeichniss der während der Reise der "Gazelle" gesammelten Ophiuriden Abhand. Königl. Akad. Wiss. Berlin 1882.

1884. Danielssen, D.C. and Koren, J Asteroidea. The North-Atlantic Expediton. Chrisinia 1884.

1884. Studer, Th. Verzeichniss der während der Reise der "Gazelle" gesammelten Asteriden und euryaliden. Abhand. Königl. Akad. Wiss. Berlin 1884.

1885. Studer, Th. Die Seesterne Süd-Georgiens. Jahrb. Der wissensch Anstalten zu Hamburg. II, 1885.

1889. Sladen, P. Report of the "Challenger". Vol. XXX, Asteroidea. London 1889.

1892. Perrier, E. Échinodermes. I. Stellérides. Mission scientifique du Cap Horn. Zoologie, T. VI. Paris 1891.

1895. Leitpoldt, Fr. Asteroidea der "Vettor Pisani" Expedition. Zeitschr. f. wiss. Zool. Bd LIX, 1895.

1896. Meissner, M. Die von Dr. Plate aus Chile und Feuerland heimgebrachten Seesterne. Arch. f. Naturgesch. 1896.

1898. Ludwig, H Die Ophiuren der Sammlung Plate. Zool. Jakob. Suppl. Bd. 41898.

1899. Ludwig, H. Ophiuroideen, in Hamaburger magalhaensische Sammelreise. Hamburg 1899.

1899. Verrill, A. E. Revision of certain genera and species of Starfishes. Trans. Connectiicut Acad. Vol. X.

1899. Verrill, A. E. North American Ophiuroidea Ib. Vol. X.

1900. Döderlein, L. Die Echinodermen. Zoologische Ergebnisse einer Undesuchungs-fahrt nach...Westspitzbergen... auf "Olga". Oldenburg 1900.

1901. Kœhler, R. Échnides et Ophiures. Resultats der voyage du S. Y. "Belgica”. Anvers 1901.

1902. Bell, J. Echinoderma, in Reports on the Collections of Natural History... of the "Southern Cross". London 1902.

1903. Ludwig, H. Seesterne. Resultts du vyage du S. Y. Belgica” Anvers 1903.

1904. Meisnner, M Aseroideen, in Hamburger magalhaensich Sammelreise. Hamburg 1904.

1904. Loriol, P. de. Notes pour server à l'étude des Échinodermes $2^{\mathrm{e}}$ série, fasc. 2. Bâle et Genëve, 1904.

1905. Ludwig, H. Asterien und Ophiuren der schwedischen Expedition nach den Magalhaenslândern. Zeitschr. f. wiss. Zool. Bd LXXXII, 1905. 
1905. Bell, J. Echinoderma found off the coast of South Africa. Part 2. Asteroiden. Marine Investigations in South Africa. Vol. III. Cape Town 1905.

1906. Kœhler, R. Échinodermes. Expédition Antarctique Française commandée par le Dr. Charcot. Paris 1906.

1907. Kœhler, R. Révision de la Collection des Ophiures du Muséum de Paris. Bullet. Scientif. France Belg. Vol. XLI. Paris 1907.

1908. Kœhler, R. Astéries, Ophiures et Échinides de 1'"Expedition Antarctique Nationale Écossaise". Trans. Roy. Soc. Edinburgh. Vol. XLVI.

1908. Bell, J. Echinoderma, in National Antarctic Expedition. Natural History. Vol. IV. London 1908.

1909. Benham, W. B. The Echinoderma.... of subantarctic Islands of New Zealand - Subantarctic Islands of New-Zealand. Rec. Canterbury Mus. Vol. I. Wellington 1909.

1910. Clark, Lyman H. The Echinoderms of Peru. Bull. Mus. Comp. Zool. Harvard College. Cambridge 1910.

1911. Fisher, W. K. Asteroidea of the North Paacific. Bull. of the U S. Nat. Museum. No. 76. Part I, 1911.

1911. Döderlein, L. Über japanische und andere Euryalæ. Beiträge zur Maturgeschichte Ostasiens herausgegeben von Dr. F. Doflein Abh. Akad. München 2. Suppl. 1911.

1911. Kœhler, R. Astéries, Ophiures et Échinide. British Antarctic Expedition 1907-09. Vol. II, part 4.

1912. Kœhler, R. Échinodermes (Astéries, Ophiures et Échinides). Deuxiéme Expédition Antarctique Française commandéed par le Dr. Charcot. Paris 1912.

1914. Kœhler, R. Anasterias octoradiata, nouvelle Astérie de la Géorgie du Sud, in Report on the South Georgia Epedition. Sc. Bulletin of the Museum of the Brooklyn Institute of Arts and Sciences. Vol. 2, No. 4.

1914. Verrill, E. A. Starfishes. Harriman Alaska Series. Vol. XIV. Smithsonian Institution, Washington.

1914. Kœhler, R. Contribution to the study of Ophiurans of the United States National Museum. U. S. Nat. Mus. Bulleten 84. Washington.

1915. Clark, Lyman H. Catalogue of recent Ophiurans. Mem. Mus. Comp. Zool. Harvard College. Vol. XXV, No. 4. Cambridge 1915.

1915. Matsumoto, H. A monograph of Japanese Ophiuroidea, arranged according to a new Classification. Journ. of the College of Science. Imperial University, Tokyo. Vol. XXXVIII, art. 1. Tokyo 1915.

1916. Clark, Austin H. A new genus of Ophiurans Journal of the Washington Acad. of Science. Vol. VI. No. 12. Washington.

1917. Bell, J. Echinoderma. Part I Actinogonidiata. British Antarctic ("Terra Novæ") Expedition 1910. London 1917.

1917. Kœhler, R. Échinodermes (Astéries, Ophiures et Échinides) recueillis par M. Rallier du Baty aux îles de Kerguelen, en 1913-1914. Annales Instit. Océanograph. T. VII, fasc. 8.

1917. Döderlein, L Die Asteriden der Siboga-Expedition. I Die Gattung Astropecten. Siboga Expeditie. XLVIa. Leiden.

1920. Döderlein, L. II. Die Gattung Luidia. Ib. XLVIb.

1920. Kœhler, R. Échinodermes recueillis par 1'"Expédition Antarctique Australienne" au cours de l'Expédition de 1"'Aurora" pendant les années 1911-1914. Astéries, Australian Antarctic Expedition. Scientific Reports, Series C. Vol. VIII, part I. Sydney 1920. 
1922. Kœhler, R. II. Ophiures. Ib. part 2. 


\section{Explanations of the Plates}

\section{Pl. I}

Fig. 1. Labidiaster crassus; entire specimen seen by the dorsal surface; slightly reduced.

Fig. 2. Labidiaster crassus; lateral view of an arm; slightly enlarged.

Fig. 3. Labidiaster radiosus; lateral view of an arm; slightly enlarged.

Fig. 4, 5, and 6. Granaster nutrix; three different specimens seen by the ventral view and enlarged about two times.

Fig. 7 and 8. Allostichaster incequalis; two specimens from San Antonio seen by the dorsal surface (collection of Loriol). Natural size.

Fig. 9. Cryptasterias brachiata; entire specimen seen by the dorsal surface, slightly enlarged.

Fig. 10. Cryptasterias brchiata; lateral view of an arm. X 2.6.

\section{Pl. II}

Fig. 1. Podasterias meridionalis; dorsal surface. X 1.4.

Fig. 2. Podasterias Brandti; dorsal surface of a specimen with six arms. X 1.6.

Fig. 3. Podasterias Brandti; dorsal surface of a specimen with five arms. X 1.7.

Fig. 4. Podasterias Brandi, var. glomerata; dorsal surface. X 1.6.

Fig. 5. Comasterias radiata; dorsal surface of a specimen with ten arms X 2.

\section{PI. III}

Fig. 1. Cosmasterias radiata; dorsal surface of a specimen with eight arms. X 2.2.

Fig. 2. Comasterias radiata; ventral surface of the same. X 2.2.

Fig. 3. Ctenasterias georgiana; dorsal surface of a specimen collected 24 April 1909. X 2.3.

Fig. 4. Ctenasterias georgiana; enlarged porton of the dorsal surface of the same. X 10 .

Fig. 5. Ctenasterias georgiana; dorsal surface of a specimen from Marmite Bay (South Georgia). X 2.2.

Fig. 6. Ctenasterias georgiana; enlarged portion of the dorsal surface of the same X 10 .

Fig. 7. Ctenasterias georgiana; dorsal surface of a specimen from station 22 . X 7 .

Fig. 8. Podasterias Steineni; dorsal surface of the specimen from station 59. X 1.8.

Fig. 9. Podasterias Steineni; portion of the dorsal surface of an arm treated with potash. X 4.

Fig. 10. Ctenasterias georgiana; enlarged dorsal surface of the specimen from station 22 shown in fig. 7 X 14.

\section{Pl. IV}

Fig 1 to 7. Kalyptasterias conferta.

Fig. 1 and 2. Lateral views of two arms of specimen A (dried). X 1.4.

Fig. 3. Dorsal surface of specimen C. Natural size.

Fig. 4. Dorsal surface of specimen B. Natural size.

Fig. 5. Dorsal surface of specimen A. Natural size.

Fig. 6. Ventral surface of the same. Natural size.

Fig. 7. Lateral view of an arm of the same X 1.4. 


\section{PI. V}

Fig. 1 to 6. Sporasterias pedicellaris.

Fig. 1. Specimen from West Falkand (see p. 131) (5 December 1907); dorsal surface. X 1.5.

Fig. 2. Specimen from station 42; dorsal surface X 1.6.

Fig. 3. Specimen from Port Louis; doral surface. X 1.6.

Fig. 4. Specimen from station 44; dorsal surface. X 1.8.

Fig. 5. Specimen from station 42 ; dorsal surface. X 1.6.

Fig. 6. Portion of the dorsal surface of an arm of a specimen from station 3. X 3.2.

\section{PI. VI}

Fig. 1. Sporaster pedicellaris; specimen from station 39. Dorsal surface. X 1.7.

Fig. 2. Sporaster pedicellaris; specimen from station 42. Lateral view of an arm. X 2.2.

Fig. 3. Sporaster pedicellaris; small specimen from station 54. X 2.

Fig. 4. Sporaster pedicellaris; specimen from station 44. Dorsal surface. X 1.5.

Fig. 5. Sporaster pedicellaris; another specimen from station 44. Lateral view of an arm. X 3.5.

Fig. 6. Anasterias octoradiataI; dorsal surface. X 1.4.

Fig. 7. Sporaster pedicellaris; specimen from Port Louis. Lateral view of an arm. X 3.5.

Fig. 8. Sporaster pedicellaris; specimen from station 42. Lateral view of an arm. X 3.5.

Fig. 9. Sporaster pedicellaris; another specimen from station 42. Laeral view of an arm. X 3..

Fig. 10. Sporaster pedicellaris; specimen from station 40. Dorsal surface. X 2.

\section{PI. VII}

Fig. 1. Allostichaster incequalis; ventral surface. X 1.8.

Fig. 2 Allostichaster incequalis; dorsal surface. X 1.8.

Fig. 3. Allostichaster incequalis; lateral view of an arm treated with potash. X 3.5.

Fig. 4. Sporasterias antarctica; lateral view of an arm treated with potash. X 3.5.

Fig. 5. Cycethra verrucosa; dorsal surface (station 54). X 1.8.

Fig. 6. Cycethra cingulata; dorsal surface. X 2.2.

Fig. 7. Cycethra ciningulate; ventral surface. X 2.2.

Fig. 8. Cycethra ciningulate; specimen from the Jardin des Plantes; dorsal surface. X 3.

Fig. 9. Cycethra ciningulate; another specimen from the Jardin des Plantes; dorsal surface. X 3.

Fig. 10, Cycethra ciningulate; enlarged portin of the dorsal surface of the same. X 4.

Fig. 11. Cycethra verrucosa; lateral view of an arm of the specimen from station 54 shwn in fig. 5. X 2.5 .

Fig. 12. Cycethra verrucosa; lateral view of an arm. (Station 52). X 6.

Fig. 13. Cycethra verrucosa; lateral view of an interarm arc (Station 59). X 3. 


\section{PI. VIII}

Fig. 1. Echinaster diffidens; dorsal surface (Statiin 6). X 2.

Fig. 2. Echnaster diffidens; ventral surface of the same. X 2.

Fig. 3. Cycethra verrucosa; dorsal surface (Station 54). X 1.4.

Fig. 4. Cycethra verrucosa; ventral surface (Station 59). X 1.6.

Fig. 5. Cycethra verrucosa; enlarged portion of the dorsal surface of an arm from the same specimen treated with potash. X 3.

Fig 6. Cycethra verrucosa; portion of the ventral surfaced of an arm seen from the internal surface to show the ambulacal vesicles. X 2.

Fig. 7. Cycethra verrucosa; portion of the dorsal surface of an arm treated with potash from a specimen of station 52 . X 4 .

Fig. 8. Cycethra verrucosa; specimen with four arms; dorsal surface (Station 52). X 2.

Fig. 9. Cycethra verrucosa; dorsal surface (Station 52). X 2.

Fig. 10. Cycethra Lahillei; dorsal surface. (Specimen from the collection of Loriol), X 1.5.

Fig. 11. Cycethra Lahillei; ventral surface of the same. X 1.5.

\section{PI. IX}

Fig. 1. Remaster Gourdoni; dorsal surface. X 4.

Fig. 2. Asterina fimbriata; ventral surface (Station 8). X 3.

Fig. 3. Ganeria Hahni; ventral suface. X 1.7.

Fig. 4. Ganeria Hahni, dorsal surface of the same X 1.5.

Fig. 5. Asterina fimbriata; ventral surface (Specimen from Chile). X 3.

Fig. 6. Asterina fimbriata; ventral surface (Station 54). X 3.

Fig. 7. Asterina fimbriata; dorsal surface (Specimen from Station 41, Port Louis). X 3.3.

Fig. 8. Asterina fimbriatta; dorsal surface of the specimen from Chile shown in fig. 5. X 3 .

Fig. 9. Echinaster diffidens; ventral surface (Station 5). X 3.

Fig. 10. Echinaster diffidens; dorsal surface (Station 22). X 2.

\section{Pl. X}

Fig. 1. Acondontaster elongatus, var. abbreviatus; ventral surface. X 1.7.

Fig. 2. Acondontaster elongatus, var. abbreviatus; dorsal surface of the same. X 1.7.

Fig. 3. Acondontaster elongatus, var. abbreviatus; enlarged portion of the dorsal surface.X 5.

Fig. 4. Diplopteraster Nordenskjöldi; specimen with seven arms (dried). Dorsal surface slightly enlarged.

Fig. 5. Diplopteraster Nordenskjöldi; ventral suface of the same, slightly enlarged.

Fig. 6. Diplopteraster Nordenskjöldi; enlaaged portion of the dorsal surfaced of he same. X 3 .

Fig. 7. Diplopteraster Nordenskjöldi; dorsal surface of an individual with six arms. X 1.3.

Fig. 8. Diplopteraster Nordenskjöldi; ventral surface of the same. X 1.3. 


\section{Pl. XI}

Fig. 1. Peridontaster Grayi; specimen A, ventral surface. X 1.4.

Fig. 2. Peridontaster Grayi; dorsal surface of the same, slightly enlarged.

Fig. 3. Peridontaster Grayi; specimen B, ventral surface. X 1.4.

Fig. 4. Peridontaster Grayi; specimen C, portion of the dorsal surface. X 2.4.

Fig. 5. Diplopteraster verrucosus; dorsal surface. X 1.6.

Fig. 6. Pseudontaster moderatus; central region of the ventral surface. X. 5.

Fig. 7. Pseudontaster moderatus; ventral surface. X 1.2.

\section{PI. XII}

Fig. 1. Diplopteraster verrucosus; ventral surface. X 1.6.

Fig. 2. Astropecten cingulatus; dorsal surface. X 1.5.

Fig. 3. Leptoptychaster mendosus; enlarged portion of the dorsal surface. X 8 .

Fig. 4. Leptoptychaster mendosus; dorsal surface. X 1.4.

Fig. 5. Leptoptychaster mendosus; ventral surface. X 1.8.

Fig. 6. Ripaster longispinus; lateral view of an arm. X 2.

Fig. 7. Ripaster longispinus; ventral surface of an arm seen from the internal side to show the ambulacral vesicles. X 2 .

Fig 8. Ripaster longispinus. Lateral view of another arm. X 2.

Fig. 9. Peridontaster Grayi; specimen D; dorsal surface. X 2.

Fig. 10. Peridontaster Grayi; ventral surface of the same. X 2.

\section{Pl. XIII}

All the figures except fig 4 are shown in nearly true size.

Fig. 1. Podasterias meridionalis of station 6; dorsal surface.

Fig. 2. Podasterias Brucei from station 6; dorsal surface.

Fig. 3. Leptoptychaster accrescens; dorsal surface.

Fig. 4. Pseudontaster conspicuus; mouth region. X 2.4.

Fig. 5. Pseudontaster conspicuus; ventral surface.

Fig. 6. Pseudontaster conspicuus; dorsal surface.

\section{PI. XIV}

Fig. 1. Gorgonocephalus chilelnsis; portion of the dorsal surface of the disc. X 2 .

Fig. 2. Ophiochondrus falklandicus; dprsal surface. X 7.

Fig. 3. Ophiochondrus falklandicus; ventral surface of the same. X 7.

Fig. 4. Ophioripa ingrata; specimen with six arms from station 59. X 3.5.

Fig. 5. Ophioripa ingrata; dorsal surface of a specimen with five arms (Station 58). X 4.

Fig. 6. Ophioripa 108ngrate; ventral surface of the same. X 6.

Fig. 7. Amphiura Eugeniae; ventral surface X 5.

Fig. 8. Amphiophiura antarctica; dorsal surface. X 8.

Fig. 9. Amphiophiura antarctica; ventral surface of the same. X 8 . 
Fig. 10. Ophionotus hexactis; dorsal surface of a specimen with seven arms from station 22 . X 3.5.

Fig. 11. Amphipholis patagonica; specimen from Juan Fernandez; dorsal surface. X 12.

Fig. 12. Amphipholis patagonica; ventral surface of the same. X 12.

\section{PI. XV}

Fig. 1 to 4. Amphiura alternans; station 37.

Fig. 1. Amphiura alternans; dorsal surface. X 5.

Fig. 2. Amphiura alternans; ventral surface of another specimen. X 4.

Fig. 3. Amphiura alternans; ventral surface of the specimen shown in Fig. 1. X 5.

Fig. 4. Amphiura alternans; ventral surface of another specimen. X 5.

Fig. 5. Ophiomastus conveniens; dorsal surface. X 7.

Fig. 6. Ophiomastus conveniens; ventral surface. X 9.

Fig. 7. Ophiomages cristatus; lateral view of an arm X 5.

Fig. 8. Ophiomages cristatus; dorsal. X 2.4.

Fig. 9. Ophiomages cristatus; dorsal view of the disc, more enlarged. X 6.

Fig. 10. Ophiomages cristatus; ventral surface. X 6. 


\section{Table of contents}

\begin{tabular}{|c|c|c|c|}
\hline ASTEROIDS & 6 & Pseudontaster moderatus sp, nov. & 89 \\
\hline Labidiaster radiosus & 6 & Ceramaster patagonicus & 94 \\
\hline Labidiaster crassus sp. nov. & 7 & Astropecten cingulatus & 95 \\
\hline Anasterias tenera & 11 & Ripaster longispinius & 95 \\
\hline Anasterias Victoriae & 12 & Leptoptychaster accrescens & 98 \\
\hline Anasterias octoradiata & 14 & Leptoptychaster mendosus sp nov. & 98 \\
\hline Sporasterias antarctica & 14 & Bathybiaster Liouvillei & 100 \\
\hline Sporasterias pedicellaris sp. nov. & 18 & & \\
\hline Cryptasterias brachiate sp. nov. & 25 & Ophiuroids & 101 \\
\hline Podasterias Brandti & 27 & Gorgonocephalus chilensis & 191 \\
\hline Podasterias Brandti var. glomerata & 29 & Asgtrotoma Agassizii & 102 \\
\hline Podasterias Steineni & 30 & Astrochlamys brunneus & 103 \\
\hline Podasterias meridionalis & 31 & Ophiochondrus falklandicus nov. sp. & 103 \\
\hline Podasterias Brucei & 35 & Ophiacantha vivipara & 104 \\
\hline Comasterias radiata sp. nov. & 36 & Ophiodiplax disjuncta & 104 \\
\hline Comasterias lurida & 38 & Ophioripa ingrata & 106 \\
\hline Ctenasterias georgiana & 40 & Amphiura alternans nov. sp. & 107 \\
\hline Kalyptasaterias nov. gen. & 43 & Amphiura complanata & 109 \\
\hline Kalyptasterias conferta nov. sp. & 43 & Amphiura Eugeniae & 110 \\
\hline Allostichaster incequalis nov. sp. & 50 & Amphiura magellanica & 112 \\
\hline Granaster nutrix & 53 & Amphiura Mortenseni & 112 \\
\hline Asterina fimbriata & 55 & Amphipholis patagonica & 113 \\
\hline Echinaster diffidens sp. nov. & 58 & Amphiodia chilensis & 114 \\
\hline Henricia Pagenstecheri & 60 & Amphioplus affinis & 115 \\
\hline Cycethra verrucosa & 60 & Amphioplus peregrinator & 116 \\
\hline Cycethra cingulata sp. nov. & 68 & Ophiactis asperula & 116 \\
\hline Ganeria falklandica & 71 & Ophiomages nov. gen. & 118 \\
\hline Ganeria Hahni & 72 & Ophiomages cristatus nov. sp. & 118 \\
\hline Perknaster aurantiacus & 73 & Ophioceres incipiens & 121 \\
\hline Cryaster Aurorce & 73 & Ophiocten amitinum & 122 \\
\hline Porania antarctica & 74 & Ophiomasgtus conveniens nov. sp. & 122 \\
\hline Lophaster antarcticus & 75 & Ophionotus Victoria & 124 \\
\hline Cuenotaster involutus & 75 & Ophionotos hexactis & 125 \\
\hline Remaster Gourdoni & 76 & Ophiura Lymani & 126 \\
\hline Diplopteraster verrucosus & 76 & Ophiomaria Döderleini & 126 \\
\hline Diplopterasere Nordenskjöldi nov. sp. & 77 & Ophioperla Ludwigi & 127 \\
\hline Pteraster Hunteri & 81 & Amphiophiura antarctica nov. sp. & 128 \\
\hline Acodontaster elongatus var. & & Ophiurolepis resistens & u30 \\
\hline abbreviatus nov. var. & 81 & Ophiurolepis gelida & 130 \\
\hline Asterodon singularis & 84 & ADDITIONS AND CORRECTIONS & 131 \\
\hline Gnathaster validus & 84 & Luidia africana & 132 \\
\hline Gnathaster elegans & 85 & Astrothamnus tuberculatus nov. sp. & 133 \\
\hline Peridontaster Grayi & 86 & List of cited works & 136 \\
\hline Pseudontaster conspicuus & 88 & Explanation of plates & 139 \\
\hline
\end{tabular}




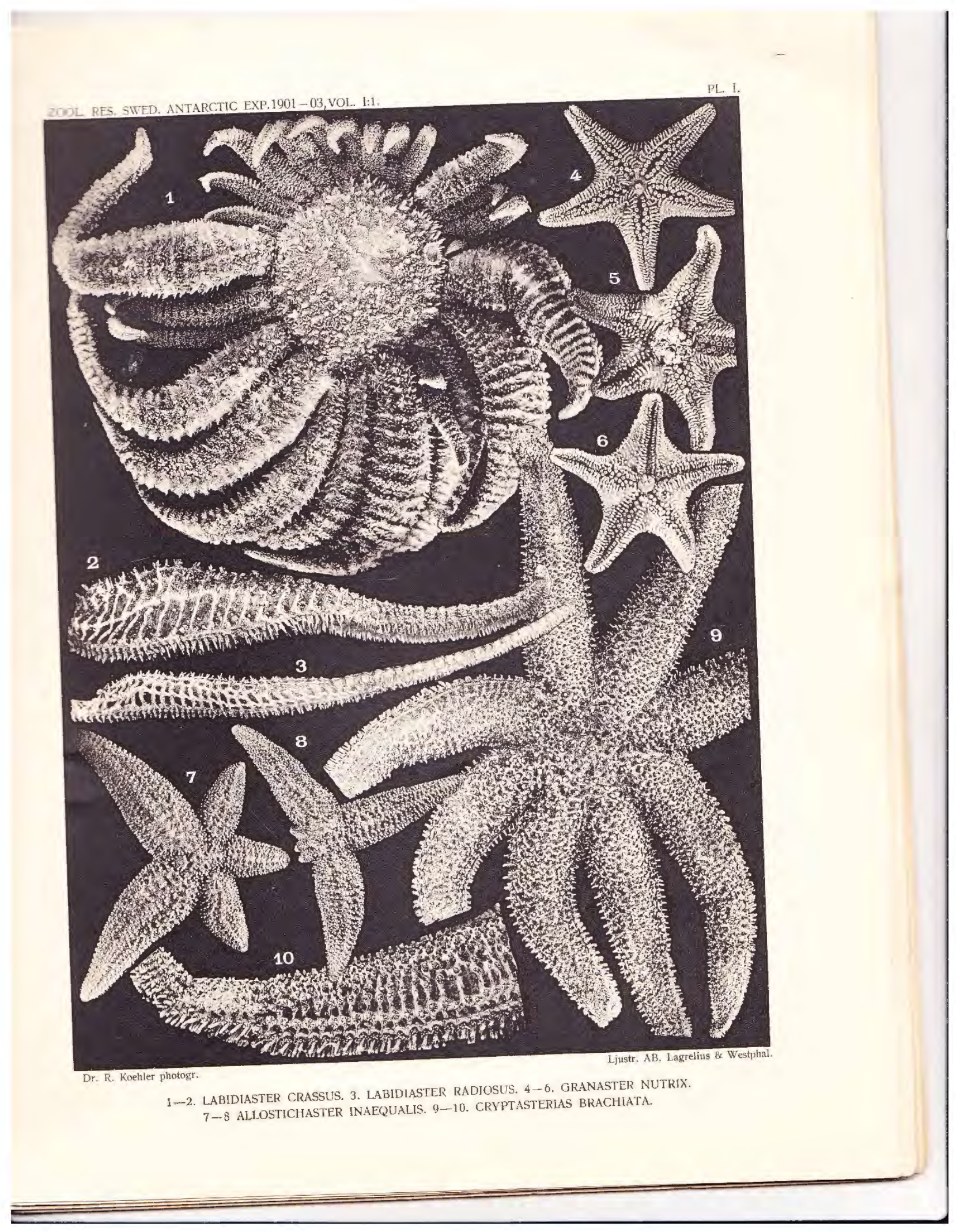




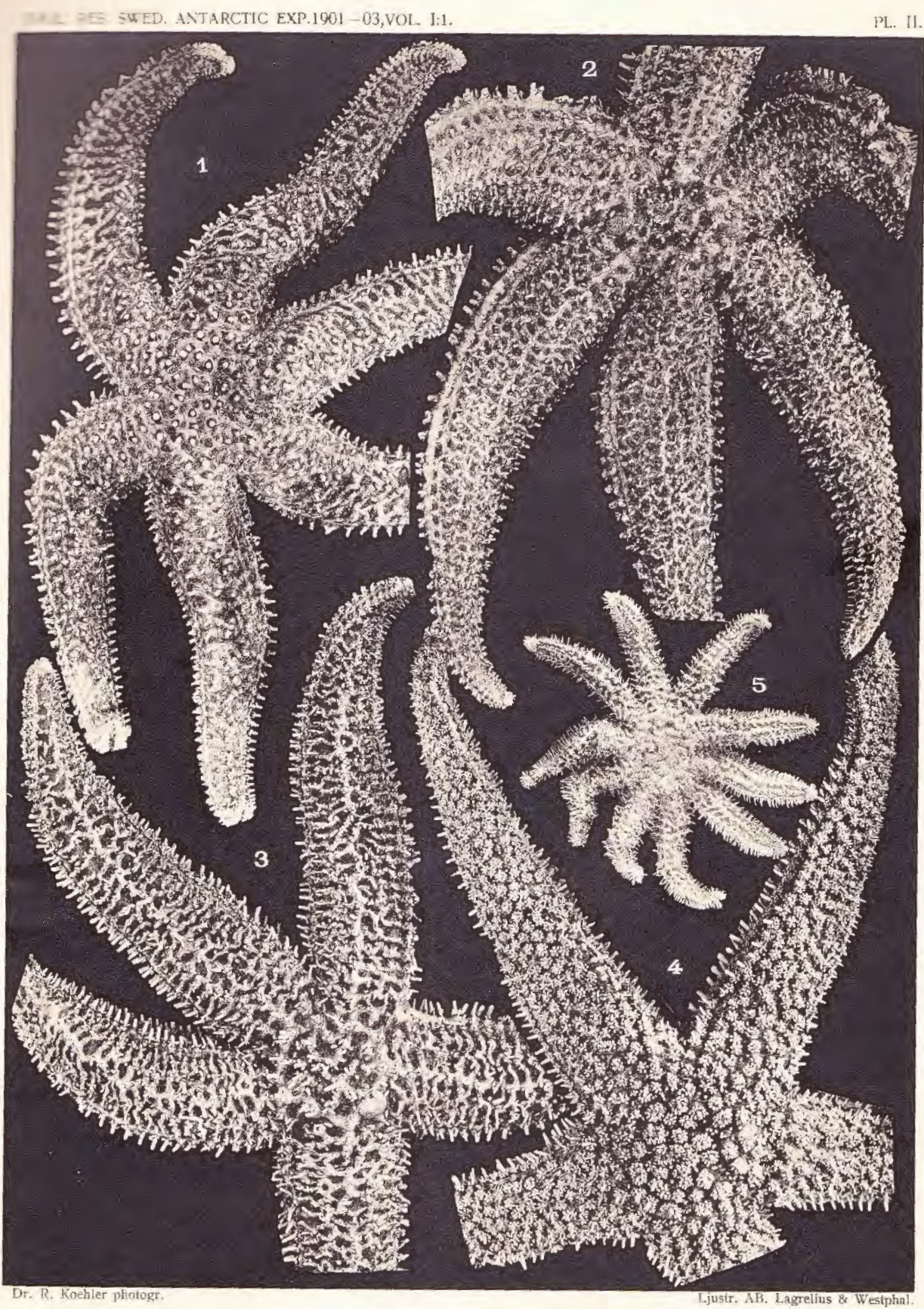

1. PODASTERIAS MERIDIONALIS, 2-3. PODASTERIAS BRANDTI,

4. PODASTERIAS BRANDT VAR, GLOMERATA. 5. COSMASTERIAS RADIATA. 


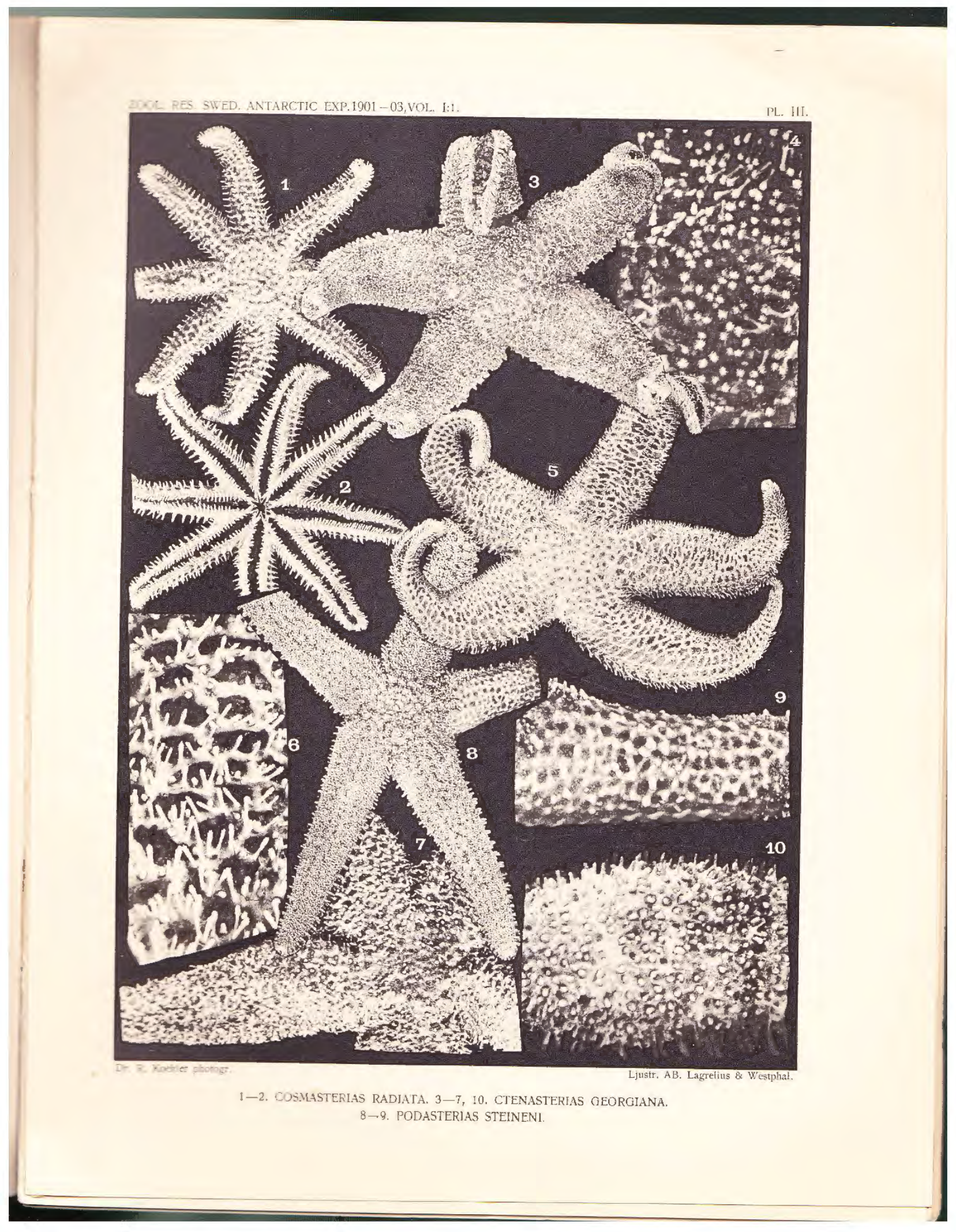




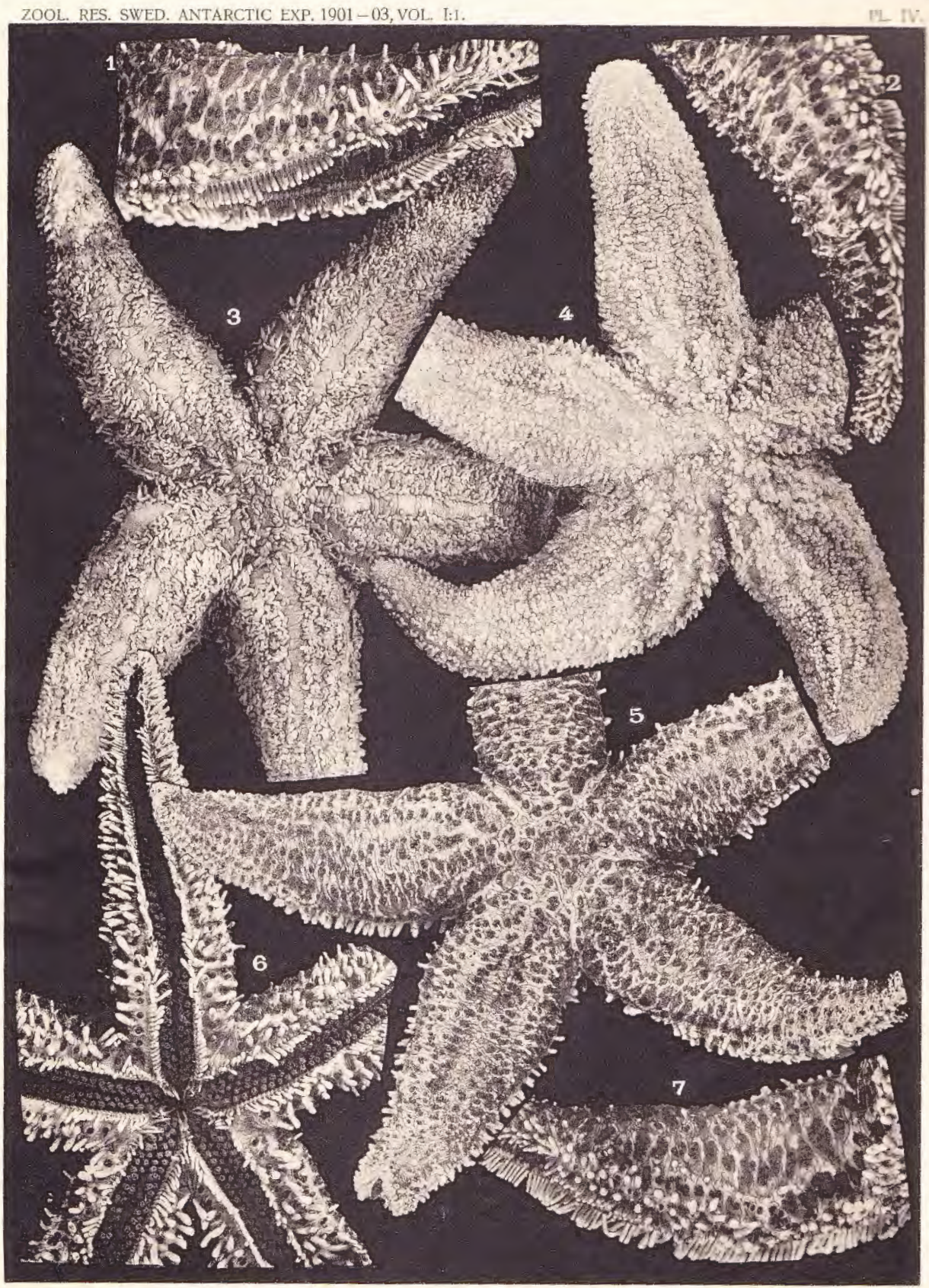

Dr. R. Kochler photogr.

L.justr, AD. Lagrelitus \& Westpha!

$1-7$, KALYPTASTERIAS CONFERTA 


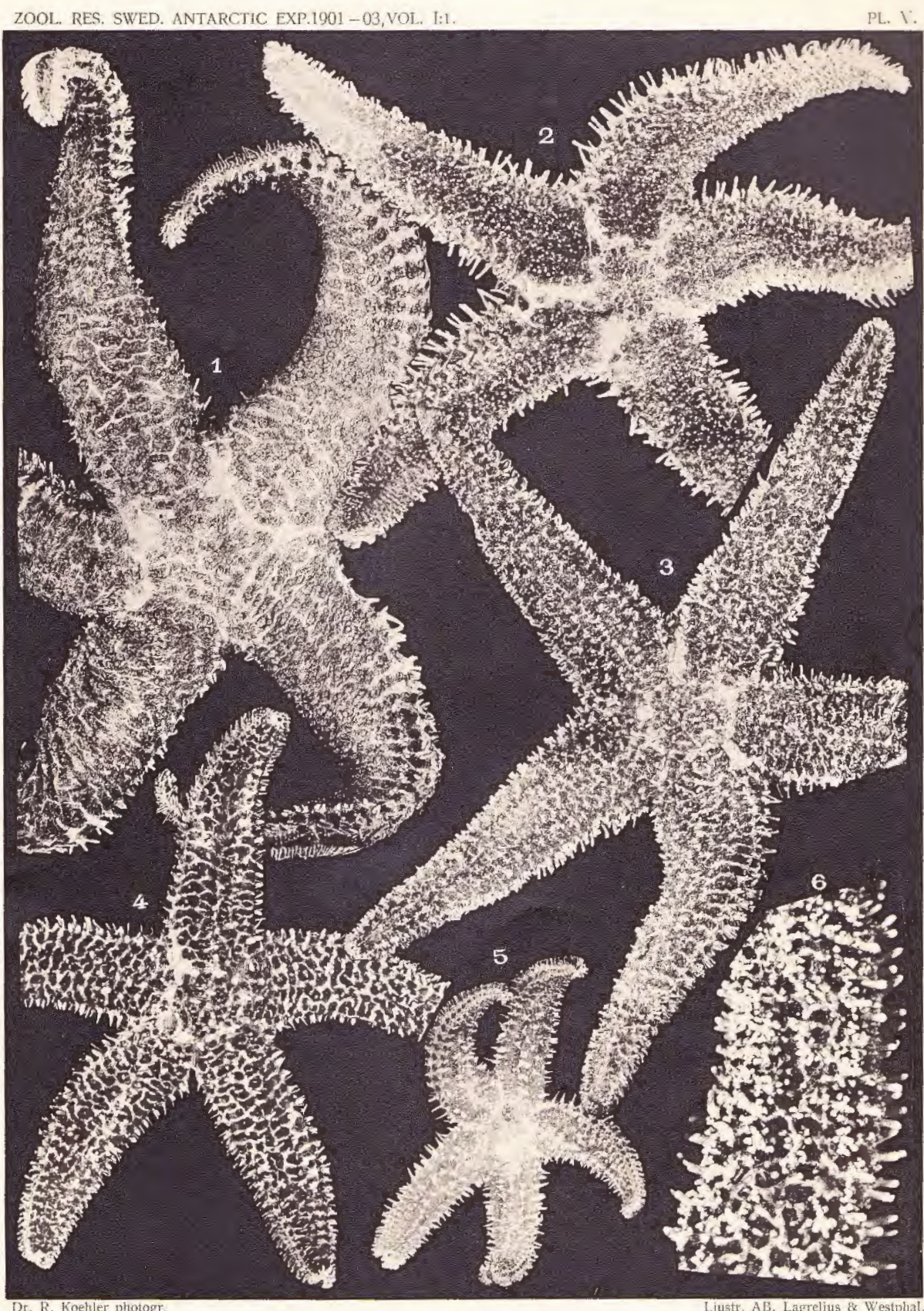

1-6. SPORASTFRIAS PEDICELLARIS. 


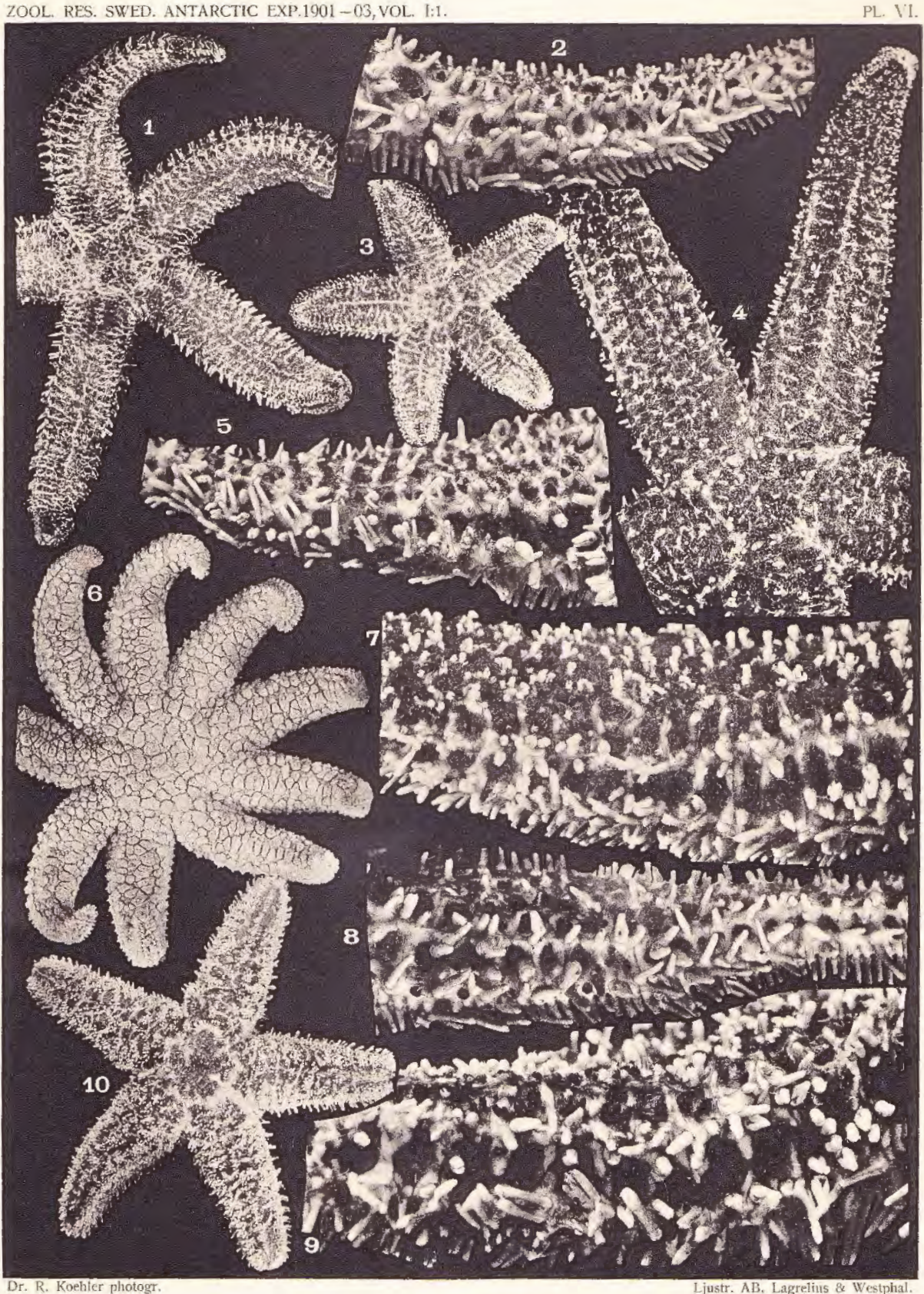

\footnotetext{
$1-5,7-10$. SPORASTERIAS PEDICELLARIS. 6. ANASTERIAS OCTORADIATA.
} 


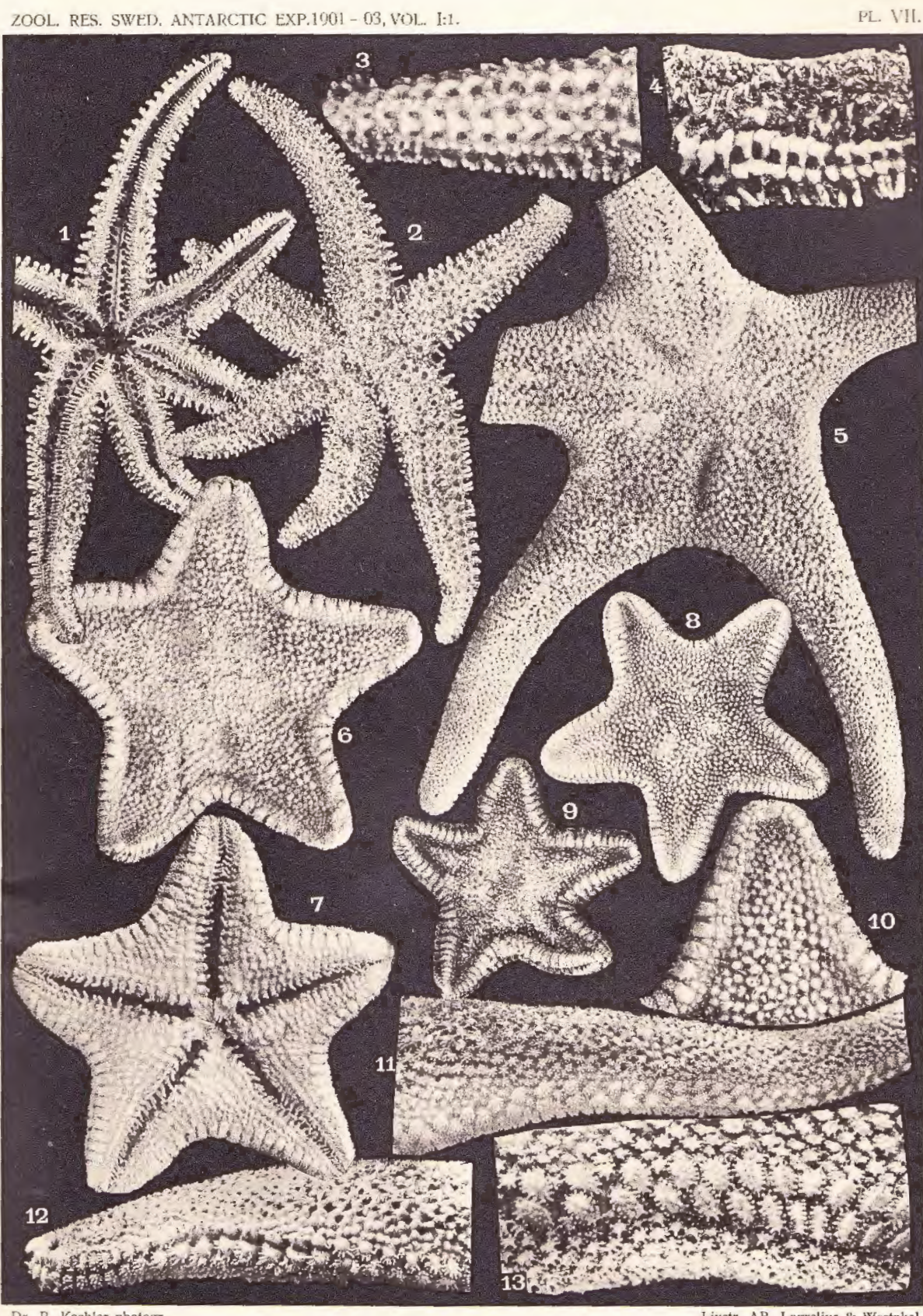

Dr. R. Koehler photogr.

Ljustr. AB. Lagrelius \& Westphal.

1-3. ALIOSTICHASTER INAEQUALIS, 4. SPORASTERIAS ANTARCTICA.

5, 11-13. CYCETHRA VERRUCOSA, 6-10. CYCETHRA CINGULATA. 


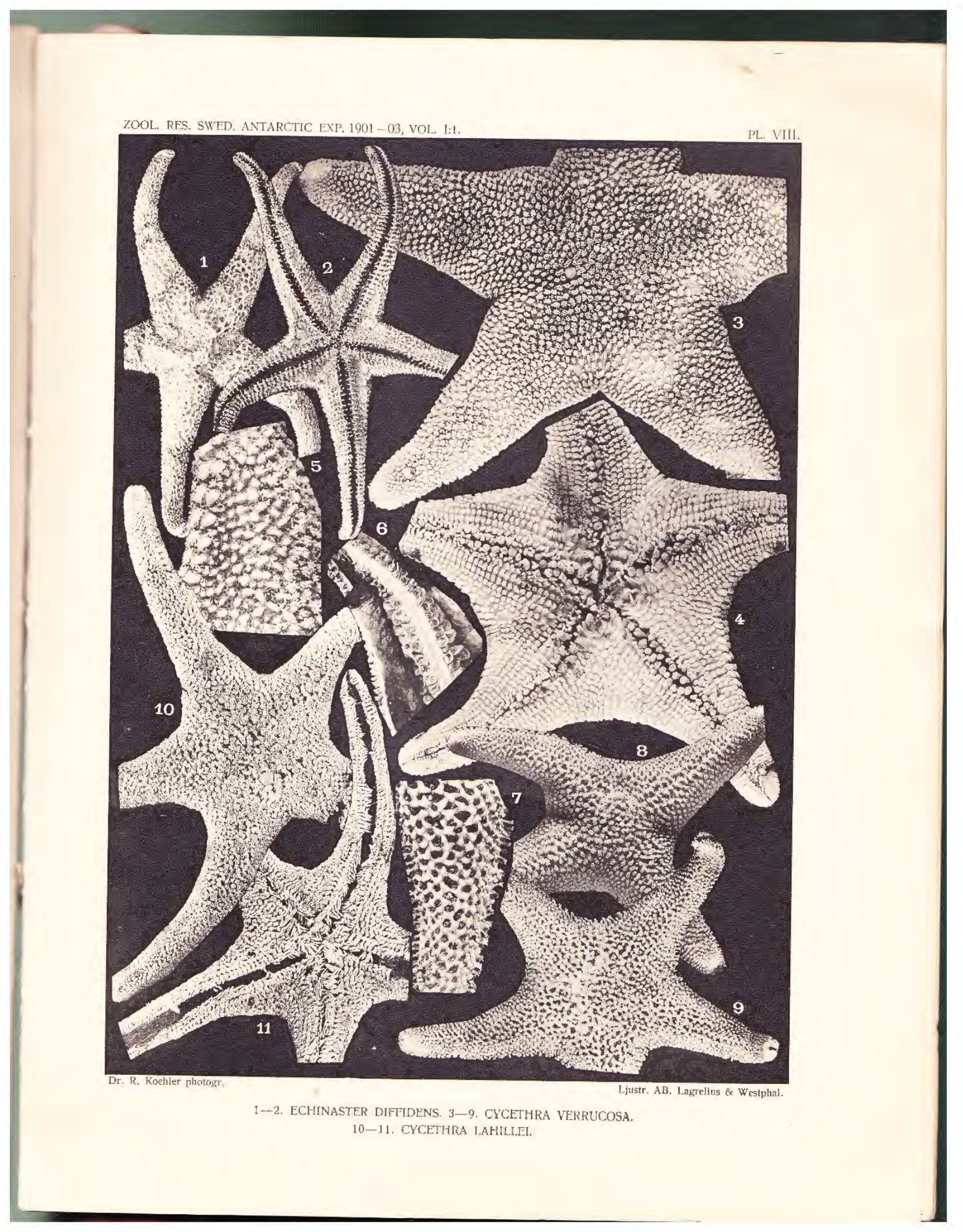




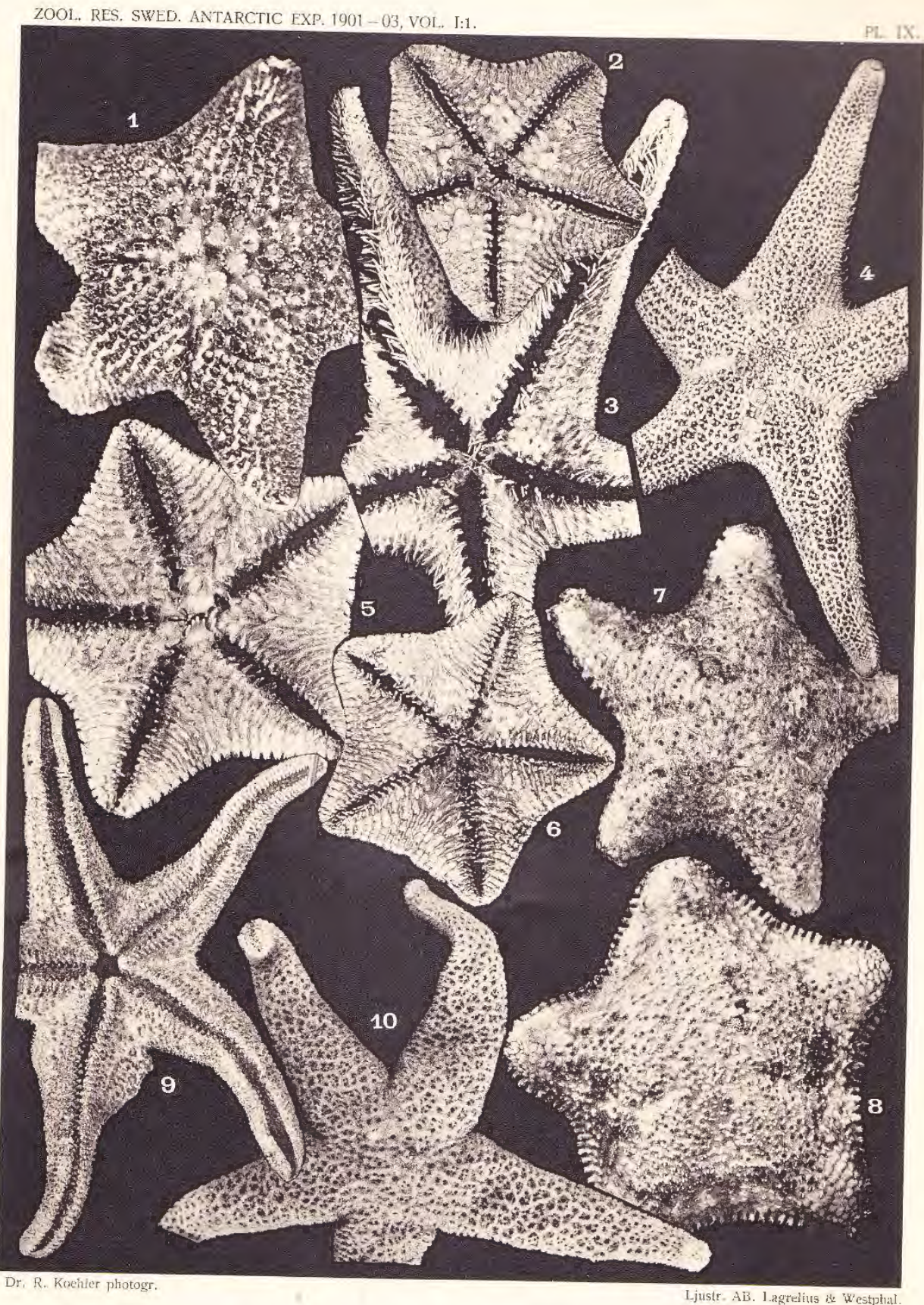

Dr, R. Koefiver photogr.

Ljustr. AB. l.agtelins is westphia

1. REMASTER GOURDONI. 2, 5-8. ASTERINA FIMBRIATA.

3-4. GANERIA HAHNI. 9-10. ECHINASTER DIPFIDENS. 


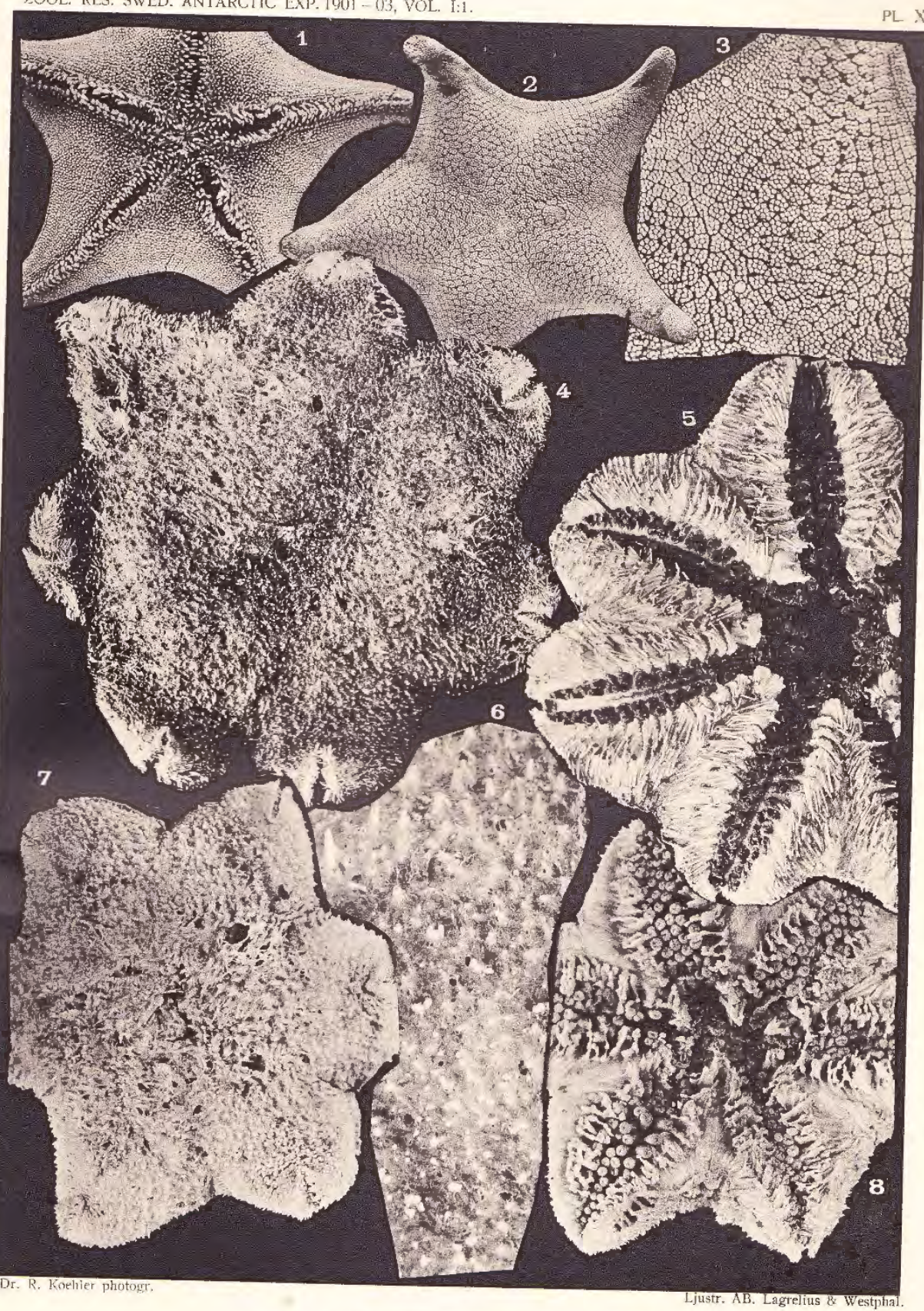

1-3. ACODONTASTER ELONGATUS VAR. ABBREVIATUS

4-8. DIILOPTERASTER NORDENSKJÖLDI. 
ZOOL. RES. SWED. ANTARCTIC EXP.1901 -03,VOL. I:1.

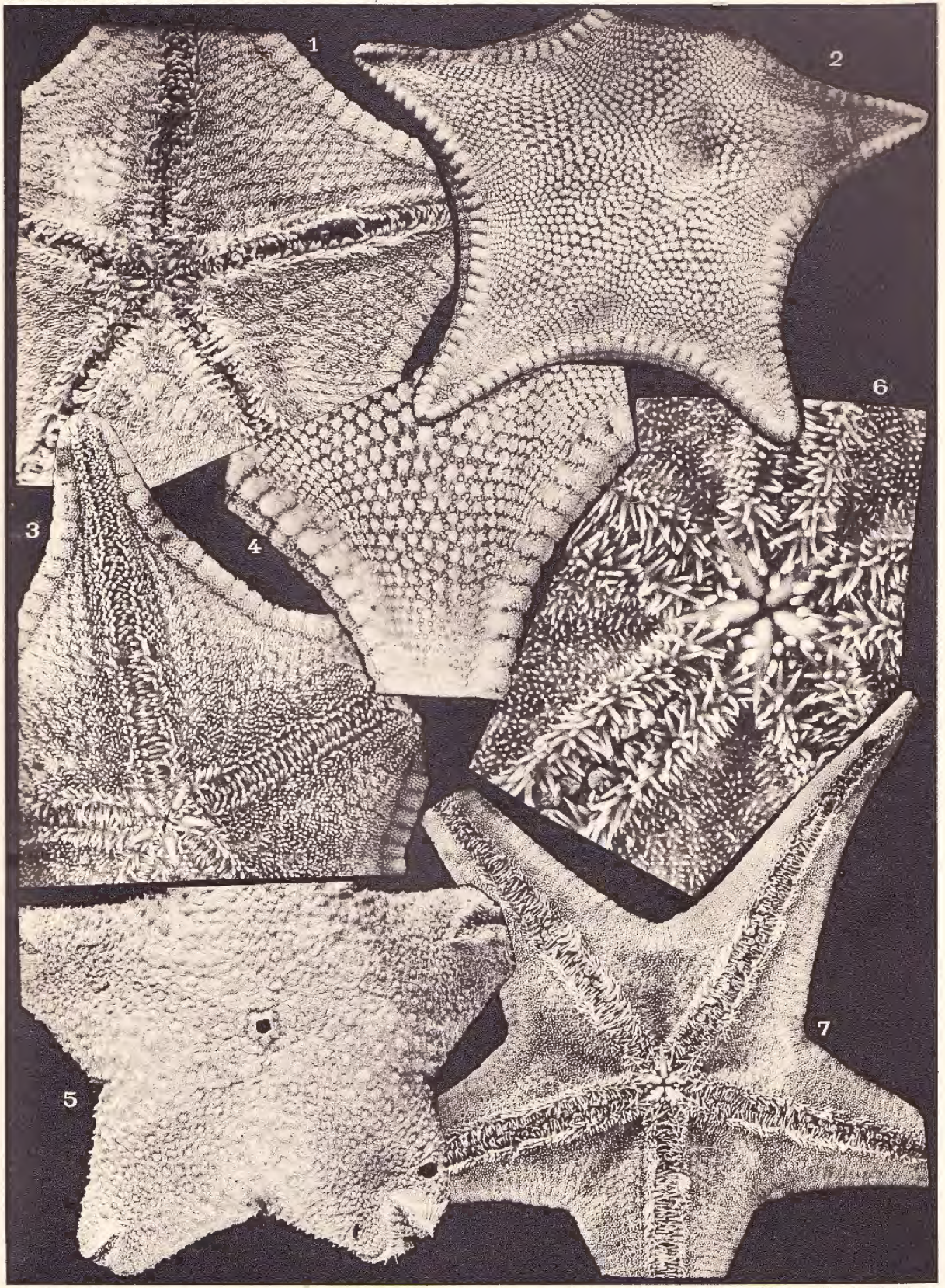

Dr. R. Koehler photogr.

Ljustr, AB. Lagrelins \& Westphal.

1-4. PERIDONTASTER GRAYI. 5. DIPLOPTERASTER VERRUCOSUS. 6-7. PSEUDONTASTER MODERATUS. 


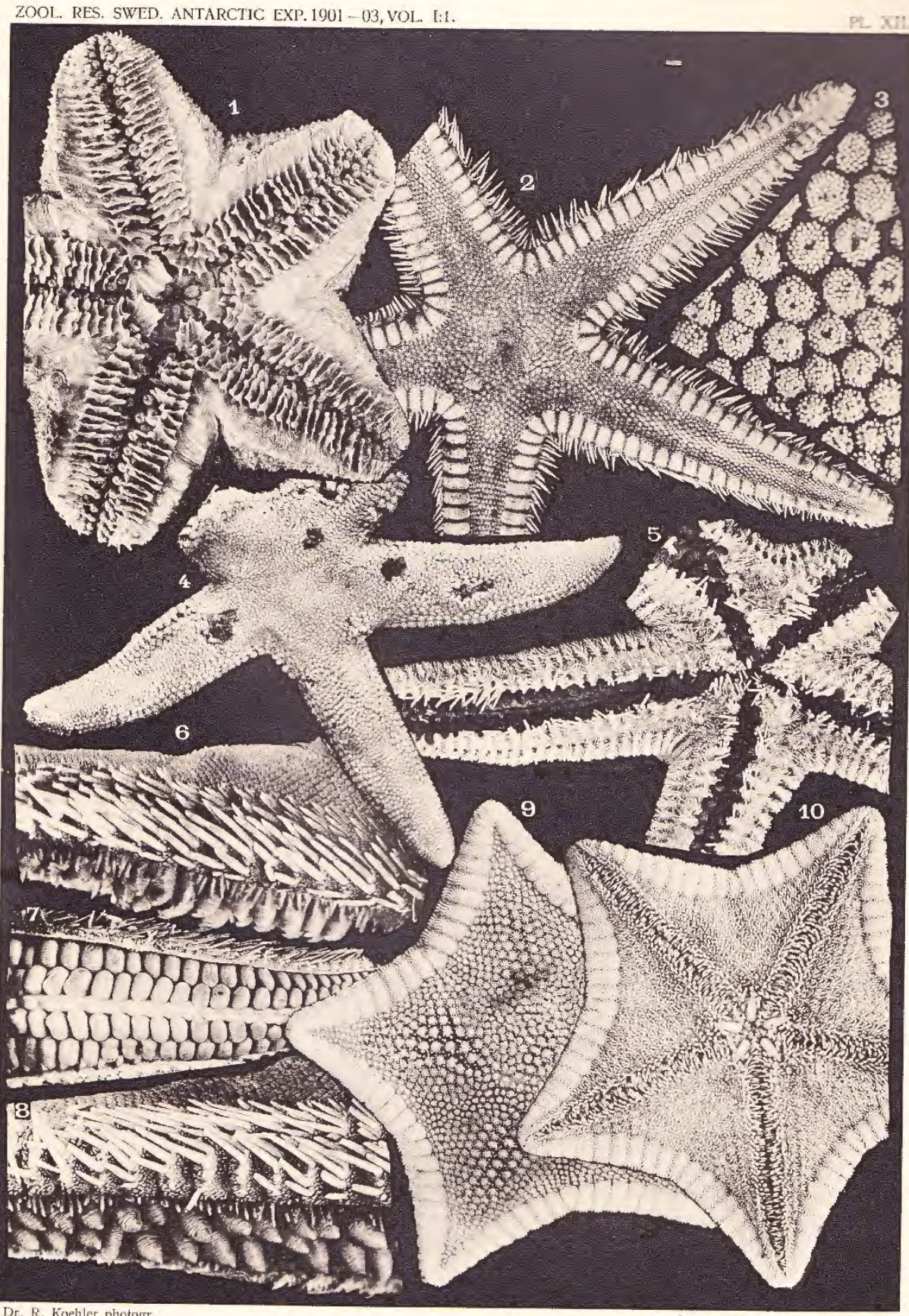

Dr. R. Koehler photogr.

I.justr. AB. Lagrelius \& Westratal

1. DIPLOPTERASTER VERRUCOSUS. 2. ASTROPECTEN CINGULATUS.

3-5. LEPTOPTYCHASTER MENDOSUS. 6-8. RIPASTER LONGISPINUS. 9-10. PERIDONTASTER GRAYI. 
ZOOJ.. RES. SWED. ANTARCTIC EXP. 1901 -03, VOL. I:1.

PL. XIII.

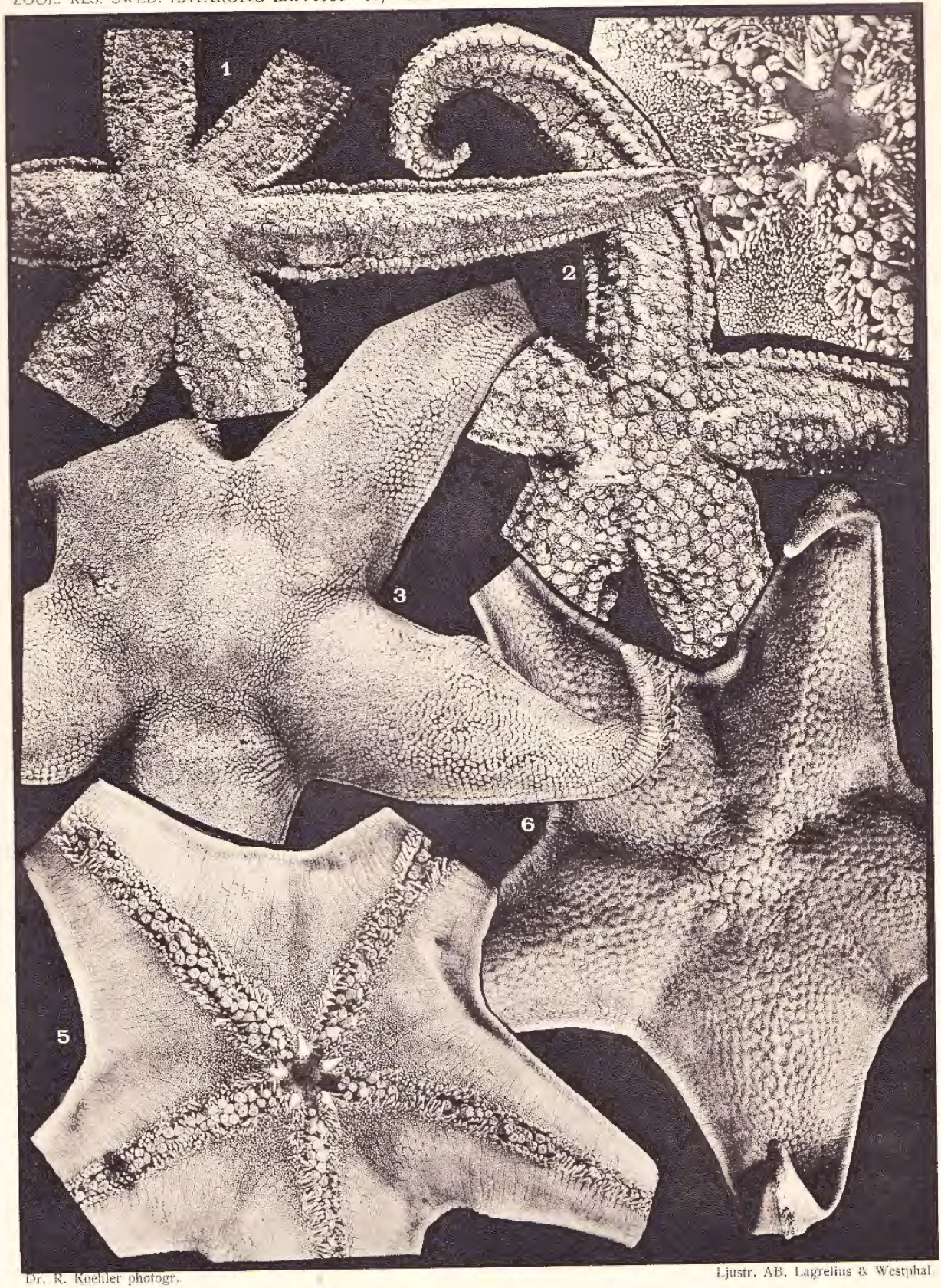

1. PODASTERLAS MERIDIONAI.IS. 2. PODASTERIAS BRUCEI.

3. LEPTOPTYCHASTER ACCRESCENS. 4-6. PSEUDONTASTER CONSPCULS. 


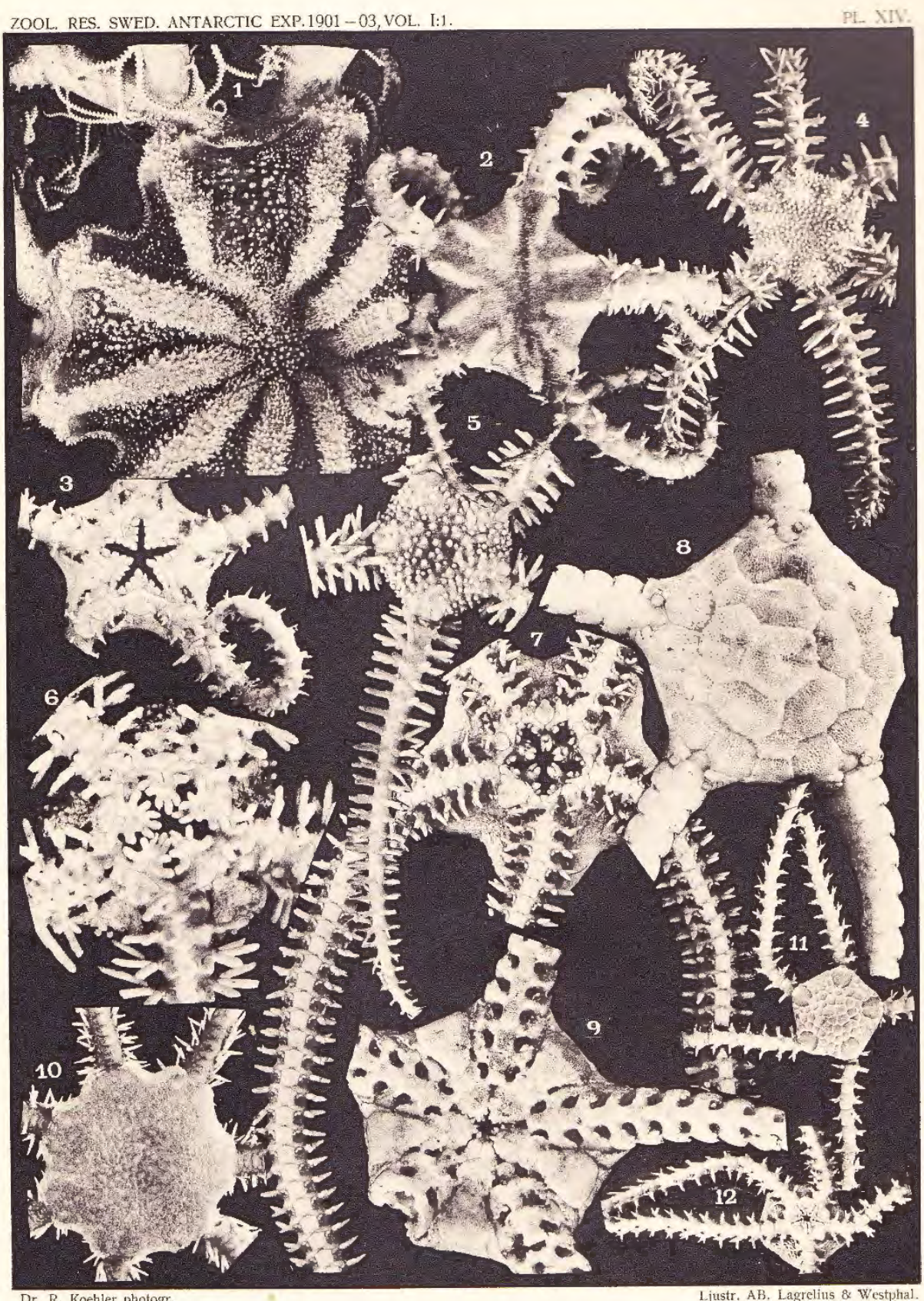

Dr. R. Koehler photogr.

1. GORGONOCEPHALUS CHILENSIS. 2-3. OPHIOCHONDRUS FALKLANDICUS,

4-6. OPHIORIPA INGRATA. 7. AMPHIURA EUGENIAE.

8-9. AMPHIOPHIURA ANTARCTICA. 10. OPHIONOTUS HEXACTIS.

11-12. AMPHIPHOLIS PATAGONICA. 


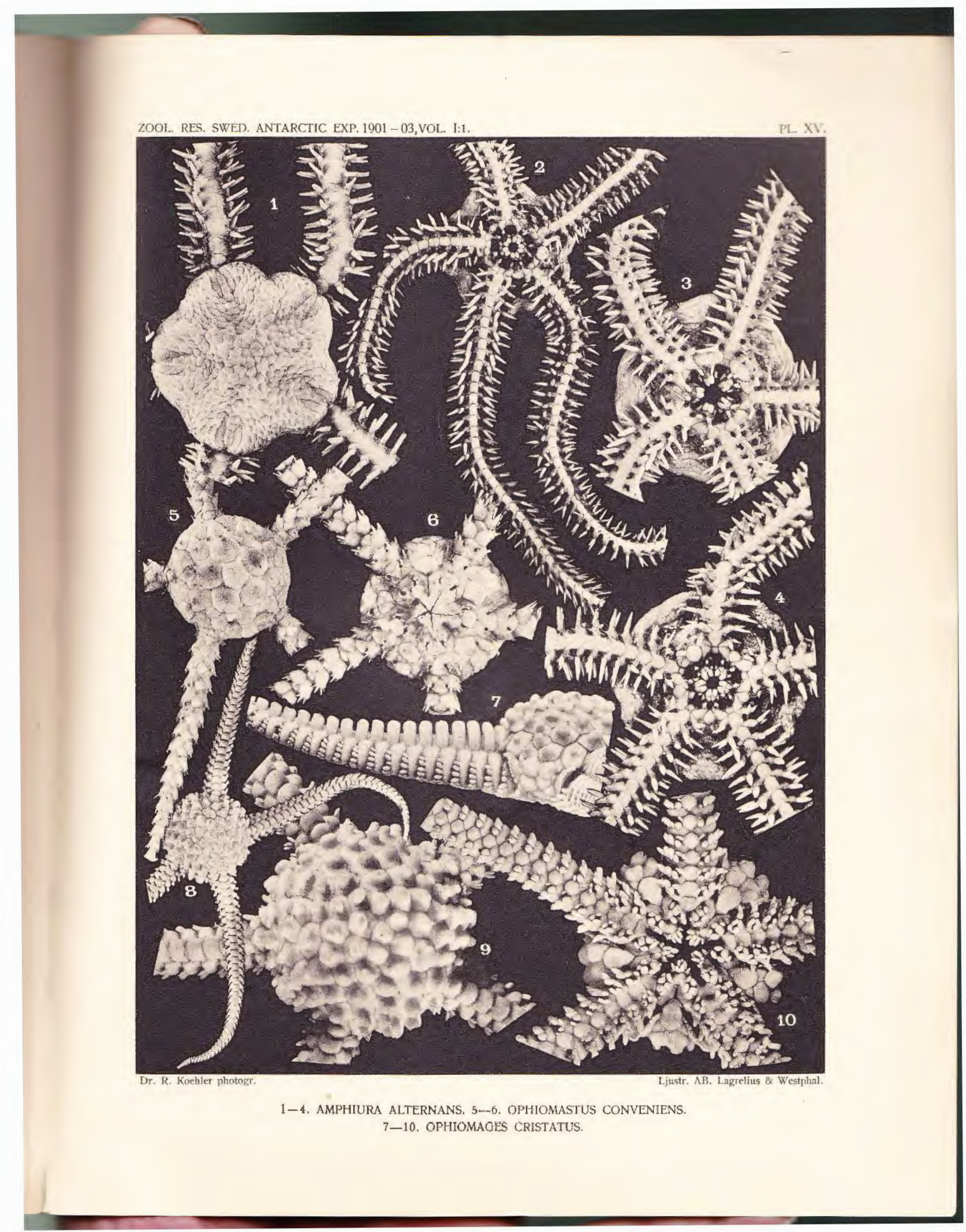

